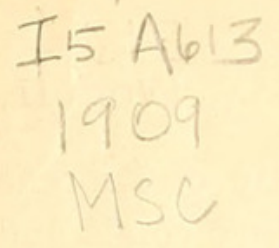

\title{
REPORT ON THE FISHES TAKEN BY THE BENGAL FISHERIES STEAMER "GOLDEN CROWN."
}

\author{
PART I.-BATOIDEI. \\ By N. Annandale, D.Sc., Superintendent, Indian Museum.
}

\section{INTRODUCTION.}

The trawler "Golden Crown"' was purchased in England by the Bengal Government in the early part of the year Igo8 and commenced work in the Bay of Bengal at the beginning of the monsoon season in June of that year. Since then she has made numerous trips, most of which have been confined to the northern parts of the Bay. Her work has not been scientific, and she is not equipped for research of any kind; but the Commissioner of Fisheries has permitted me to retain for the Museum specimens of the fish captured on each trip. The collection thus obtained has served to supplement the ichthyological investigations of Lieutenant-Colonel A. W. Alcock and his predecessors and successors as Surgeon Naturalist on the R.I.M.S. " Investigator" '; for the trawl of the "Golden Crown,' being of the type commonly used in commercial fishing, is of a much larger size, and therefore capable of holding much larger fish, than any likely to be used for scientific purposes in Indian seas. It has, moreover, been used mainly in water of a depth between 20 and 30 fathoms, whereas the "Investigator" dredges mainly, but not solely, at much greater depths. The collections obtained by the two vessels are therefore complementary to one another.

The "Golden Crown", has trawled along the greater part of the coast from Gopalpur in the Ganjam district of the Madras Presidency to Oyster Island off the coast of Burma, but mostly in Balasore Bay, off Konarak and Puri in Orissa, off the entrance to the Eastern Channel of the river Hughli, off the Mutlah Lightship at the entrance to the Mutlah river, and in the vicinity of Cox's Bazaar, Chittagong. Most of the ground covered has been muddy, but occasionally fine sand, coarse sand, and " coral grounds"' have been worked. The so-called coral grounds, however, have not been coral reefs but places where the bottom has become sufficiently solid to afford a support for sedentary organisms of various kinds. Off Gopalpur in about 24 fathoms, for instance, enormous numbers of Tenagodes shells were brought up in the trawl, interwoven into rock-like masses with a Lithistid sponge; off Konarak a recent conglomerate of sand and decomposed shells was found to afford a lodging to numerous Gorgoniids and Antipatharians, some of the latter reaching a gigantic 
size; while off the coast of Arakan true fossiliferous rocks, apparently of Miocene age, were encountered, their surface being densely coated with solitary corals and molluscs of various kinds.

It has been decided that the Museum shall publish a report on the fish captured by the "'Golden Crown," and the present paper is the first part of that report. Dr. J. Travis Jenkins, Scientific Adviser on Fisheries to the Government of Bengal, and Mr. B. L. Chaudhuri, Assistant Commissioner of Fisheries, will deal with the Teleosteans, while the systematic study of the Elasmobranchs falls to me. Probably Dr. Jenkins and I will deal jointly with the Selachians, as soon as we feel that the collection is sufficiently representative to be treated in a satisfactory manner.

Since Dr. Jenkins came out to India, in November, I908, I have been indebted very greatly to him for selecting and preserving specimens and for information about specimens not preserved and the nature of the localities. It has not been possible for me to go out on the trawler myself, but Dr. Jenkins has done so regularly and, quite apart from his own work, has shown himself a most zealous coadjutor in the work of the Museum. Captain R. E. Lloyd, I.M.S., has also gone out on the trawler for one trip, and I am indebted to him for some interesting observations. I must express my obligations to the Commissioner of Fisheries for allowing me to retain specimens for the Museum and for obtaining a grant of Rs. 400 from the Government of Bengal towards the expense of illustrating the report; to Mr. B. L. Chaudhuri for much help as regards the collection, and to the skipper, Captain Mann, and European crew of the "Golden Crown." To deal with large and powerful animals such as a full-grown saw-fish in such a way that they shall be suitable for scientific examination is a matter not devoid of difficulty and physical danger, and until November rgo8 I was dependent on Capt. Mann and his hands as regards the specimens retained for the Museum.

The Batoidei, being mostly bottom-haunting species, are more commonly captured in a trawl than any other large fish. Consequently it has been possible to obtain a fairly complete collection with great expedition. Indeed, between June Igo8 and March Igog about sixty per cent. of the forms now known to inhabit the seas of British India have been captured by the "'Golden Crown," while of the remaining forty per cent. at least half of the species live either at great depths or on the surface of the sea and would not therefore be taken in a trawl except by accident.

In preparing the report on the Batoidei of the "Golden Crown "' I have made use not only of the old collection in the Indian Museum, but also of those in the Museum of Madras and Trivandrum, both of which, thanks to their respective heads, Mr. E Thurston and Lieut.-Col. F. W. Dawson, I have had the privilege of examining lately. The specimens from the "Golden Crown"' have been sent up to the Museum in ice, and I have thus had an opportunity, in many cases, of comparing them in a fresh condition with specimens long preserved dry or in alcohol. This has proved a very valuable opportunity, for it has been found almost impossible to identify certain species by means of the published descriptions on the basis of fresh material only. These 
descriptions, including the measurements given, have evidently, in many cases, been based solely on badly stuffed Museum specimens, and the figures reproduced have had the same foundation.

It may be well to give a definite statement as to the measurements recorded in this paper. Considerations of time and space have rendered them less complete than I would have liked, for expedition is necessary, as well as a considerable amount of spare room, if several large rays preserved in rapidly melting ice are to be measured in a tropical climate before they can go bad, especially if a proportion of them are finally to be preserved as museum specimens. Whenever possible, moreover, photographs and water colour sketches have been taken as well as the measurements, in order that an accurate record of the colours and outlines of the different species may be preserved. The measurements themselves have been taken with a tape across or along the specimens, - not from point to point. This method has been adopted as providing a more accurate standard for comparison than that of measuring from point to point. Except when it is otherwise stated, the measurements have been taken on the fresh specimen before it has been dissected.

The illustrations, except when it is otherwise stated, are reproductions of photographs of frozen specimens.

The following list contains the names of the Batoidei as yet recorded or here mentioned as occurring in the seas of British India and Ceylon. I have not dealt further, however, with most of the deep-sea forms.

\section{LiST OF THE BATOIDEI RECORDED FROM INDIAN SEAS.}

The names of the species not examined in connection with this report are printed in italics. Those of species taken by the "Golden Crown"' are marked with a*; those of species not described or recognized by Day in the "Fauna"' with a §; those species of which the types are in the Indian Museum with a $\dagger$.

\section{Family PRISTIDÆ.}

I. Pristis cuspidatus.*

2. ,, perottetii.*

3. ,, pectinatus.*

3a. ,, , var. annandalei. $* \xi^{\prime}$

4. ,, zysron.*

Family RHINOBATID盾.

5. Rhamphobatis ancylostomus.*

6. Rhinobatis djeddensis.*

7. ,, halavis

8. ,, granulatus.*

9. ,, thouini.

Io. ,, columnæ.*

II. , schlegelii.*\$
Family RAJID玉.

I2. Raja mamillidens. $\dagger^{\dagger}$

I3. ,, johannis-davisi. $§ \dagger$

I4. ,, reversa. $\S \dagger$

I5. ,, sp. nov. $\$$

I6. , powellii. $\uparrow$

I6a. ,, philipii (?) (=R. powellii). $§ \dagger$

I7. Platyrhina schonleinii.

Family TrygonID无.

I8. Trygon microps.*\$†

I9. ,, uarnak.*

20. ,, gerrardii.*

2I. ,, favus, sp. nov. $* \S \dagger$

22. ,, bleekeri.* 
23. Trygon alcockii, sp. nov.*§†

24. ,, jenkinsii, sp. nov.*§†

25. ', marginatus.*

26. ,, bennettii.

27. ,, imbricata.*

28. ,, zugei.*

29. ,, kuhlii.*

30. Hypolophus sephen.*

3I. Taniura melanospilos.

32. Urogymnus asperrimus.*

33. ,, lævior, sp. nov.ई

34. Pteroplatea micrura.*

35. ,, zonura.*\$

36. , , tentaculata. $* \$$

Famfly TORPEDINID死.

37. Torpedo marmorata. $\S \dagger$.

38. Narcine timlei.*

39. ,, brunnea, sp. nov.* ${ }^{\prime}$

40. ,, mollis. $\oint^{\dagger}$
4I. Benthobatis moresbyi. $\S \dagger$

42. Astrape dipterygia.*

43. Bengalichthys impennis, gen. et sp. nov. $* \S \dagger$

\section{Family Myliobatid死.}

44. Rhinoptera javanica.

45 .

,, adspersa.

46. Myliobatis nieuhofii.*

$46 \mathrm{a}$, ,, ,, var. cornifera,

47. ,, maculata.*

48. Aëtobatis guttata.*

49. ,, flagellum.*\$

Family CERATOPTERIDA.

50. Dicerobatis eregoodoo.

5I. ,, thurstoni.

52. ,, kuhlii.

53. Ceratoptera orissa.

- From this list it may be seen that of the fifty-three distinct species here recognized as occurring in Indian seas, no less than thirty-three have been taken during the past year by the "Golden Crown." Of the remaining twenty, seven probably live only in water deeper than that in which the operations of the fishery steamer have been conducted, while at least four (the members of the family Ceratopteridæ) are surface forms and would not usually be taken in a trawl. In the list there are twenty-one specific and two varietal names not to be found in Day's volume in the "'Fauna,'” or there regarded as synonyms. Of these, nine belong to species described within the last few years by Alcock' or Illoyd " and, with two exceptions, taken in deep water by the " Investigator,' while twelve are here recorded for the first time or have recently been recorded for the first time in the Records of the Indian Museum. A new genus, five new species and a new variety are described in this report.

\section{Suborder BATOIDEI.}

Family PRISTID $\approx$ (Saw-fishes).

The saw-fishes, which abound in the Bay of Bengal and make their way up some of the larger rivers, are very destructive to edible fish. Their livers yield an oil which should prove valuable (see Mr. Hooper's analysis, postea) and the flesh of the young is edible, although there does not seem to be much demand for it.

Alcock, A Descriptive Catalogue of the Indian Deep-Sea Fishes (Calcutta, I899), and Illustrations of the Zoology of the R.I.M.S. "Investigator," Fishes, pls. viii, xxvi, xxvii.

Lloyd, Ann. Mag. Nat. Hist. (7), vol. xviii, p. 3 II (I906); Rec. Ind. Mus., i, p. 5 (I907), and Ill. Zool. "Investigator," Fishes, pls. xxxix-xli. Also " A Description of the Deep-Sea Fish caught by the R.I.M.S. "Investigator" since the year I900," in Mem. Ind. Mus., ii, I909 (incd.). 
Only one genus can be recognized, namely Pristis, with five species, four of which cccur in the Bay.

\section{Key to the Indian Species of Pristis.}

I. Teeth absent from the base of the saw for a considerabie distance.

(a) From 25 to 35 teeth on each side of the saw. Anterior dorsal fin arising behind the root of the pelvic fins $\quad \ldots \quad \ldots$. . cuspidatus.

II. Teeth present on the base of the saw.

(a) Not more than 22 teeth on each side of the saw. Anterior dorsal fin in advance of the pelvic fins for the greater part of its length.

P. perottetii.

(b) Twenty-five or more teeth on each side of the saw. Anterior dorsal fin above the pelvic fins $\quad \ldots \quad$.. $\quad \ldots \quad \ldots$ P. pectinatus.

(c) Twenty-six or more teeth on each side of the saw. Anterior end of anterior dorsal fin distinctly behind the anterior end of the root of the pelvic fins

$$
\text { . . . . . P. zysron. }
$$

\section{Pristis cuspidatus, Latham.}

This species is easily distinguished from all others by the following characters :-

(a) The rostral teeth commence at a considerable distance from the base of the rostrum;

(b) Both edges of the rostral teeth are sharp, the hinder edge having a distinct barb in young individuals ;

(c) The lower lobe of the caudal fin is pointed and quite distinct.

(d) The teeth in the mouth are smaller and relatively broader than in the other species.

The broad groove which runs outwards and upwards from the outer edge of the nostril is also noteworthy, as well as the small size of the cutaneous fold on the anterior edge of the nostril.

Young specimens of this species have been caught by the " Golden Crown ' on almost every voyage, but large ones are somewhat rare.

The following measurements are those of the largest specimen ( $q$ ) as yet taken, and of a large male. The former was captured at the beginning of August off Orissa, the latter in January off the mouth of the Ganges. The head, saw and fins of the female and the saw of the male are preserved in the Indian Museum.

Extreme length (including saw)

\& $\quad 8$

Length of saw

Breadth of saw at base

,, ,, ,, at tip

Distance of first rostral tooth from base of saw

Breadth across pectoral fin

Width of mouth

\begin{tabular}{|c|c|c|}
\hline & & $\sigma^{\prime}$ \\
\hline 3097 & $\mathrm{~cm}$. & $245^{\circ} \mathrm{O} \mathrm{cm}$ \\
\hline $76 \cdot 4$ & , , & $75^{\circ} \mathrm{O}$ \\
\hline $7 \cdot 0$ & , , & $8 \cdot 5$ \\
\hline $3 \cdot 8$ & ") & $4^{\circ} \mathrm{O}$ \\
\hline $17 \cdot 7$ & , & 16.5 \\
\hline & , & 82.5, \\
\hline I $3 \cdot \mathrm{O}$ & , , & II' 25, \\
\hline
\end{tabular}


Breadth of pectoral fin ,, , , pelvic fin ..

Length of pectoral fin . .

,, , , pelvic fin . .

Breadth of first dorsal fin

,. , , second dorsal fin

Height of first dorsal fin

,, . , second dorsal fin

Length of dorsal lobe of caudal fin

Greatest breadth of dorsal lobe of caudal fin . .

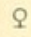

\%

$39^{\circ} \mathrm{g}^{\mathrm{cm}}$.

$35^{\circ} \mathrm{O}$,

32.5

$23^{\circ} \mathrm{O}$

$35 \cdot 5$

$34^{\circ} \mathrm{O}$

$35^{\circ} \mathrm{O}$

$25^{\circ} \mathrm{O}$

$40 \cdot 5$

$27^{\circ} \mathrm{O}$
$27.5 \mathrm{~cm}$.

$26 \cdot 25$,

$35^{\circ} \mathrm{O}$,

The rostral teeth are narrow in these specimens, measuring Io $\mathrm{mm}$. in breadth at the base and $2 \mathrm{I} \mathrm{mm}$. in length where they are not worn. They are very slightly retroverted and show no signs of a barb on the posterior edge, as the rostral teeth of all young examples of the species $(=P$. semisagittatus, Shaw) do (see Müller and Henle, Syst. Beschr. d. Plagiostomen, p1. 60, I84I). The male has 27 teeth on either side of the saw; the female 27 on the right and 28 on the !eit.

The colour of young individuals is a dark leaden grey on the dorsal surface, fading to pale grey on the belly. The back of old specimens is considerably paler than that of the young and is tinged with green in life.

Pristis cuspidatus is confined to the seas of India and the Malay Archipelago. It is common at the mouths of the Ganges.

There is an interesting abnormal (stuffed) specimen of this species in the Museum. The anterior dorsal is entirely absent, but a slight scar on the skin of the back would suggest that it had been removed accidentally. In front of this scar there is a longitudinal band of small, broadly heart-shaped, flattened denticles, which is broadest posteriorly and becomes gradually narrower in front, reaching slightly beyond the anterior margin of the pelvic fins. The specimen is a young one, measuring about 80 $\mathrm{cm}$. in length and was purchased in the Akyab marker in rgo6.

\section{Pristis perottetii, Müller and Henle.}

This species is distinguished from $P$. pectinatus and $P$. zysron by the small number of its rostral teeth (not more than 22 pairs) and by the position of its first or anterior dorsal fin, which originates considerably further forward on the body than the pelvic fins.

This species is very common in the estuaries of the Ganges and Brahmaputra, which it ascends for at least a hundred miles, often being captured in fresh water. The following are the measurements of two large females taken by the "Golden Crown,"' A in November off Arakan and B in October off Orissa.

A. B.

Fixtreme length (including saw)

Length of saw

Breadth of saw (at base)
$656 \cdot \mathrm{o} \mathrm{cm} \cdot 56 \mathrm{I} \cdot \mathrm{O} \mathrm{cm}$.

. I $45^{\circ} \mathrm{O}, \mathrm{I} 30^{\circ} \mathrm{O}$,

. $27^{\circ} 0,, 22 \cdot 7$, 


\begin{tabular}{|c|c|c|c|c|c|c|}
\hline Breadth of saw (at tip) & . & . & . & II $\cdot 2$ & $\mathrm{~cm}$. & $7.8 \mathrm{~cm}$ \\
\hline Width of mouth & . & . & . & $45 \cdot 6$ & ,, & . \\
\hline Breadth of pectoral fin ... & . & $\cdots$ & $\cdots$ & I $26 \cdot 6$ & , , & $\cdots$ \\
\hline ,, ,, pelvic fin $\quad$. & $\cdots$ & . & . & $63 \cdot 3$ & , , & . \\
\hline Length of pectoral fin & . & . & . & IOI 3 & , , & . \\
\hline ,, $\quad$,, pelvic fin $\quad$. & . & . & . & $8 \mathrm{I} \cdot \mathrm{O}$ & , , & . \\
\hline Breadth across pectoral fin & . & . & . & $304^{\circ} \mathrm{O}$ & ,, & $228 \cdot 0$, \\
\hline Breadth of first dorsal fin & . & . & . & $63 \cdot 3$ & , , & . \\
\hline ,, , , second ,, ,, & . & . & . & $35 \cdot 3$ & ,, & . \\
\hline Height of first dorsal fin & . & . & . & $63 \cdot 3$ & ,, & . \\
\hline ,, ,, second ,, ,, & . & . & . & $63 \cdot 3$ & , , & . \\
\hline
\end{tabular}

It will be seen from these measurements that the proportionate length of the saw varies considerably. In specimen $A$ it is slightly over $\frac{1}{5}$ of the total length, while in $\mathrm{B}$ it is just about ${ }_{4}^{1}$. The teeth in these specimens are very stout, with the posterior edge strongly grooved. They measure in A $27 \mathrm{~mm}$. in breadth at the base and from $73-78 \mathrm{~mm}$. in length, in B I $8-20 \mathrm{~mm}$. in breadth at the base and $50-68 \mathrm{~mm}$. in length. The teeth at the tip bend forwards slightly in each case. A has I7 and B I8 pairs. The number on the sides of the saw, however, is not always the same I have examined specimens with 22 teeth on one side of the saw, but none with so many on both sides. Several have 20 on one side and 2I on the other.

The adult female of this species is dull grey on the dorsal surface, almost white on the belly, and the male does not appear to differ from the female in coloration.

Pristis perottetii is found in all tropical seas and estuaries and is closely related to P. antiquorum of the Mediterranean and Atlantic, from which it may be distinguished by the fact that in the latter the first dorsal fin is situated immediately above the pelvic fins.

\section{Pristis pectinatus, Latham.}

This species is easily distinguished from $P$. perottetii by the larger number of its rostral teeth (25-34 pairs). From P. zysron it may be distinguished by the fact that the anterior edge of the first dorsal is situated almost immediately over that of the pelvic fins.

The saw is short and tapers considerably, but Day is not correct in saying that it is always twice as broad at the base as at the tip, the proportion being sometimes about 4 to 3 . The rostral teeth are rather slender and are grooved posteriorly; at the base of the saw they are, in old specimens, three or four times as distant from one another as they are at the tip. I have not seen a specimen in which they had the same number on both sides of the saw. The true teeth, in the mouth, resemble those of $P$. perottetii. The head and forepart of the body are flatter in $P$. pectinatus than in any other species I have seen. The second dorsal fin is always slightly smaller than the first.

Although this is caommon species in the estuaries of the Ganges and is well represented in the collection of the Indian Museum, I have found no complete specimens 
of the typical form among those sent me from the "Golden Crown." A number of severed saws, however, appear to belong to this form.

\section{Pristis annandalei, Chaudhuri. (P1. v, fig. 4.)}

P. annandalei, Chandhuri, Rec. Ind. Mus., ii, p. 39I, text-figure.

I do not now think that this form is more than a variety of $P$.pectinatus, if, indeed, it is not the typical adult male of that species. The main difference lies in the coloration, and this is not only a character that is lost in dried specimens, but is also one that may very well be sexual or even seasonal. In all the species of the genus variation occurs as regards the exact proportions and outlines of the fins and saw, and I do not think, after comparing dried specimens, that the structural features which separate $P$. annandalei from the specimens of $P$. pectinatus in the Museum, are beyond the limits of such variation, although I agreed with Mr. Chaudhuri at the time he described his species that it was new. When fresh it exhibited a brilliancy of coloration much superior to anything that I have seen in any other specimen of the genus. The back was of a bright ashy grey, which faded into blue on the sides and then changed to pale yellow. The anterior margins of the dorsal fins were bluish grey, but the body of all the fins was orange-yellow suffused with red. The claspers were of a bright brownish red, and there was a conspicuous orange-red line running down each side of the saw and interrupted by each tooth. The following are the measurements of this specimen, which was taken in July off the coast of Burma in shallow water.

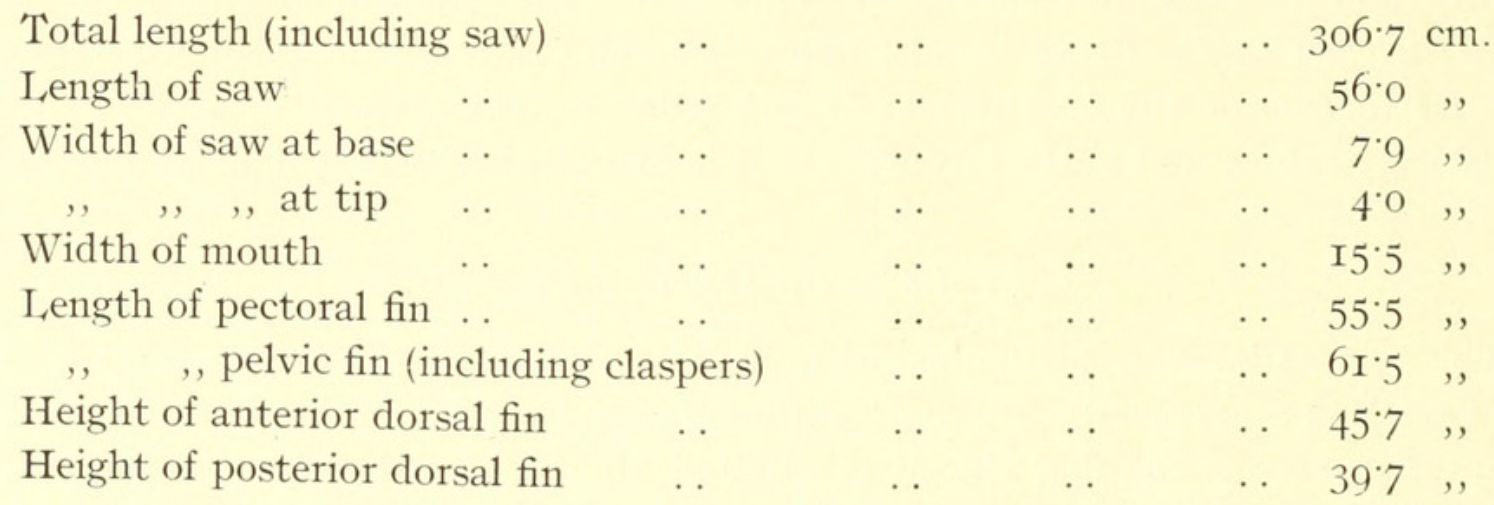

The rostral teeth are slender, measuring only from 7 to $8 \mathrm{~mm}$. in width at the base and from $2 \mathrm{I}$ to $26 \mathrm{~mm}$. in length. There are 24 on the right and 25 on the left.

A successful cast of this specimen was made and was coloured from a water-colour sketch of the fresh specimen. Figure 4 , plate v, is a reproduction of a photograph of this cast. The skeleton and part of the skin have also been preserved in the Indian Museum, the number in the Museum register of fishes being $\mathrm{F} \frac{2}{2} \frac{3}{1} \underline{3}$.

Pristis zysron, Bleeker.

The rostrum in this species is longer in proportion to the body than that of $P$. pectinatus; the rostral teeth are stouter, and in old specimens they are often as much as 
ten times as distant from one another at the base as they are at the tip of the saw. They frequently have the same number on the two sides of the saw. The posterior dorsal fin is usually rather larger than the anterior one. There is a narrow yellowish streak along the side of the saw in large individuals of this species, as there is in all adult specimens of $P$. pectinatus, but even in the males the colours are dull.

Day says that P. zysron is perhaps more common in the seas of India than P.cuspidatus, but this remark probably applies to the Arabian Sea rather than the Bay of Bengal. Several large specimens have, however, been taken by the " Golden Crown." The measurements of two males are as follows :-

Total length (including saw)

Length of saw

Width of saw at base

,, ,, ,, ,, tip

Breadth across pelvic fin

$\begin{array}{ll}\ldots & \ldots \\ \ldots & \ldots \\ \ldots & \ldots \\ \ldots & \ldots \\ \ldots & \ldots\end{array}$

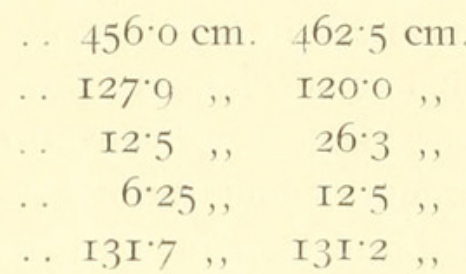

The second of these specimens has 28 pairs of rostral teeth, the first has 25 on one side and 26 on the other. I should not be surprised ultimately to obtain a series of specimens linking P. pectinatus and P.zysron together. Undoubtedly there has been much confusion as regards the two species, and I am by no means satisfied that they are distinct. The large size of adult specimens and the difficulty with which they are preserved, however, militate against the acquisition of such a series. All the ordinary specimens of $P$.pectinatus I have seen have been less than Io feet long with the saw, while the two of $P$. zysron $I$ have examined in detail have been over I 5 feet. I doubt whether either form grows as large as $P$. perottetii.

\section{Family RHINOBATID巫 (Guitar-Fishes, Spear-Sharks).}

Shark-like rays (having the gills on the ventral surface) with the anterior part of the body depressed but comparatively little expanded and the pectoral fin-rays not extending forwards to the sides of the head. The snout rounded or produced, without rostral teeth. No electric organ. Two dorsal fins, without spines.

This family is divided by Günther, as by most other ichthyologists, into three genera, viz., Rhynchobatus, Rhinobains and Trygonorhina. Trygonorhina, which is distinguished from Rhinobatus by having the anterior nasal valves confluent, is only known from the S. Pacific, but Rhynchobatus and Rhinobatus are both well represented in Indian seas. Two very dissimilar species, however, are held by most authors to constitute the former genus, although they differ from one another considerably not only in the shape of the snout but also in the structure of the head. These two species are $R$. ancylostomus and $R$. dieddensis. The former in my opinion is not congeneric with the latter and as Gill's generic name Rhamphobatis is available for it, I have placed it in that genus. As regards $R$. djeddensis, moreover, I liave been confronted with a difficulty in the matter of the proper genus to which it should be assigned. It is supposed to be distinguished from the species of Rhinobatus by certain rather ill-defined 
characters, which are discussed beiow. I cannot regard it as generically distinct from its allies usually placed in Rhinobatus.

The two Indian genera recognized in this paper are, therefore, Rhamphobatis, Gill (I86I), and Rhinobatis, Bloch and Schneider (I8OI).

\section{Genus Rhamphobatis, Gill.}

Head rounded in front, not produced into a rostrum. Back bearing large compressed bony tubercles arranged in rows. Teeth lozenge-shaped, transverse, with many sinuous, parallel transverse ridges.

I have made a careful comparison between the skull of the one species of this genus and that of Rhinobatis djeddensis. The cranial cartilages are somewhat different in the two species. In the latter a single rostral cartilage projects forward between the nasal capsules ; its ventral surface is hard, solid and undivided, but there is a broad and lengthy longitudinal depression on the dorsal surface. In Rhamphobatis, on the other hand, a pair of rostral cartilages, which are much broader and flatter than the single one in Rhinobatis and only joined to one another at the base by membrane, arise in the same position and only unite as cartilages near the tip of the snout. The condition in Rhinobatis gramulatus, $R$. schlegelii and $R$. halavi is exactly the same as in $R$. djeddensis.

There is, moreover, a distinct difference between the teeth of Rhamphobatis and those of all the species of Rhinobatis I have examined. In the latter genus, although the teeth differ considerably in the different species, they may be described in all cases as having a single transverse ridge, which sometimes is raised in the centre so as to be almost conical. In Rhamphobatis, on the other hand, the teeth bear numerous wavy transverse ridges, none of which is much better developed than the others.

\section{Rhamphobatis ancylostomus (Bloch and Schneider). (P1. v, fig. 5.)}

Pectoral fins with the anterior margins not joined by skin to the sides of the head. A median dorsal ridge of large, compressed, irregular tubercles running from just behind the spiracles a little more than half way to the first dorsal fin ; a similar ridge on either side running along the internal margin of the orbit and spiracle and. continued in a somewhat less conspicuous fashion round the anterior margin of the former; a patch of similar tubercles in front of each of these lateral ridges, which are continued posteriorly, after a considerable interruption, by short and feeble ridges in a straight line with them; a still shorter and feebler outer lateral ridge on either side parallel to the main one. The two dorsals and the caudal fin about equidistant from one another; the posterior rather smaller than the anterior; the lower lobe of the caudal long and pointed. A strong ridge on the side of the tail. Mouth strongly undulated, the two downward projections on the upper jaw and the three upward projections on the lower jaw approximately equal; the teeth lozenge-shaped, the breadth $\frac{5}{6}-\frac{6}{7}$ of the length ; ten distinct ridges on the unworn teeth; teeth much smaller on the excavations of the jaw, than on the projections. 
There is a cast of a young specimen coloured from life in the Trivandrum Museum. It is of a bright salmon-pink body colour with numerous, narrcw, irregular black transverse bars. In older individuals the pink fades to a dull greenish shade, while the black bars become fainter and anastomoye into a more or less regular reticulation, at first enclosing round white spots and finally becoming almost obliterated, so that only a faint marbling persists. In old specimens, however, scme dark linear markings usually remain on the base of the pectoral fins. In the male fgured on plate $\mathrm{v}$, fig. 5, these markings took the exact form of a ? symmetrical on the two sides.

Five specimens have been taken to my knowledge by the 'Golden Crown,' four of them fully adult. One ( $q$ ) was captured in October off the Orissa coast, and two $(\diamond, q)$ in December off the mouth of R. Hughli. The measurements of the former and of one of the latter were as follows :-

Total length

Mouth to vent

Width of mouth ...

Distance between eyes

Anterior border of pectoral fins

Anterior border of pelvic fins . .

Anterior border of Ist dorsal . .

Anterior border of 2nd dorsal . .
Breadth across pectoral fins

Length of upper lobe of caudal fins

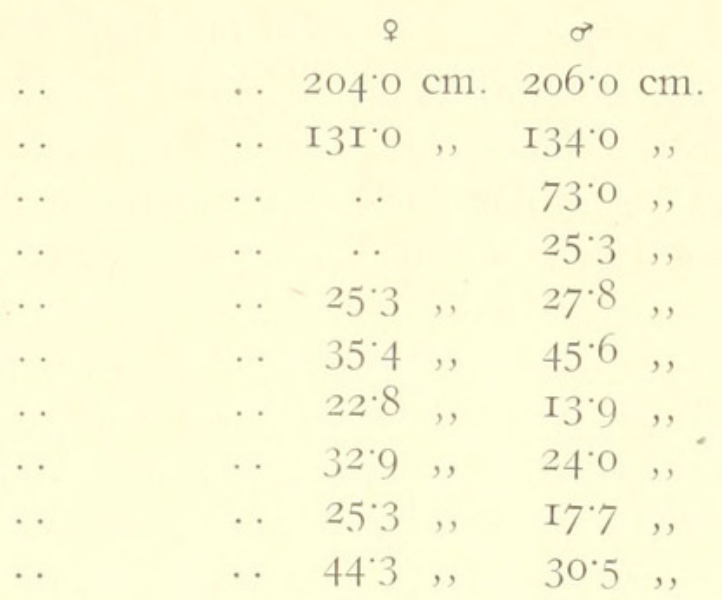

Day's figure (Fishes of India, vol. ii, pl. cxciii, fig. 3) is evidently taken from an immature specimen. I therefore reproduce a photograph of the male whose measurements are given above.

\section{Genus Rhinobatis, Bloch and Schneider.}

Head produced into a more or less elongated and narrow rostrum without lateral teeth.

Back bearing tubercles of various kinds in rows, or uniformly covered with granular denticles. Teeth lozenge-shaped or almost circular, with a single transverse ridge or a central conical projection. Anterior nasal valves not confluent.

Müller and Henle in separating " Rhynchobatus " from the species they included in " Rhinobatus" relied mainly (see Syst. Beschr.d. Plagiostomen, pp. II I and II3) on the shape of the nasal valves, the position of the spiracles relative to the eyes and the outline of the anterior part of the body, while Günther (Cat. Fishes, viii, pp. 440.44I) and Day (Faun. Brit. Ind., Fishes, i, pp. 39, 40, 42) lay great stress on the fact that the anterior margin of the pectoral fin is quite free in Rhynchobatis and is joined to the snout by a membrane in Rhinobatis. Day also notes that the anterior dorsal fin is opposite the pelvic fins in the former genus and far behind them in the latter.

The differences noted by Müller and Henle undoubtedly exist, but they seem hardly to be of generic value, considering the variation that occurs within the limits of the genus Rhinobatis (sensu stricto), nor does the difference in the position of the 
dorsal fins seem to be of very great importance; in some species (e.g., P. schlegelii) the first dorsal is much nearer the pelvic fins than it is in others (e.g., R. gramulatus). As regards the freedom or otherwise of the anterior border of the pectoral, I fail to see any absolute difference at all in fresh or well-preserved specimens. Undoubtedly, however, there is a certain gradation in respect of this character; in $R$. djeddensis the fin projects more freely than it does in $R$. gramulatus, but in $R$. gramulatus it projects more freely than in $R$. halavi. The fact that the lower lobe of the caudal is distinct in $R$. djeddensis and not so in the other species would not be regarded as a generic difference in other families of the suborder. Indeed, "Rhynchobatus "' seems to me to be less widely separated from such a form as Rhinobatis gramulatus than Pristis cuspidatus is from such a form as P. perottetii.

\section{Key to the Indian Species of Rhinobatis.}

I. Anterior dorsal fin above pelvic fins. Tail with a distinct lower pointed $\begin{array}{llllllll}\text { lobe } & \ldots & \ldots & \ldots & \ldots & \ldots & \end{array}$

II. Anterior dorsal fin wholly behind the pelvic fins.

A. No fold of skin on the interval between the anterior angles of the nostrils.

$\mathrm{A}^{\prime}$. Interval between the posterior angles of the nostrils not markedly less than the length of one nostril.

(a) A row of sharp spines running down the centre of the back. Snout acutely pointed _. . R granulatus.

$\left(a^{\prime}\right)$ An interrupted row of obtuse spines on the back. Snout $\begin{array}{llllll}\text { obtuse } & \ldots & \ldots & \ldots & \ldots & R \text {. halavi. }\end{array}$

$\mathrm{A}^{\prime \prime}$. Interval between the nostrils posteriorly less than half the length of one nostril $\quad \ldots \quad \ldots \quad \ldots \quad \ldots$ thouini.

B. The anterior nasal valve on each side continued as a fold of skin extending towards the other nostril.

(b) Back with a median row of large, smooth tubercles crossed by a vertical line of similar tubercles on the shoulder $R$. columna.

$\left(b^{\prime}\right)$ Back finely granular with faint indications of a mid-dorsal row of enlarged tubercles $\quad \ldots \quad \quad \quad \ldots \quad R$. schlegelii.

Of the six species enumerated in this key four have been taken by the " Golden Crown,' ' while a fifth is fairly well represented in the old collection of the Indian Museum. I have not seen $R$. thoumi. $R$. schlegelii is here recorded from Indian seas for the first time; $R$. djeddensis has been taken in very large numbers, while $R$. gramulatus is represented by a single specimen in the "Golden Crown"' collection and by several in that of the Indian Museum; of $R$. columne several specimens have been taken by thetrawler.

6. Rhinobatis djeddensis (Forskål).

Rhynchobatus djeddensis, Günther, op. cit., p. 44I ; Day, op. cit., p. 40.

Snout pointed, measured from the mouth between $\frac{1}{5}$ and $\frac{1}{4}$ of the total length; the concavity on the dorsal surface extending forwards for a considerable distance. 
Back in the adult bearing several rows of regular, compressed bony tubercles, which also surround the anterior margin of the orbits. The ventral lobe of the tail almost equal to the dorsal lobe in the young, relatively smaller in the a fult. The posterior dorsal fin smaller than the anterior, which is situated over the pelvic fins. There are two conspicuous ridges on the posterior margin of the spiracle. The jaws have each a single undulation, which is not very deep. The teeth are large, suboval transversely, and bear a single transverse central ridge, which becomes obsolete as they are worn, the breadth of each tooth is to the length as 5 to 3 or 3 to 2 ; the teeth on the central concavity of the upper jaw are smaller than the others.

In the young the back is of a rather pale greyish olive-green, which takes a bluish tinge on the eyelids. The lateral and caudal fins and the greater part of the snout are pink. On each side, near the centre of the base of the pectoral, there is a large round black spot, which is surrounded by much smaller white spots. Numerous similar white spots are scattered on the sides of the body and a few appear on the pectorals. In older specimens the olive-green becomes darker and greyer, the spots tend to disappear, although perhaps they never become quite obsolete, and the pink changes to grey.

It is unnecessary to describe this common and well-known species at any great length. It is by far the most abundant species of its family in the catches of the "'Golden Crown,', whose trawl brings up numerous examples on every trip. The largest specimen I have seen measured $8 \mathrm{ft}$. 9 inches $(258 \mathrm{~cm}$.). It was a female with seven fully formed young ones in one oviduct, the other oviduct being empty and its corresponding ovary containing large eggs.

The unborn young measured $34 \mathrm{~cm}$. in length and bore yolk-sacs, which were smaller than those of some young ones captured free. In the case of the latter the yolk-sac was as big as a small orange. There does not appear to be any arrangement for supplying the unborn young with maternal nourishment in the case of this species. Day mentions that the young are very common off the Coromandel coast about March; they are also abundant at the head of the Bay of Bengal in September and October.

\section{Rhinobatis halavi (Forskål).}

Rhinobatus halavi and Rh. obtusus, Gthr., op.cit., pp. 442, 443 ; Rh. halavi, Day, op. cit., p. 43 .

I have not the material on which to base a fresh description of this species, as regards the synonymy of which I merely follow Day. No specimens have been taken by the " Golden Crown "' and there are only dried or immature specimens in the Museum. A stuffed female measures $128 \mathrm{~cm}$. in total length, and we have a much smaller one in spirit, as well as several other skins. The short, obtuse snout is characteristic.

The teeth resemble those of Rh. granulatus but their transverse ridge is not so strongly convex. 


\section{Rhinobatis gramulatus.}

Rhinobatus granulatus, Gthr., op. cit., p. 443 ; Day, op. cit., p. 42.

Snout pointed, variable in length, as a rule from $4 \frac{1}{2}$ to $5 \frac{1}{2}$ times in the total length; the dorsal concavity triangular, narrow. The interval between the nostrils posteriorly not or hardly greater than the length of the nostril; the anterior nasal valve variable in size, usually small, not produced inwards beyond the limits of the nostril. The two dorsal fins situated considerably behind the posterior margin of the pelvic fins, equal or subequal, separated by rather more than the length of anterior fin. The lower lobe of the caudal rounded, not distinctly marked off from the dorsal lobe.

The back, the central ridge of the snout and the anterior part of each dorsal fin covered in the adult with somewhat irregular, granular or obtusely pointed, small denticles, which become smaller from the mid-dorsal line outwards. There is a distinct row of sharp retroverted spines extending along the mid-dorsal line from a little behind the spiracles to the anterior dorsal fin, and as a rule there are several similar spines on the anterior margin of the orbit. The lateral fins and the sides of the snout are naked. In the young (=Rhinobatus philippi, Müller and Henle) there are two sharp, retroverted spines on either shoulder, forming with the slightly enlarged denticles which surround them a line crossing the mid-dorsal line at right angles. On either side of the rostral ridge there is a line of similar spines; the dorsal line extends backwards between the two dorsals.

The colour of the adult is described by Day as " reddish grey superiorly, becoming dull white beneath.', The young is greenish grey on the back ; the snout pure white, with the exception of the central ridge, which is of the same colour as the back.

The jaws are very feebly undulated, and it is not possible to recognize definite upward and downward projections and corresponding concavities in them. The teeth are small, transversely rhomboid, but with the four angles somewhat rounded. The transverse ridge runs across the tooth near the inner margin and is markedly convex in its centre, so that the exposed surface of the tooth as a whole has a tubercular appearance. There is no marked difference in the size of the teeth at different points on the jaw.

Only one specimen of this species appears to have been taken by the " Golden Crown,' a young female from off the Orissa coast. There are, however, several other specimens in the Museum collection. The largest (stuffed) measures I $85 \mathrm{~cm}$. in total length.

\section{Rhinobatis columna, Bonaparte.}

Rh. columnæ, Bonaparte, Fauna Italica, Pesci, No. I52, plate.

? Rh. horkelii, Mïller and Henle, op. cit., p. I22, pl. 4I.

Snout sharply pointed, about $6 \frac{1}{2}$ times in the total length; the distance between the outer angles of the nostrils rather more than $\frac{1}{2}$ and less than $\frac{2}{3}$ of that between the mouth and the end of the snout. The anterior nasal valve produced 
into a fold which does not reach or barely reaches the lateral margin of the nostril. The back very flat; the breadth across the widest part of the pectorals $2 \frac{1}{2}$ times in the total length. Pectoral fins broadly rounded; tip of pelvic fins nearly reaching base of first dorsal, which is separated from second dorsal by more than twice its own length. Rostral ridges narrowly separated. Back minutely granular with a row of smooth, rounded tubercles extending down the centre from a short distance behind the eyes to the posterior dorsal fin; a semicircle of similar tubercles extending round the inner margin of each orbit, and a short interrupted row crossing the mid-dorsal line at right angles in the scapular region. Colour of young dark greyish brown with indistinct marblings of a darker shade and with numerous somewhat obscure, round, whitish spots ; edges of snout white in smaller specimens; all the fins becoming pale at the edge; ventral surface white. The larger specimens I have examined are darker than the smaller ones and have less white on the snout, which in some is of the same colour as the back.

The mouth is straight; the teeth are small and almost flat, the ridge across them being feebly developed. They are of the same size on all parts of the jaw.

Several specimens of this species were obtained off the entrance to the Eastern Channel of the mouth of the river Hughli by the " Golden Crown ', in February, Igog. The largest, a male with the claspers evidently immature and not reaching the tip of the pelvic fins, measured $42.9 \mathrm{~cm}$. in length. Except as regards colour, these specimens agreed closely with Mülier and Henle's figures of $R$. horkelii, which appears to be separated from $R$. undulatus mainly on account of its darker snout. A pale snout is characteristic of the young, however, not only in $R$. columnce but also in $R$. djeddensis, $R$. halavi, $R$. schlegelii and $R$. gramulatus. The same is true as regards white spots, at any rate in the case of $R$. djeddensis and $R$. schlegelii.

Both Günther and Day state that in $R$. columna ${ }^{1}$ the continuation of the anterior nasal valve almost meets its pair on the other side. In Bonaparte's original figure, however, this is not represented as being the case. My specimens agree much more closely with Günther's description of $R$. undulatus than they do with his description of $R$. columna, but I feel bound to follow Bonaparte's figure in my identification. Some confusion probably exists between these two species, but I have not the material to clear it up.

Rhinobatis schlegelii, Mïller and Henle.

Rhinobatus schlegelii, Gthr., op. cit., p. 445 .

Snout long, pointed, but shorter than that of $R$. gramulatus; the central concavity of the rostral ridge elongated and narrow. The two ridges on the posterior border of the spiracle very strongly developed. Anterior nasal valve produced into a flap which extends beyond the edge of the nostril inwards towards the middle line but does not nearly meet its fellow of the opposite side. Posterior nasal valve

1 Since the above was written I have been able to examine a small Italian specimen of $R$. columna preserved in sp rit. It appears to $b$ e browner than my In lian specimens and lacks all trace of white spots. Otherwise it agrees with them very closely, except that perhaps the tubercles on the back and round the orbits are a little less prominent.-April I8th, I9og. 
strongly dilated on the margin of the nostril. Anterior dorsal fin slightly behind the pelvic fins, the claspers reaching as far as its anterior margin in the male; both dorsal fins short and high, subequal, separated by several times the length of the anterior fin. Denticles minutely granular all over the dorsal surface, barely enlarged on the mid-dorsal line.

Colour of the dorsal surface uniform brownish grey or olive-green in the adult; sides of the snout pale in young specimens; numerous faint white spots all over the dorsal surface of the body in the unborn young.

Jaws nearly straight. Teeth small, with the transverse ridge so strongly convex that when viewed in profile they appear to be almost conical with a flattened base.

Several adult specimens of this species were obtained by the " Golden Crown" off the entrance to the Eastern Channel of the river Hughli in a depth of about 30 fathoms in February, I909, and a small male, which was presented by Mr. J. H. Row and identified by Col. Alcock, has been in the Museum for some years. It was taken in the Mutlah river, which connects the Salt Lakes near Calcutta with the sea. Günther mentions an adult female of $700 \mathrm{~mm}$. and an adult male of $750 \mathrm{~mm}$. from Japan. A female from the Eastern Channel with five young in its oviduct measured $500 \mathrm{~mm}$., while an apparently adult male measured $336 \mathrm{~mm}$. The transverse diameter across the pectoral fins was in the former case $187.5 \mathrm{~mm}$. The young from the oviduct of this specimen measured r $20 \mathrm{~mm}$. in length and $44 \mathrm{~mm}$. across the disk. Their snouts, although produced, terminated much more abruptly than was the case in the adult, the two sides being nearly parallel. In the mother the length of the snout (measured from the eyes) was contained 5.62 times in the total length, while in the young it was contained 6.66 times.

$R$. schlegelii has been recorded from the east coast of Africa as well as from Chinese and Japanese seas.

\section{Family RAJID王 (Skates).}

Head and body forming a rhombic disk, much flattened; the pectoral fins extending to the snout; tail quite distinct. Skin usually bearing spines and large denticles. Tail with a longitudinal fold on each side and a caudal fin, which is degenerate in some genera; dorsal fins present. No electric organ. No serrated caudal spine.

In Day's works on Indian ichthyology only one member of this family is recorded as occurring in Indian seas, viz., Platyrhina schonleinii. In recent years, however, six species of Raja of which four are markedly distinct from one another, although each species is founded on a single specimen) have been described by Alcock or Lloyd. A specimen which I take to belong to Alcock's Raja powellii was recently taken in shallow water off 'Trivandrum on the west coast of India and has been presented to the Indian by the Trivandrum Museum; but the members of the family belong essentially, so far as Indian seas are concerned, to the deep-sea fauna. Captain R. E. Lloyd has therefore dealt with them in a paper (to be issued in the Memoirs of the Indian Museum almost simultaneously with this one) on the deep-sea fishes taken by the " Investigator "' since the publication of Col. Alcock's monograph. No Rajidæ have been taken by the " Golden Crown." 
Family TRYGONID瓜 (Sting-Rays and Butterfly Rays).

Head and body forming a rhombic or subc rcular disk; pectoral fins meeting in front of the snout; tail quite distinct. Tail without longitudinal folds, sometimes with dorsal and ventral cutaneous, rayless flaps; dorsal fins absent or very small, a recumbent serrated spine usually present on the tail. No electric organ. Of the true rays this family is the best represented in the Indian seas, in which it is practically confined to shallow water. Four genera and twelve species are recorded by Day; to these, seven species are here added, one having recently been described and three being described below for the first time, while three were previously known but had not been found (or recognized) in Indian seas. One of the forms regarded by Day as distinct is here regarded as synonymous with another. Fifteen species have been taken by the " Golden Crown."

The Trygonidæ, although their flesh is coarse, are eaten by many castes of Indians, who attribute to them certain tonic and aphrodisiac qualities. The tails of the larger species are made into whips and walking.sticks, and there is no doubt that an extremely valuable oil could be manufactured out of their livers (see Mr. Hooper's analysis, postea). The fishery or estuarine species in the river Hughli, however, which is referred to by Blyth (Journ. A siat. Soc. Bengal, xxix, p. 35, i860), appears to have completely died out.

The five Indian genera may be distinguished as follows :-

\section{Key to the Indian Genera of Trygonida.}

I. Tail with a serrated spine, without cutaneous folds or with them rudimentary and not reaching the tip. Teeth flattened, with a transverse ridge or (rarely) with a sharp cusp; jaws not angular .. . . Trygon.

II. Tail with a serrated spine, with a cutaneous fold several times as deep as itself but not extending normally to the tip. Teeth flat, without a transverse ridge;

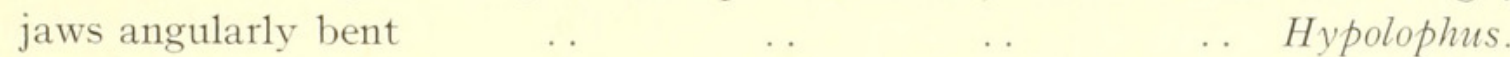

III. Tail without a serrated spine. Teeth without a definite transverse ridge Urogymmus.

IV. Tail with a serrated spine and a cutaneous fold extending to the tip Taniura. V. Disc very broad and short, angular. Tail feeble, with or without a small dorsal fin, normally with a serrated spine. Teeth saddle-shaped, with one or more $\begin{array}{lllllll}\text { sharp cusps in front } & \ldots & \ldots & \ldots & \ldots & & \ldots\end{array}$

The first four genera in this key are very near one another and should perhaps be regarded as subgenera. In Trygon the serrated spine is occasionally absent, while in Hypolophus individuals occur in which, probably owing to injury in early life, the cutaneous fold extends to the extremity of the tail.

In diagnosing the species of this family it is particularly important that attention should be paid to fresh specimens. Many species grow to so large a size that it is practically impossible to preserve them in alcohol, while the characteristic markings disappear and the natural proportions are distorted in stuffed skins.

With reference to measurements it is necessary that an exact statement should be made as regards the methods adopted, for there are several different ways in which 
each of the more important measurements might be taken. So far as the Trygonidæ are concerned I have measured the length of the disk from the tip of the mouth to the base of the tail and have not included the length of the pelvic fins. A more exact measurement might be obtained on the ventral surface, but for diagnostic purposes the one adopted is sufficiently accurate. The breadth of the disk has been measured across the back with a tape, not from point to point. This method gives a more accurate idea of the bulk of a flat fish than that of measuring from point to point, but of course it makes the deeper species, such as Trygon microps, appear to have a larger expanse of pectoral fin than is actually the case. The snout has been measured from a point just in front of the eyes, the interorbital space from the inner margin of one orbit to that of the other, the tail from the posterior end of the disk.

The genera of Trygonidæ are, for the most part, sufficiently defined in the above key, so far as the Indian forms are concerned. Urolophus, which is recorded from Java and may very probably occur within our area, is distinguished from Trygon by the possession of a rayed caudal fin and, in some species, a rudimentary dorsal one.

Genus Trygon, Adanson.

Disk distinct from tail (which is always powerful), more or less flattened, never very much broader than long. No rayed caudal or dorsal fins; at least one serrated caudal spine, except in abnormal specimens; a rayless caudal fold sometimes present on the dorsal or ventral surface of the tail, or on both surfaces, but never much deeper than the tail itself. Teeth as a rule flat with a transverse ridge, rarely bearing a sharp spine.

In the genus Trygon, an important specific character consists in the number, proportion, and outline of the cutaneous processes on the floor of the mouth behind the cutaneous fold that hangs down from the roof. These can only be investigated properly by dissecting out the mouth. Although they are not absolutely constant in any one species, the evidence they afford as to the distinction between allied species such as T. uarnak and T. favus is very valuable, for the differences they display are often strongly marked in allied species. The character of their variation is best illustrated by examples. In T.gerrardii (plate ii, fig. 6) there are usually four processes, the two central ones being much stouter and longer than the two lateral ones. As a rule the central ones are pointed, but in one specimen dissected (plate ii, fig. $6 a$ ) they are blunt and fringed at the tip. In another specimen the two lateral processes are absent. In what seems to be a normal specimen of $T$. microps there are three central processes joined together at the base so as to form a deeply serrated ridge, but in three out of the five individuals I have dissected the arrangement of these processes is not quite symmetrical, while in one there are four central processes with traces of a fifth.

$$
\text { Key to the Indian species of Trygon. }
$$

I. Large species (adults over $40 \mathrm{~cm}$. across the disk, young over $\mathrm{I}_{5} \mathrm{~cm}$.) as a rule with a single large serrated spine ${ }^{1}$ on the tail; cutaneous caudal fold, if present, inconspicuous. 
A. All the denticles with stellate bases.

(a) Distance between the eyes less than half the length of the snout. Base of tail broad and flat $\quad \ldots \quad$.. T.microps.

B. All or most of the dorsal denticles with round or polygonal bases.

(a) Dorsal denticles forming a regular wine-glass-shaped figure with well-defined borders.

$\left(a^{1}\right)$ Distance between the eyes less than half the length of the snout $\quad . \quad \ldots \quad$. . T. bleekeri.

$\left(a^{2}\right)$ Distance between the eyes more than half the length of the snout .. $\quad$. $\quad \ldots$ T. gerrardii.

(b) Denticles not forming a regular figure on the back.

$\left(b^{1}\right)$ Dorsal denticles, if present, confined to the middle line. Dorsal surface pink or red .. . T. bennettii.

$\left(b^{2}\right)$ Dorsal denticles absent from the pelvic fins, flat and rounded. Dorsal surface olive-brown with faint pale spots scattered all over the disk T.alcockii, sp.nov.

$\left(b^{3}\right)$ A row of sharp spines running down the middle of the back and the base of the tail. Dorsal surface olive-brown, without spots .. T.jenkinsii, sp. nov.

$\left(b^{\star}\right)$ Flat dorsal denticles irregularly interspersed with small stellate ones on the body ; the pectoral fins covered with small stellate denticles. Dorsal surface grey$\begin{array}{lllll}\text { ish } & \ldots & \ldots & \ldots & T \text {. marginatus. }\end{array}$

$\left(b^{5}\right)$ Flat dorsal denticles irregularly interspersed with small stellate ones, which are absent from the pectorals. Dorsal surface of adult pale brown with darker markings; of young white with black spots T. uarnak.

$\left(b^{5}\right)$ No stellate denticles. Dorsal surface of adult dark brown with a bold honeycomb pattern of dull yellow.

T. favus, sp. nov.

II. Small species (adults less than $40 \mathrm{~cm}$. across the disk, young not more than Io $\mathrm{cm}$.).

A. Distance between the eyes about one-third the length of the snout. Dorsal surface dark brown . .

T. zugei.

B. Distance between the eyes less than half the length of the snout. Dorsal surface pale brown _. . . T.imbricata.

C. Distance between the eyes almost as great as the length of the snout. Dorsal surface grey with bluish spots ..

T. kuhlii.

The only species named in the key I have not seen is Trygon bennettii. Duméril (Nat. Hist. Poissons, i, p. 596, I865) records a specimen of this species measuring 43 cm. across the disk, while one of Henle and Müller's was rather larger ' ' Plagiostomen,'” p. I6I). All the figures I have seen, however, look as though they represent young 
individuals. The adults of the other species included in Section I of my key grow over 2 feet $(60 \mathrm{~cm}$.) in diameter, but $T$. gerrardii does not greatly exceed this limit.

Trygon microps, Annandale. (P1. iv, fig. I ; pl. ii, figs. 3, 3a; pl. iii, fig. I.)

T. microps, Annandale, Rec. Ind. Mus., ii, p. 393, pl. xxvii.

Size large (large female over $222 \mathrm{~cm}$. across the disk, large male over Igo $\mathrm{cm}$.).

Colour white; the dorsal surface of the disk suffused with rose-pink, without definite markings ; tail grey above, becoming darker distally.

Disk rhombic, wider than long by more than one-quarter of the width; the pectoral angles rather greater than right angles. Snout rounded as a whole, but with a small terminal projection which is covered with enlarged denticles. Distance from eyes to tip of snout greater than that from eye to eye; length of snout $3 \frac{1}{2}$ to $4 \frac{1}{2}$ in length of disk.

Eyes very small, dark in colour, little prominent; spiracles large, without dorsal flaps, their area more than eight times that of the eyes.

Tail without cutaneous fins, not longer than disk, consisting of a broad, flat, proximal part about half as long as the disk, and a slender, cylindrical distal part of approximately the same length, a single massive spine borne at the junction of the two parts ; a very low ridge on the ventral surface of the distal part.

Skin soft and delicate, without enlarged tubercles on the disk, bearing numerous minute, spiny denticles (pl. ii, figs. $3,3 a$ ), all of which have stellate bases. The denticles larger on the tip of the snout and the region surrounding the eyes and spiracles than elsewhere, sometimes extending to the ventral surface at the edge of the pectoral fins. The proximal part of the tail armed with much larger denticles, which are largest on the sides and only bear very short stellate spines on the ventral surface; distal part densely clothed with denticles similar to but smaller than those on the sides of the proximal part.

Mouth large; upper jaw undulating slightly, lower jaw practically without undulation; a coarsely digitate cutaneous flap hanging down from the roof of the mouth; usually five short finger-like processes on the floor of the mouth, three in the centre joined together at the base and one at either side (pl. iii, fig. I). Teeth white; the transverse ridge very conspicuous in the unworn teeth, the part anterior to it being slightly concave and considerably greater in area than that posterior to it, which is convex.

Two specimens, both females, have been taken by the "Golden Crown,'” one (the type) off the coast of Chittagong in I7 fathoms in August, and a second, larger specimen off the coast of Orissa in October. In all the specimens examined, the tail looks as though it had been mutilated, but I cannot be quite sure that it is not in its normal condition. The larger specimen gave birth to a young one on board the trawler, but the young one was unfortunately thrown overboard. Owing to a clerical error, which I have been able to rectify by measuring a cast of the type specimen, the tail was represented in my original description of the species as being two feet longer than was actually the case. 
I909.]

N. Annandale: Report on the Batoidei

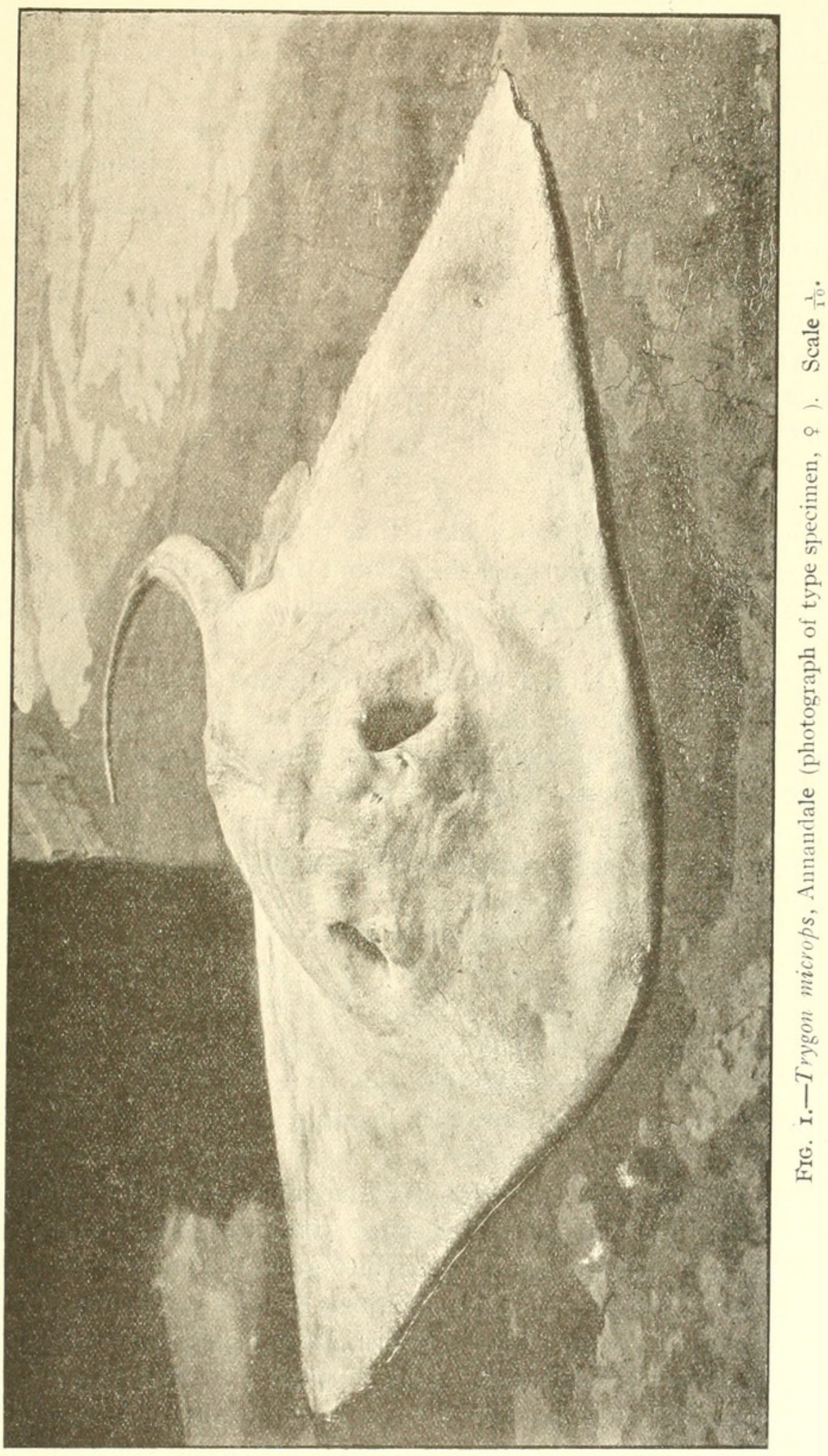


Since this was written three other specimens, including two males, have been taken in 24-27 fathoms off the Ganjam coast (March I909). The claspers of the male are remarkably short. The following are the measurements of two males and two females :-

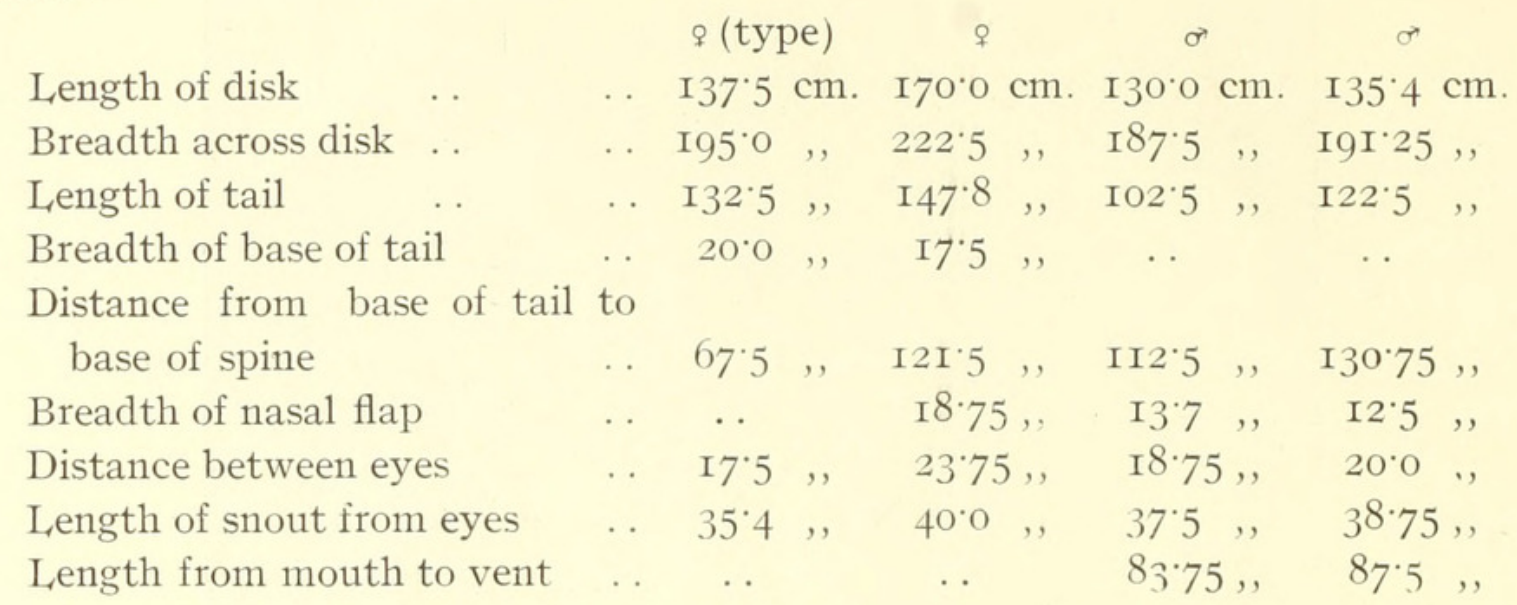

From these measurements it is clear that the proportions are somewhat variable in this species, the relative lengths of the tail and the disk especially being very different in the different individuals. It is very unfortunate that the young one was not preserved.

This is not only the largest species of the genus I have seen, but it differs from the other Indian forms in the shape of the tail and in the fact that all the denticles have stellate bases. The photograph reproduced on plate iv, fig. I, is of the type, and was taken as soon as the specimen was brought ashore. It shows the peculiarities of the tail very clearly.

The type specimen (skin and skull dried, mouth in spirit) is numbered $\mathrm{F} 2 \frac{4}{1}^{0}$ in the registers of the Indian Museum.

Trygon narnak (Forskå1). (P1. i, figs. I, 2 ; p1. ii, figs. I, Ia ; p1. iii, fig. 2.)

T. uarnak, Günther, op. cit., p. 473.

T. punctata, $i d$., ibid., p. 474 (young).

Size large (over $157 \mathrm{~cm}$. across the disk in large individuals, not less than $23 \mathrm{~cm}$. in young).

Colour in young white; the dorsal surface covered with large round or oval black spots; the pectoral and pelvic fins edged with pink in life ; the tail boldly ringed with black. As the fish grows, the white ground of the dorsal surface gradually changes first to grey and then to pale brown, the spots become dark brown in colour and coalesce in various ways to form larger spots or complicated figures. A similar change as regards colour takes place on the tail, but the dark rings remain distinct. There is often a dark margin to the ventral surface of the disk.

Disk with the lateral angles broadly rounded; the length, considerably less than the transverse diameter. In the young the broadest part of the disk is situated at a point not much more than half the distance between the base of the tail and the 
tip of the snout; while in the adult this point is situated at nearly four-fifths of the distance. All the proportions of the disk, however, are variable. The angle of the snout is rather variable but in fresh specimens it is, as a rule, slightly less than a right angle; in the unborn young it is, at any rate in some specimens, obtuse. The length of the snout, measured from the eyes, is about $\frac{1}{5}$ of the total length of the disk in the adult and between $\frac{1}{3}$ and $\frac{1}{4}$ in the young. The outline of the front of the disk is somewhat sinuous in the adult but forms almost a simple concave curve in the young.

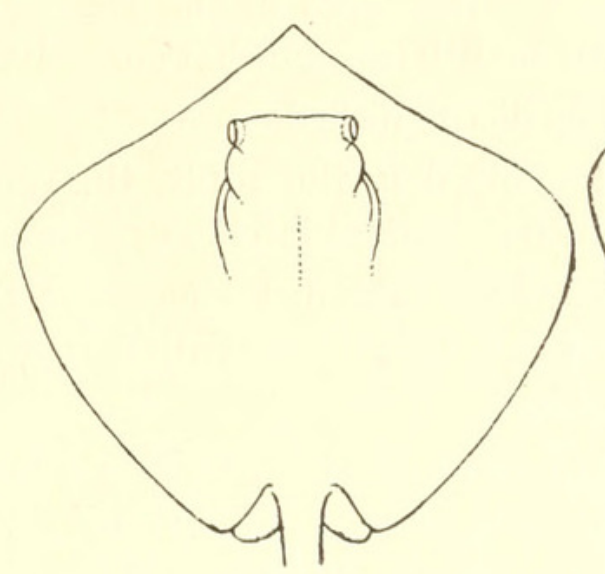

A.

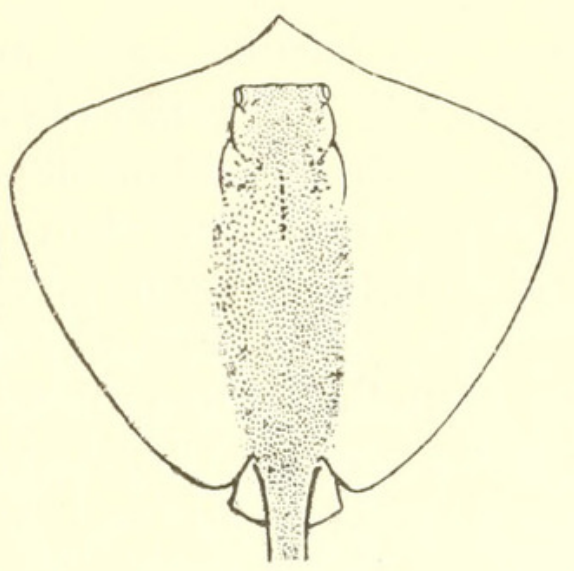

B.

FIG. 2.-Diagram showing the difference in outline between the young $(A)$ and the adult $(B)$ of Trygon uarnak.

Eyes large and prominent, especially in the young. The dorsal wall of the spiracle forming a convex longitudinal flap.

Tail' more than twice as long as the disk, cylindrical, tapering, armed with a single rather slender serrated spine, which is situated much nearer the base than the tip of the tail. No cutaneous folds above or below.

Skin tough. In the young there are as a rule several relatively large rounded tubercles in the mid-line of the scapular region, and these, although at first they are sometimes practically alone, are usually surrounded by smaller, heartshaped, nearly flat denticles which have the narrower end pointing backwards. In the adult the middle of the back is somewhat sparsely covered with similar but relatively smaller denticles, with which are interspersed numerous small, spiny ones with stellate bases. These become more numerous on the posterior part of the disk and the base of the tail, which is completely surrounded by little almost granular denticles with the spiny denticles scattered among them. This arrangement is continued for the whole length of the tail. There are no denticles on the periphery of the disk or on the ventral surface, but those on the back do

I In a large proportion of the larger specimens of the genus Trygon the tail is mutilated; it is often difficult to tell whether mutilation has occurred or not. 
not disappear abruptly as the bare area is reached, but gradually become smaller and form no definite outline to the area they cover.

Mouth large. The jaws are almost straight. The teeth are large, usually more or less deeply tinged with brown in fresh specimens; in the back of the jaws, where they are not worn, each has two distinct transverse ridges, a secondary shorter one running parallel to the median ridge and in front of it. There are normally four processes on the floor of the mouth, subequal in size, the two lateral ones being only smaller than the two median, and situated at about an equal distance apart. A somewhat similar process projects into the mouth from the cutaneous fold which covers the inner base of the teeth of the lower jaw; the fold which hangs down from the roof of the mouth is somewhat coarsely digitate.

Two colour varieties of T. uarnak can be distinguished-

Var. $a$. Anterior part of the disk spotted in the adult, the spots combining on the posterior part into irregular blotches or figures.

Var. $b$. The whole of the dorsal surface of the disk covered in the adult with an irregular network of dark lines, often with dark spots or streaks in the centre of the meshes.

Var. a must be considered the typical form of the species as Forskal says in his original description " tota maculata" (Descr. Anim., p. I8, No. I6b, I775).

Var. $b$ may be identical with $T$. undulatus, Bleeker. According to Blyth it is identical with McClelland's T. variegatus, but I have not seen any specimen on which the markings were so scanty and so open as they are represented in the figures published by the latter author (cf. Blyth, Journ. Asiat. Soc. Bengal, xxix, p. 43, and McClelland, Calc. Journ. Nat. Hist., i, p. 66, pl. 2, fig. 2).

Day, judging from his description (Malabar Fishes, p. 277; Fishes of India, vol. ii, p. 735 ; and Faun. Brit. Ind., Fishes, vol. i, p. 53), had seen the true T. uarnak, but unfortunately his figure in the Fishes of India (p1. cxciv, fig. I) represents not this species but $T$. gerrardii, a smaller and otherwise different species which has been confused with T. narnak by several authors, notably by Müller and Henle (" Plagiostomen,'” p. I59, vars. I and 3).

I have been able to examine a very large series (some hundred specimens) of this species, representing every stage between the unborn young and the adult over five feet in diameter. Specimens have been taken practically every trip by the "Golden Crown," but Dr. Jenkins tells me that large individuals are particularly abundant in about 30 fathoms of water off the mouth of the river Hughli on a muddy bottom.

$$
\text { Trygon gerrardii, Gray. }
$$

T. gerrardi, Günther, op. cit., p. 474 .

T. uarnak, Day, Fishes of India, vol. ii, pl. cxciv, fig. I.

To describe this species it is only necessary to indicate the points in which it differs from T. uarnak.

Size moderate (largest specimen $67.5 \mathrm{~cm}$. across the disk).

Disk shaped and proportioned much as in the young of T. warnak. 
Colour of the dorsal surface of the young brownish slate-colour without spots, the tail being banded with black and white; the edge of the pectorals pale. As the fish grows, the colour darkens to a warm brown, and large, round, widely separated cream-coloured spots appear on the posterior part of the disk and on the pelvic fins. In still older specimens the ground colour darkens considerably, the cream-coloured spots become obsolete, and the banding on the tail disappears.

The skin is tough as in T. narnak, but the arrangement of the denticles is quite different, at any rate in the adult. In the young they resemble those of the adult of T. uarnak, except that none of them have stellate bases or spiny processes. In adult and half-grown fish, however, they form a compact pavement-like surface. which occupies the middle of the disk from the head backwards and has welldefined limits, towards which they are little smaller than they are elsewhere. The outline of this surface resembles a wine-glass or flower-vase with the mouth directed forwards. On the tail this figure is continued, representing here the stem of the vase; but it ends, in front of the serrated spine, in a point. The denticles are confined to the dorsal surface of the base of the tail and do not extend either to the ventral surface of the basal part or beyond the spine on the dorsal surface.

Mouth.-The central part of both jaws is practically straight, but on either side of it on the upper jaw there is a distinct concavity, corresponding to a similar convexity of the lower jaw. The teeth are nearly white; a single stout transverse ridge runs across the centre of each (unworn) tooth, separating two equal convex surfaces, each of which is strongly corrugated longitudinally. There are normally four processes on the floor of the mouth as in T. uamak, but the two central ones are much stouter than the lateral ones and somewhat widely separated from them.

Although I have not been able to examine so large a series of this species as I have been able to examine in the case of $T$. uamak, I have seen a considerable number of specimens. T. gerrardi is well represented in the collection of the Indian Museum and is commonly sold in the Burmese coastal markets during the winter months. A considerable number of specimens was taken off the coasts of Burma, Chittagong and Orissa by the "Golden Crown', in the late summer and autumn of last year and in the winter of this. Apparently the species is only taken in shallow water, at any rate in winter.

$$
\text { Trygon favus, sp. nov. (P1. i, fig. } 3 \text {; pl. iii, fig. Io.) }
$$

Closely allied to $T$. uarnak, from which it may be distinguished by the following characters :-

Size moderately large (type ( $f$ ) I $30 \mathrm{~cm}$. across the disk).

Disk very flat, with the pectoral fins even more broadly rounded than in $T$. uarnak, and the snout somewhat more produced; its length about $3 \frac{2}{5}$ in the total length of the disk. Eyes widely separated, small.

Tail rather less than twice as long as the disk.

Colour.-Dorsal surface very dark brown with a bold reticulation of dull yellow, which becomes less regular on the fore part of the disk than it is on the hind part. 
A yellow spot or streak in the middle of most of the meshes of the reticulation. Ventral surface white.

Skin devoid of denticles with stellate bases.

Mouth large. Jaws as in T. gerrardii. Teeth white; the transverse ridge feeble even on the unworn teeth. On the floor of the mouth there are two bluntly triangular processes with irregularly serrated margins and joined together by a similarly serrated ridge.

I have only seen two specimens of this species, both females. They were taken together off the coast of Orissa in October by the "Golden Crown." In spite of their striking coloration I was inclined to regard them as representing a variety of T. uarnak, until I came to examine the interior of their mouths and to analyse the measurements of both forms. Unfortunately only the two mouths and the skin of the back of one specimen could be preserved. One of the mouths, and this piece of skin, therefore, constitute the "'type,"' which is numbered $\mathrm{F} 2 \underline{4} 111$ in the registers of the Museum.

A good photograph of the specimen of which these relics have been kept is given on pl. i, fig. 3 .

Trygon bleekeri, Blyth. (P1. iii, fig. 9.)

T. bleekeri, Day, Fishes of India, vol. ii, p. 738, pl. cxcv, fig. 3 ; Faun. Brit. Ind., Fishes, p. 54.

Size fairly large (adults II 2 - II9 $\mathrm{cm}$. across the disk).

Disk slightly broader than long. The snout narrow, acutely pointed, strongly produced, measuring more than $\frac{1}{3}$ of the total length of the disk and twice as long as the distance between the eyes.

Colour.-Dorsal surface dark brown, unspotted. Ventral surface in young white with a broad margin of dark brown. As the fish grows, this margin becomes broader and finally occupies nearly the whole of the disk. In some adult specimens a distinct streak remains in the middle of the disk; in others this is more or less obscured by dark blotches or disappears almost completely. There are no pale rings on the tail.

Skin.-The scales closely resemble those of $T$. gerrardii in structure and arrangement.

Mouth.-Jaws distinctly undulated, the central part of the upper jaw forming a narrow, conical downward projection, and the lower jaw having a corresponding concavity in the middle. Teeth dark reddish brown, having a single transverse ridge, which is very distinct on the unworn teeth and divides them into two equal convex surfaces marked with longitudinal corrugations. On the floor of the mouth there are two long finger-like processes nearer one another than either is to the angle of the mouth but rather widely separated (pl. iii, fig. 9).

This species is allied to $T$. gerrardii (which it resembles in the nature and arrangements of its denticles very closely) even more nearly than it is to T. uarnak. As regards the processes in the mouth the latter species seems to be at one extreme of a series of which $T$. bleeker $i$ is at the other. 
A considerable number of specimens of $T$. bleekeri were taken by the "Golden Crown " in October off the coast of Burma and Orissa. Most of the specimens I have seen have been females, as is also the case as regards $T$. narnak. The two species are often taken together. Both seem to be commoner in the northern parts of the Bay than off the Madras coast. This is especially the case as regards T. bleekeri, which, indeed, has not been taken by the "Golden Crown'" except in the north. Both species apparently prefer a muddy bottom.

\section{Trygon alcockii, sp. nov.}

Size considerable (adult female $85 \mathrm{~cm}$. across the disk).

Disk slightly broader than long, with the pectoral angles rounded; the length from the maximum diameter to the tip of the snout contained about $2 \frac{1}{4}$ times in the length of the disk. The snout pointed, forming approximately a right angle, by no means strongly produced but considerably longer than the interorbital distance ; its length contained nearly $4 \frac{1}{2}$ times in the length of the disk.

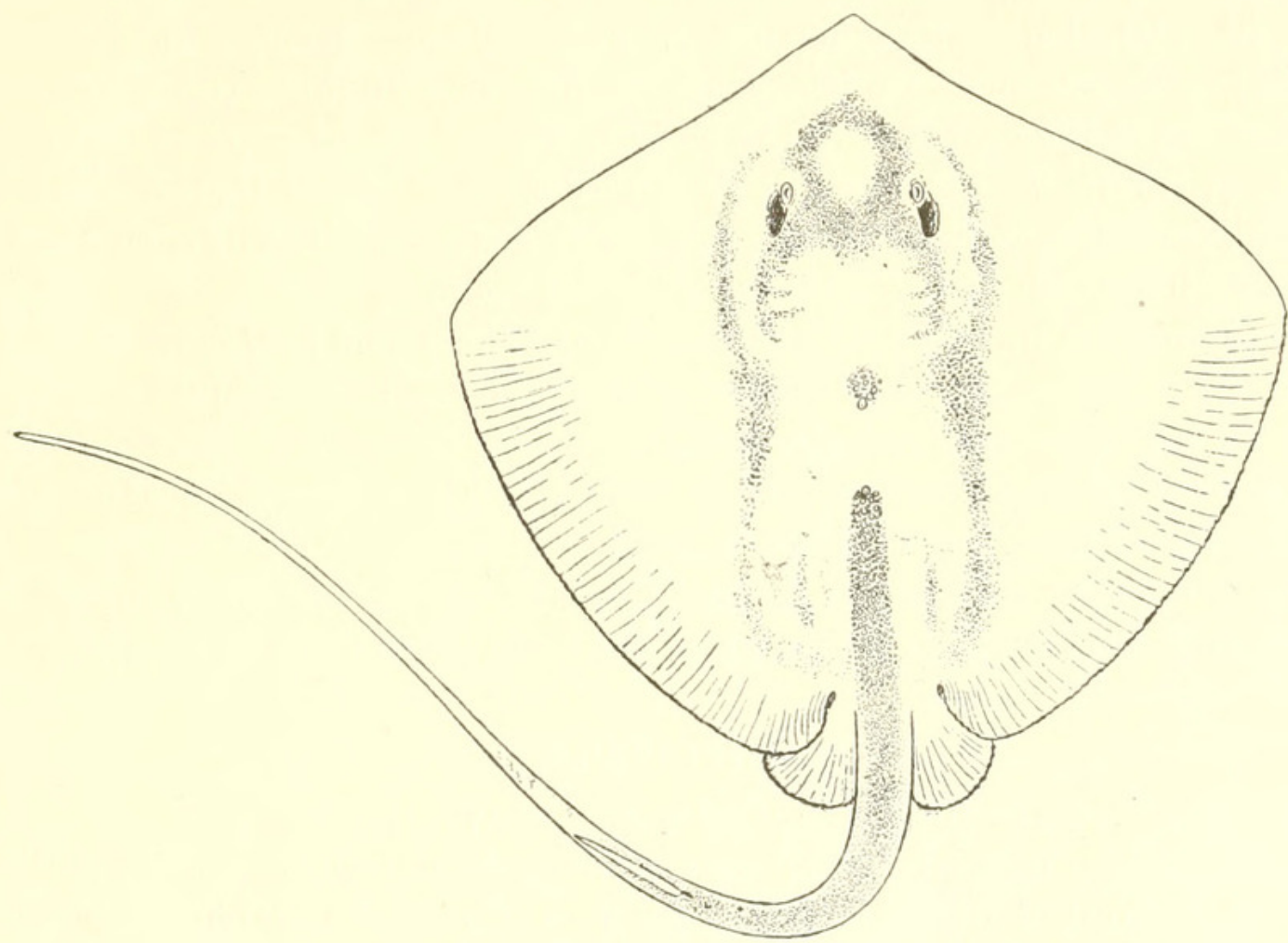

FIG. 3.-Outline of Trygon alcockii, $\times$ c. $\frac{1}{10}$.

Tail nearly cylindrical but somewhat flattened above at the base, tapering, not twice as long as the disk, without cutaneous folds, bearing a single large spine.

Colour._Dorsal surface dark olive-brown with small, obscure, pale spots scattered all over the disk and the base of the tail; the edges of the fins purplish ; the dorsal and lateral surfaces of the tail brown, without markings except at the base. Ventral surface (including base of tail) white, suffused with pink ; a rather broad purplish lateral margin marbled with white. 
Skin tough. The scales flat and more or less rounded, differing greatly in size on different parts of the head and body, to which they are confined on the disk ; the largest occurring in a small patch behind the shoulder girdle; those between the eyes and on the middle of the posterior part of the back and the base of the tail larger than those on the central part of disk, where they are so small and so deeply sunk in the skin that they are almost invisible in the fresh specimen; the tail completely covered with flat scales except as regards the ventral surface of the part anterior to the spine; this surface, the pectoral and pelvic fins bare.

Mouth small; the jaws distinctly but not strongly undulated. The teeth white, with a single distinct central transverse ridge, larger on the upper jaw at the sides than in the middle, not occupying the whole of the exposed surface of either jaw.

Two individuals were taken in a seine-net at Puri on March 2Ist during a short visit to the Orissa coast made by Dr. Jenkins and myself. One had already been cut up before the specimen could be secured, but the other (a female) has been preserved. It is the type of the species, and is numbered $\mathrm{F} 247 \pm$ in the books of the Indian Museum.

This ray is distinguished from $T$. jenkinsii by its flat scales, by its proportions, and by its coloration. The difference as regards the last point is not, however, very marked, for the pale spots are faint and soon disappear in preserved specimens, while the coloration of the ventral surface was perhaps due to some extent to suffused blood. From $T$. gerrardii, $T$. alcockii is distinguished by its larger size, shorter and stouter tail, and differently proportioned disk, as well as by the fact that its spots are scattered on the anterior as well as the posterior part of the body.

As regards the processes on the floor of the mouth in T. alcockii, I am not in a position to give a description of their normal characters, because in the one specimen I have examined they are markedly asymmetrical. I may say, however, that there are, in this specimen, four blunt processes situated at about equal distances from one another. One of them is much longer than the others.

The type of the species was certainly mature and had probably just given birth to a young one as the nutritive filaments in one uterus were highly developed.

\section{Trygon jenkinsii, sp. nov.}

Size moderately large (adult male I03.75 mm. across the disk).

Disk considerably broader than long. The pectoral angles rounded; the length from the greatest diameter to the tip of the snout $2 \frac{1}{2}$ times in the length of the disk. The snout sharply pointed, not much produced, longer than the distance between the eyes, which are large and prominent; the length of the snout contained $3 \frac{1}{2}$ to 4 times in the length of the disk.

Tail cylindrical throughout, without a trace of a cutaneous fin, not much longer than the disk is broad, sometimes bearing two serrated spines, which are long and slender. Colour.-Dorsal surface reddish olive, becoming paler at the edge of the fins, without definite markings. The tail dark grey, mottled on the ventral surface with brown and white at the base. The ventral surface of the disk dead creamy white. 
Skin fairly tough. A' few enlarged rounded denticles in the scapular region followed posteriorly by a single row of stout, short, retroverted spines with flat bases, the row extending on the tail to the base of the anterior spine; the middle of the back occupied by a pavement of small, flat, round scales, which gradually become smaller towards the periphery. The pectoral and pelvic fins naked; the tail covered with small, bluntly spinous tubercles.

Mouth.-Jaws feebly undulated; teeth white, practically uniform in size, each with a low transverse ridge situated near the posterior margin and with a distinct trans-

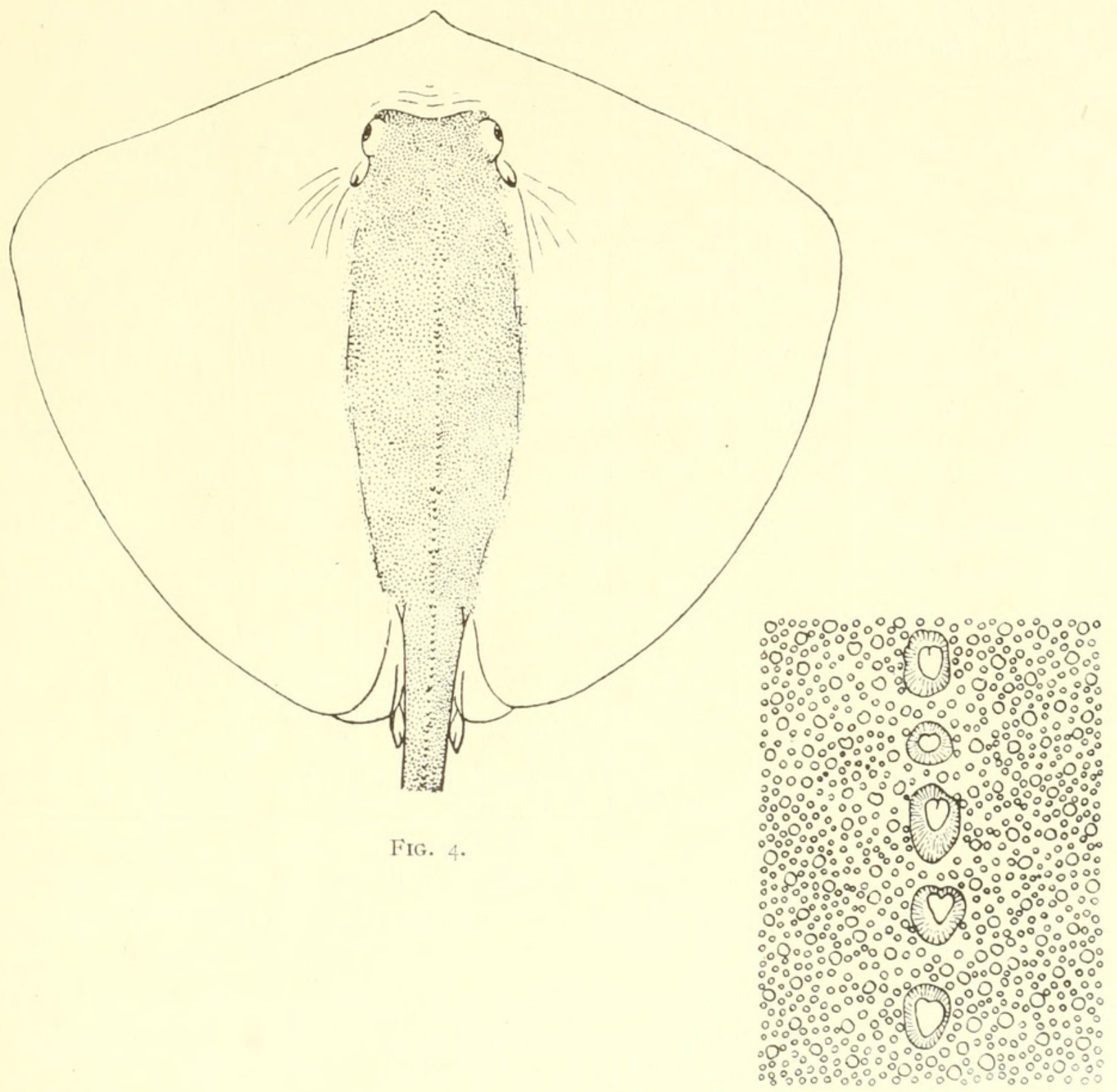

FIG. $4 a$.

FIG. 4.-Outline of fresh specimen of $T$. jenkinsii, $\times \quad$ c. $\frac{1}{9}$.

, 4a. Scales on the middle of the posterior part of the back of the same specimen, $\times \mathrm{I}_{2}^{\frac{1}{2}}$.

verse depression in front. Processes on the floor of the mouth four in number, resembling those of $T$. gerrardii but with the two central ones a little further apart. 
This species appears to resemble $T$. akajei in several respects but to differ in size, in the proportions of the disk and tail, lepidosis and character of the teeth and jaws. Possibly it may be identical with Bleeker's Trygon dadong, but on the whole I think this improbable.

Two adult males were taken by the "Golden Crown "' off the Ganjam coast in 23 to 27 fathoms in March, rgog. The type (dried skin, mouth in spirit) is numbered $\mathrm{F} 2 \frac{473}{?}$ in the Museum registers.

To facilitate comparison I give the measurements of specimens of the six allied species, Trygon uarnak, Trygon gerrardii, Trygon favus, Trygon bleekeri, Trygon alcockii and Trygon jenkinsii together. The specimen indicated with a * was measured in spirit.

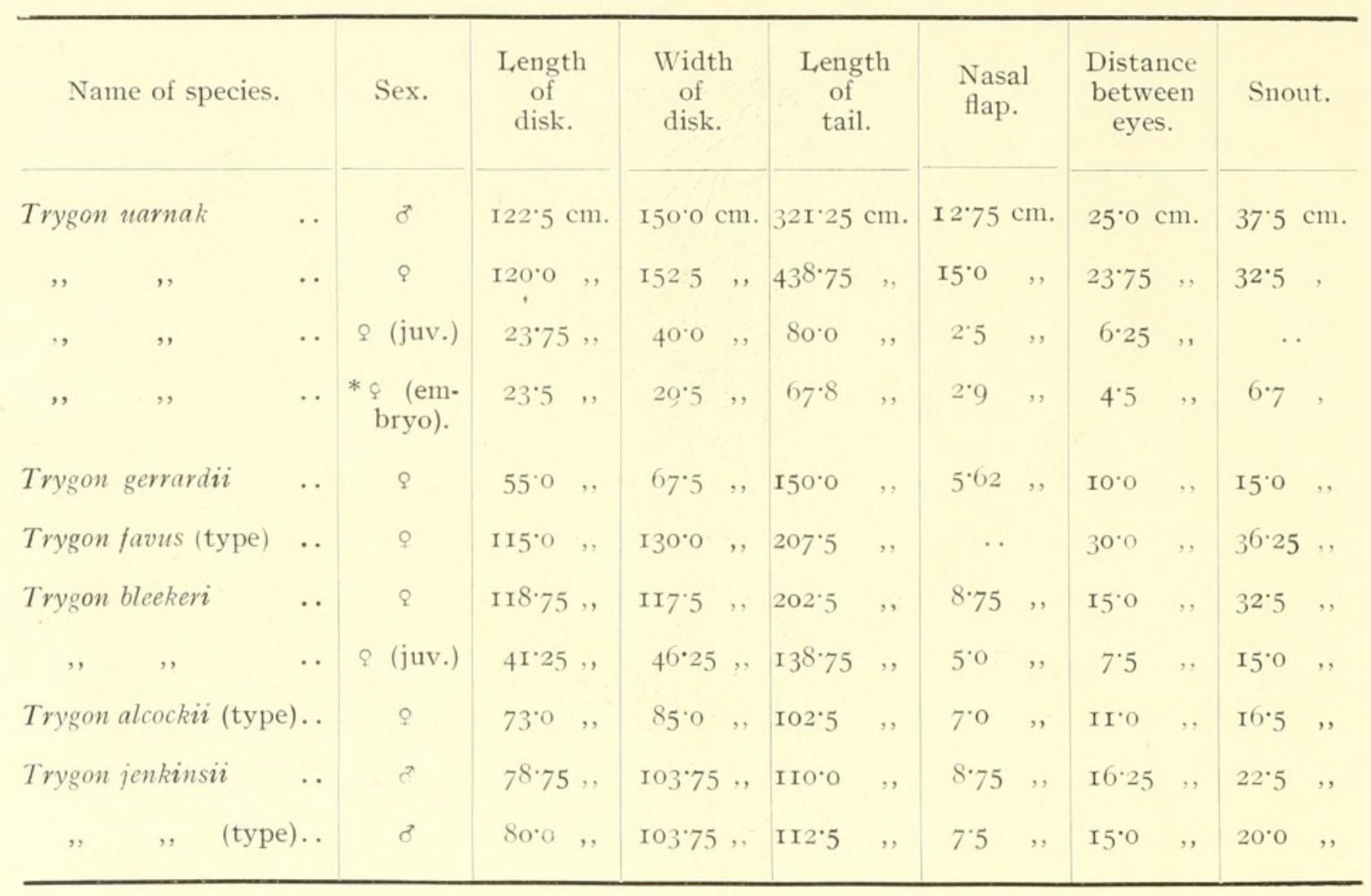

Trygon marginatus, Blyth. (P1. iii, fig. 2.)

T. marginatus, Blyth, Journ. Asiat. Soc. Bengal, xxix, p. 38 (I86I) ; Day, Faun. Brit. Ind., Fishes, p. 54.

Disk broader than long, with the pectoral angles somewhat narrowly rounded. The snout rounded as a whole, but sometimes with a short terminal projection; length of snout $3 \frac{4}{5}$ to $4 \frac{1}{2}$ times in length of disk. Eyes small.

Tail much longer than disk, without caudal folds. There is only one large serrated spine. Colour.-Dorsal surface grey, with a distinct blackish tint and without any tinge of brown. In the male a series of livid bluish marks of an irregularly crescentic outline runs round the disk at some little distance from the margin. Ventral surface white with a broad blackish margin laterally and posteriorly; this margin sometimes indistinct. Tail blackish. 
Mouth rather small; the lower jaw more distinctly undulated than the upper, which is nearly straight. Teeth faintly tinged with brown. The unworn teeth are distinctly but minutely ridged longitudinally; the transverse ridge is strong, and there is a well-marked concavity on the surface in front of it. There are two short processes on the floor of the mouth, one situated near each angle.

Skin.-The skin is delicate, but not so soft as in T. microps. The head and the centre of the back are covered with closely set, rounded, almost flat denticles, which on the tail are intermixed with stellate spines. On the back the denticles become

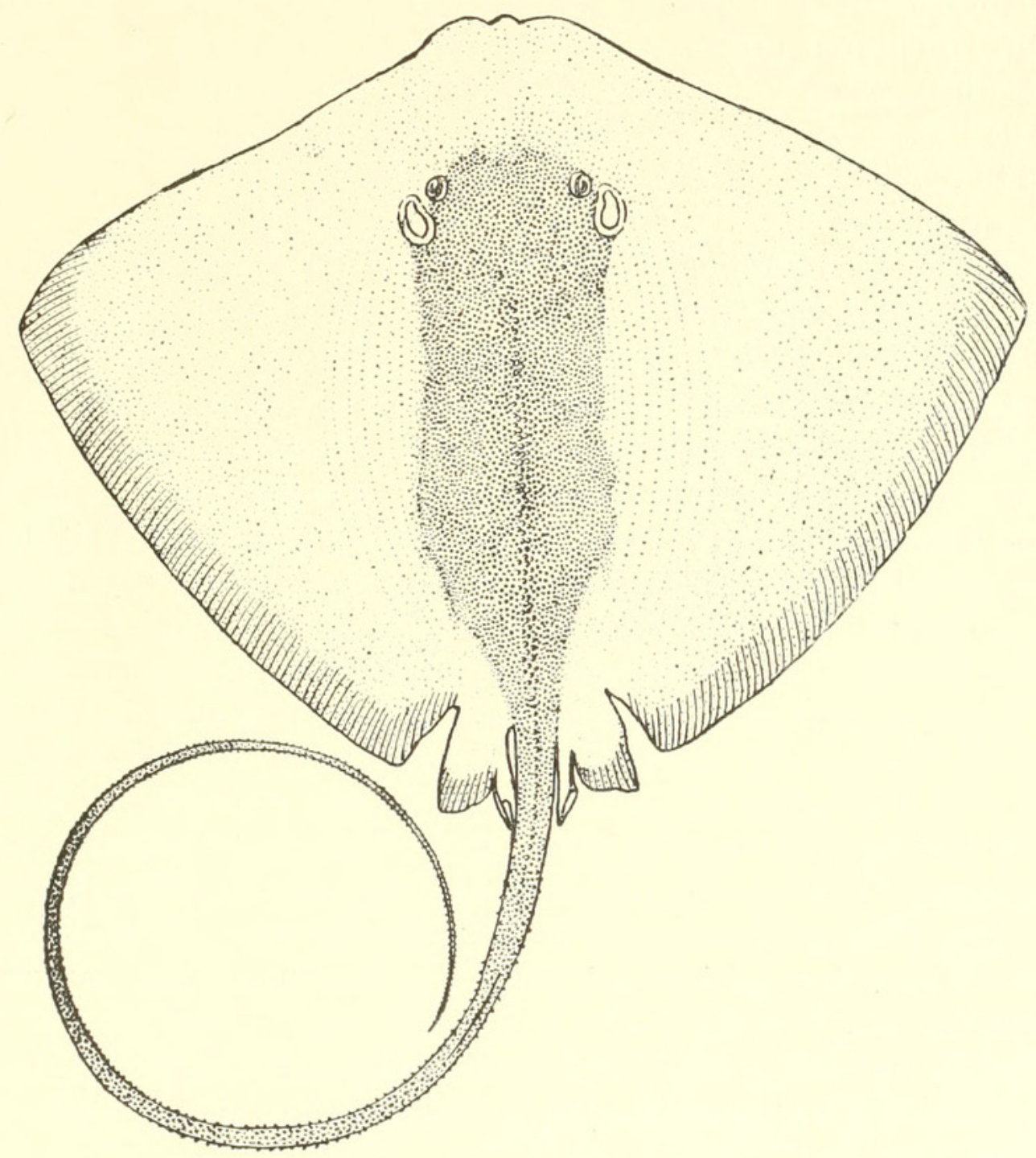

FIG. 5.-Trygon marginatus, $\sigma, \times c \cdot \frac{1}{11}$. (From stuffed specimen.)

gradually smaller from the middle outwards and do not form a clearly defined figure on the area they occupy. Externally, on either side, some of them have stellate bases - a character which becomes more marked as regards those that occur on the pectoral fins, on which they show a tendency to be arranged in longitudinal lines. They extend to the margin and sometimes over it on to the ventral surface. This description is based on a large male taken by the "Golden Crown " in October off the coast of Burma and a still larger female captured in March off the coast of 
Ganjam in about 24 fathoms. Although they do not agree in every respect with Blyth's description of the species I think these specimens must belong to it. Blyth's specimens appear to have perished and there are no others, except the ones described, in the Indian Museum, or, indeed, so far as I can discover, in any other collection. The measurements of my specimens were as follows :-

Length of disk

Breadth of disk

Length of tail

Length of snout from eyes

Distance between eyes

Nasal flap . .

Mouth to vent
○

$\begin{array}{cccc}\ldots & \text { I } 47.5 \mathrm{~cm} . & \text { IO } 2.5 \mathrm{~cm} . \\ \ldots & \text { I } 78.75, & \text { I } 36.25, \\ \ldots & \text { I } 97.5, & 220.83, \\ \ldots & 37.5, & 25.0 & , \\ \ldots & 26.5, & 2 \mathrm{I} \cdot 25, \\ \ldots & \text { I } 6.25, & \text { I5.0 , } \\ \ldots & 96.25 & \end{array}$

Trygon imbricata (Bloch and Schneider).

T. imbricata, Müller and Henle, op. cit., p. I64; Day, op. cit., p. 52.

T. walga, Müller and Henle, op. cit., p. I59, p1. 5I ; Day, op. cit., p. 55.

Size small (adults 2IO-220 mm. across the disk, young 90-IOO mm.).

Disk about as long as broad in the adult, broader in the young, always with the pectoral fins broadly rounded; the snout not greatly produced, occupying about onethird of the disk, forming an angle which is nearly a right angle ; its length from the eyes about $2 \frac{4}{5}$ times the distance between the eyes. Eyes nearly as large as spiracles, not very prominent.

Tail variable in length, sometimes barely as long as the disk, sometimes twice as long or even longer, proportionately longer in the young than in the adult. On either side there is always a thick but low ridge, while along the mid-dorsal line a narrow groove can generally be detected. Sometimes this groove contains a low fold, which is much lower than the tail and is more strongly marked on the distal half of the tail than it is on the basal, although it does not reach the tip. More rarely there is a corresponding fold on the ventral surface, but even when both are present they are low and inconspicuous. As a rule there are two narrow serrated spines on the tail.

Colour.-Ventral surface white. Dorsal surface of brownish clay-colour, occasionally with obscure darker spots and usually becoming paler on the edge of the fins. The lateral ridges on the tail white.

Skin.-The lepidosis is as variable as are the proportions of the tail, but the two characters are not correlated. In many adult individuals the back and head (but not the pectoral fins) are covered with small flattened denticles which do not differ from one another markedly as regards size or shape. There are sometimes, however, several enlarged tubercles on the midline of the scapular region, while often a row of denticles bearing backwardly directed spines can be detected in the middle line at the posterior end of the disk and on the base of the tail. They vary in size and development. Sometimes, even in adults, the disk is almost naked. 
Mouth.-The jaws are somewhat curved as a whole and regularly but not very strongly undulate. The teeth are small and white; the transverse ridge is low and

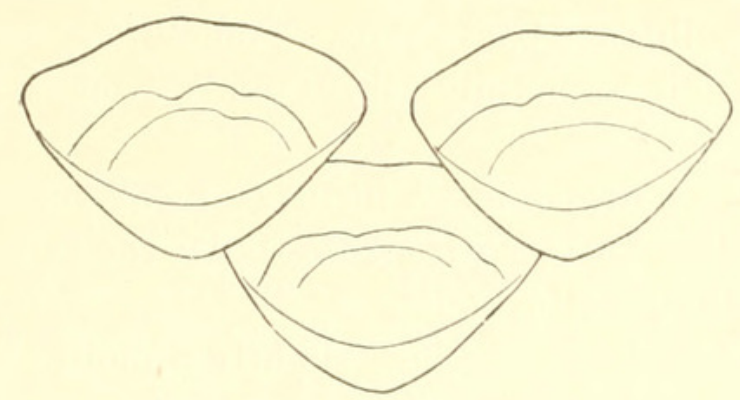

Fig. 6.-Teeth of Trygon imbricata (enlarged). From preparation in canada balsam.

somewhat irregular, the surface of the tooth posterior to it being decidedly concave. There are two short processes on the floor of the mouth, occasionally with a minute papilla between them. They are situated much nearer to one another than either is to the angle of the mouth.

At first sight the form described by Bloch and Schneider as Raja imbricata is very distinct from Müller and Henle's Trygon walga. Indeed, so long as I had only examined a comparatively small series of specimens, I was prepared to regard them at least as distinct varieties. Recently, however, I have had an opportunity of examining a large number of living specimens, among which I find every gradation between the two forms. Shortness of tail is not invariably or even usually correlated with any peculiarity in the denticles, nor is the exact form of the disk correlated with either character. Every possible gradation is found between a distinct caudal fold and a complete absence of any such character. Nor is any one peculiarity peculiar to either sex. Except that the young has a relatively wider disk, a longer tail and a paler colour, and usually fewer denticles on the disk, than the adult, there is no external difference between them, and I have seen two embryos from one mother which differed considerably as regards length of tail.

$T$. imbricata appears to be, in the strict sense of the phrase, a littoral and estuarine species. Few specimens have been taken in water even so deep as $\mathrm{I}_{5}$ fathoms by the "'Golden Crown,' but large numbers are captured in the winter season on the Orissa coast at Puri by means of seine-nets worked from the shore. The flesh is only eaten by the lowest castes of the Hindus.

\section{Trygon zugei (Müller and Henle).}

Size small (largest specimen $3 \mathrm{I} \mathrm{cm}$. across disk, smallest $8.5 \mathrm{~cm}$.).

Disk slightly broader than long; the pectoral angles broadly rounded; the greatest transverse diameter situated about half way between the base of the tail and the tip of the snout, which is sharply pointed and much produced, its length from the eyes being more than three times as long as the distance between the eyes. Eyes nearly as large as the spiracles. 
Skin smooth, richly provided with mucous glands. Sometimes a few rudimentary denticles can be detected on the posterior part of the disk and the base of the tail, but as a rule the skin is naked except for a single mid-dorsal line of large denticles with sharp spines directed backwards. Sometimes this line is only developed on the base of the tail, sometimes it extends from a point close behind the spiracles.

Tail with low dorsal and ventral folds, which commence close behind the spine and run for about a third of the length of the tail; the tail from one-and-a-half to nearly three times as long as the body.

Mouth broadly arched as a whole; the jaws slightly sinuous. The teeth white. Each

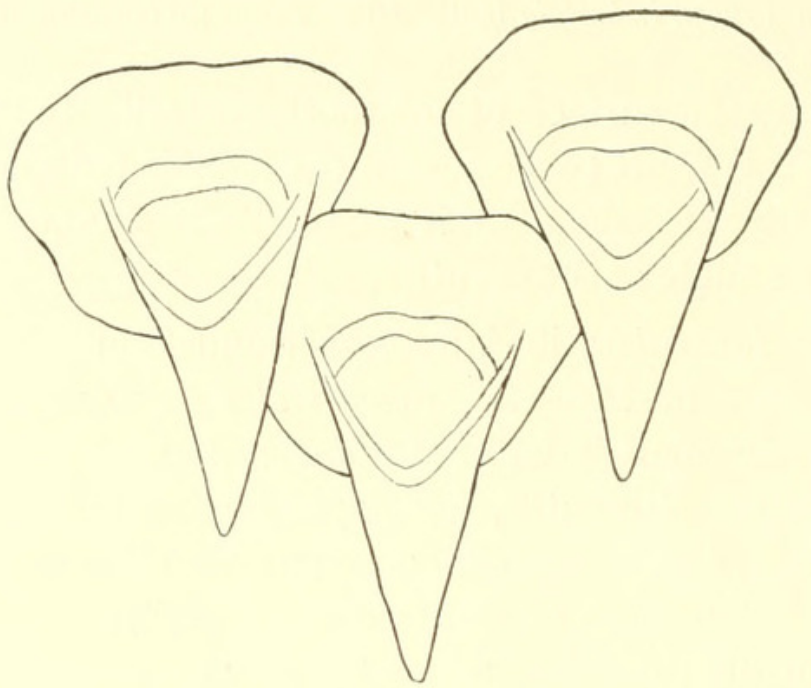

FIG. 7.-Teeth of Trygon zugei, o (enlarged). - From preparation in canada balsam.

in the male with a roundish base and a long, slender, tapering cusp, which ends in a sharp point; in the female a triangular ridge takes the place of the cusp.

Colour.-Dorsal surface dark blackish brown, no paler at the edge of the fins than on the middle of the disk. Ventral surface white, often blotched or suffused with dark pigment. Young paler above than the adult, with the edges of the pectoral fins black on both surfaces.

P. zugei does not appear to be common in the northern parts of the Bay of Bengal but a few specimens have been taken by the "Golden Crown" off the coasts of Burma and Orissa, as well as a considerable number (in February) off that of Madras. The photograph reproduced on plate iv was taken from one of the former while it was still fresh. The freezing to which it had been subjected, however, had caused the skin to shrivel a little.

\section{Trygon kuhlii (Müller and Henle).}

Size small (male $30 \mathrm{~cm}$. across the disk, female $32 \mathrm{~cm}$.).

Disk slightly broader than long: the pectoral angle rounded, the broadest diameter being considerably nearer the tip of the snout than the base of the tail. The snout 
rounded, not produced, its length from the eyes not much greater than the distance from eye to eye. Eyes very large and prominent. Spiracles narrow, extending along the outer margin of the eyes.

Tail considerably longer than the disk, armed with two or more long, slender serrated spines and bearing a long, well-developed ventral cutaneous flap and a much shorter dorsal one.

Colour.-Dorsal surface pale slate-colour ornamented with a variable number of round, bluish, black-edged spots scattered irregularly, and sometimes with smaller black spots. Ventral surface white. The proximal part of the tail rather darker than the ground of the dorsal surface of the disk, without markings; the distal part boldly banded with black and white.

Skin almost naked, sometimes bearing numerous minute rudimentary denticles on the tail and in the middle of the back. A row of large denticles with stout spines directed backwards sometimes present in the mid-dorsal line, but, at any rate in young individuals, not always present.

Mouth.-Straight as a whole; the jaws distinctly undulate. The teeth resembling those of $P$. zugei but with a considerably stouter cusp in the male. The nasal flap straight, fringed, with a longitudinal central groove on the surface.

No specimens of this species have been taken by the "Golden Crown " in the northern part of the Bay of Bengal, but a large pair $\left(\sigma^{*}, q\right)$ and several smaller specimens were captured in February, I909, off Gopalpur (Madras Coast) in 24 fathoms and a considerable number of specimens of different sizes off the same coast in March. Both P.zugei and the present species have a wide range, the former being distributed from the Arabian Sea to Japan, while the latter occurs not only in Japanese waters but also on the East Coast of Africa.

Genus Hypolophus, Müller and Henle.

Distinguished from Trygon by the form of its tail, jaws and teeth.

\section{Hypolophus sephen (Forskål).}

Trygon sephen, Day, Faun. Brit. Ind., Fishes, i, p. 5I, figs. 2I, 22.

Size large (adult $\mathrm{I}_{52} \mathrm{~cm}$. across the disk).

Disk slightly broader than long, with the pectoral angles obtusely rounded; the broadest transverse diameter widely separated from the anterior end of the disk. Snout forming an angle greater than a right angle; not produced. Eyes large and prominent.

Colour.-Dorsal surface reddish brown in the young, bluish grey in the adult, without spots; the margins of the fins and the tail (except the base) darker than the centre of the disk.

Tail.-Longer than disk in normal specimens, with a broad cutaneous flap running along the ventral surface from a point near the insertion of the serrated spine (or spines) for about one quarter of the length of the tail, its distal extremity being widely separated from the tip. Two serrated spines are usually present. 
Skin tough. The head, back and base of tail are covered with closely set, flat or nearly flat denticles, usually with three or more enlarged tubercles in the scapular region. The tail is covered for the greater part of its length with small spiny denticles, which also occur scattered on the cutaneous flap.

Mouth.-The jaws are bent almost angularly, this being particularly noticeable as regards the upper jaw, in the middle of which the teeth are smaller than they are elsewhere. The middle part of the upper jaw is deeply concave from below. The teeth are white; their surface is nearly smooth and the transverse ridge is practically obsolete. Where they are quite unworn, however, it is possible to see that the surface is divided into two areas; a posterior one, of which the outline is rounded and the surface obscurely sculptured, and an anterior one with an angular outline and marked with distinct longitudinal grooves. On the floor of the mouth there are three long slender processes situated close together in the middle, and another near each angle.

This species represents the genus Hypolophus of Müller and Henle and is certainly very distinct from any other. I am doubtful as to the necessity for recognizing subgenera in the fishes, otherwise I would certainly recognize Mïller and Henle's name as that of a sub-genus.

There are several small specimens in spirit in the collection of the Indian Museum, but the only fresh one that I have seen was a male measuring $\mathrm{I}_{5} \mathrm{I} \cdot 8 \mathrm{~cm}$. across the disk which was taken by the "Golden Crown", in August off the Burmese coast. This specimen exhibited an interesting abnormality, lacking the distal part of the tail completely. The cutaneous flap ran to the extreme tip, becoming gradually lower towards this point. The tail, however, was no longer than the disk, and I have little doubt that it had been accidentally abbreviated, although the wound had completely healed without even leaving a scar at the tip. A photograph of this specimen is reproduced on plate $v$, fig. I.

\section{Genus Urogymnus, Müller and Henle.}

Tail very distinct from the disk, without a serrated spine. Disk stout, elliptical or subcircular. Teeth flattened, without a distinct transverse ridge but with the inner margin raised. Other characters as in Trygon.

Hitherto only one species of the genus has been known, namely Urogymmus asperrimus (Bloch and Schneider), but a second is here described. Unfortunately I have only seen one fresh individual of the former, which was mutilated, and have not been able to examine the latter except as a stuffed museum specimen. The differences, however, are so very clearly marked that I do not hesitate to describe the new species.

The two species may be distinguished as follows :-

A. Pectoral fins covered with spiny denticles which have flat circular bases

U. asperrimus.

B. Pectoral fins covered wlth small rounded denticles, which at the periphery are almost granular $\quad \ldots \quad$ U. lavior. 


\section{Urogymmus asperrimus (Bloch and Schneider).}

Disk slightly broader than long, broadly arched in front but with a somewhat projecting snout, very thick vertically in the middle, sloping up abruptly from the anterior part of the pectoral fins to the top of the head.

Tail longer than disk, sometimes with a low cutaneous fold on the ventral surface.

Colour uniform greyish brown on the dorsal surface.

Skin tough, very richly supplied with slime-glands. The head, back and tail are densely covered with prominent bony tubercles, among which are scattered numerous spiny denticles with more or less stellate bases. These are particularly numerous on the tail and on the superciliary part of the head. The pectoral fins are covered with spiny denticles which have smooth circular bases. In the dried skin the area on which the bony tubercles are present is clearly marked off from that occupied by the spines with circular bases, but in the fresh specimen the bases of all the scales are more or less completely concealed in the epidermis and in the enormous amount of slime with which the skin is coated.

Mouth.-The upper jaw is divided by a shallow concavity on either side into three nearly equal convex projections. The middle part of the lower jaw, however, is nearly straight, there being a slight concavity on either side. The teeth are of a dark purple-brown; they are nearly oval (transversely) in shape and have the exposed surface minutely but deeply sculptured. On the floor of the mouth there are three long finger-shaped processes situated close together in the middie.

The only specimen I have seen fresh was captured by the " Golden Crown " in August, I9o8, off Chittagong, but there are several stuffed ones in the Madras Museum. The one taken by the "Golden Crown "' had lost the greater part of its tail owing to what appeared to be a slanting cut from above as with an axe. The wound had, however, healed. The following are the measurements of this specimen, which was a female :-

Length of disk ...

Diameter across disk

Distance between eyes

Tip of snout from eyes

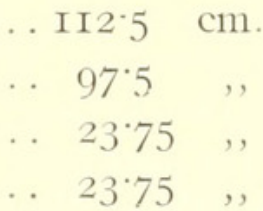

\section{Urogymmus lavior, sp. nov. \\ [Description of type (a stuffed skin) in the Madras Museum.]}

Disk broadly oval if the pelvic fins are included, almost as wide as long without them, truncated in front as a whole, but with a short projecting snout.

Tail longer than disk, without cutaneous folds.

Skin.-Dorsal surface of pectoral fins, head and anterior part of body covered with small, round, blunt tubercles, which become gradually smaller from the centre of the body outwards towards the edge of the pectoral fins, where they are almost granular. Behind the scapular region these tubercles are mixed with short spines, which have stellate bases and become more numerous on the base 
of the tail, where they greatly outnumber the rounded tubercles and finally take their place altogether. The whole of the tail is covered with spines of various sizes.

Mouth.-Upper jaw more distinctly undulated than the lower. Teeth white, practically lozenge-shaped.

This specimen was taken near the shore at Malpe, S. Canara, on the Malabar coast. Mr. E. Thurston has kindly given me the following note as to its history :"I was summoned from the dinner-table to inspect the carcase of an immense skate, whose last act, as she lay dying on the shore, was to continue the species by bringing forth twelve young ones, who were promptly salted.'

Genus P'Teroptatea, Müller and Henle.

Disk very broad in comparison with its length, lozenge-shaped, flat. Pectorals united in front. Tail feeble, normally with a serrated spine, without a rayed caudal fin, a smail rayed dorsal fin sometimes present. Teeth with a saddleshaped base and one or more backwardly-directed, sharp cusps. No processes on the floor of the mouth. Nasal valves coalescent. Skin naked or nearly so.

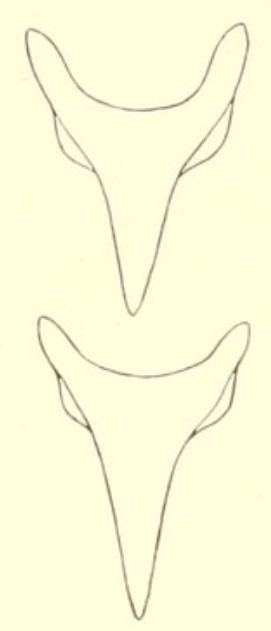

A.

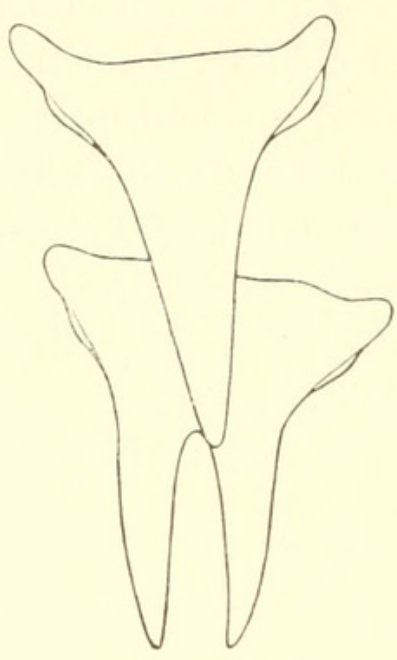

B.

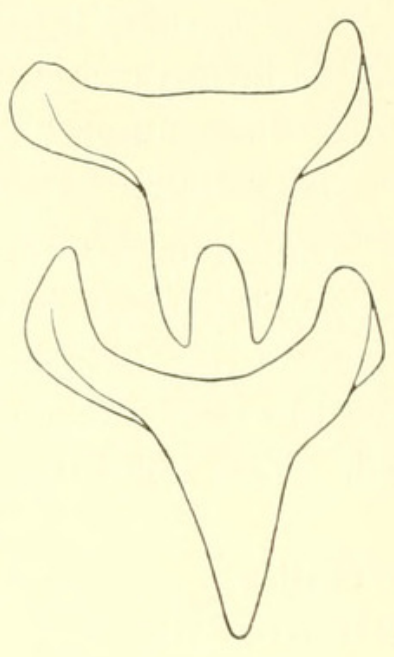

C.

Fig. 8.-Teeth of Pteroplatea (enlarged): A, P. micrura; B, P. zonura; C, P. tentaculata.

Day describes only one Indian species of this genus, but three are common in the Bay of Bengal, namely, P. micrura, P. zomura and P.tentaculata. They may be distinguished as follows:-

I. No dorsal fin.

A. No tentacle on the posterior margin of the spiracle. Dorsal surface

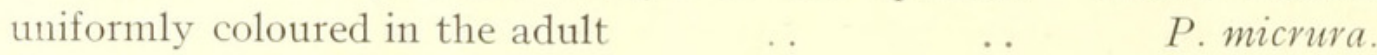

II. A small dorsal fin on the tail.

A. No tentacle on the margin of the spiracle. Dorsal surface minutely dotted with dark green and boldly spotted with greenish yellow P. zonura.

B. A small tentacle present behind the spiracle. Dorsal surface spotted and $\begin{array}{lllll}\text { blotched with greenish yellow } & \ldots & \ldots & P \text {. tentaculata. }\end{array}$ 
In general form and structure all the species of the genus are very much alike. In the Indian species at any rate the structure of the mouth and teeth differs little. The mouth is nearly straight and bears no processes on its floor or cutaneous flap on its roof. The teeth have been briefly described by several authors; Günther (Cat. Fishes, viii, p. 486) says that they are "very small, uni- or tricuspid"'; Müller and Henle describe them as " mit I-3 Spitzen"' (Syst. Beschr. d. Plagiostomen, p. I68) ; Jordan and Everman (Fishes of North America, i, p. 86) do not mention them in their account of the North American species. They are so small in the Indian forms that it is impossible to examine them properly without dissecting them out and mounting them for microscopic investigation. The figure reproduced on page 38 gives an outline of teeth of $P$. micrura, $P$. zonura and $P$. tentaculata. In the two latter species teeth with one cusp are mingled indiscriminately with teeth bearing two cusps; but apparently in $P$. micrura all the teeth have one cusp. In the two former species the unicuspid teeth are much more numerous than the bicuspid ones.

I have not detected any rudimentary denticles in the skin of the Indian forms.

-The species of Pteroplatea are eaten by some castes of Hindus but rejected by others and by Mahommedans as being " fish without fins."

\section{Pteroplatea micrura (Bloch and Schneider).}

Size moderate (adult females $74-82 \mathrm{~cm}$. across disk, males (?) smaller, young I6 cm.).

Disk as a rule rather less than twice as broad as long, with the pectoral angles subacute in the adult, distinctly rounded in the young. The snout hardly projects at all, the anterior margin of the disk forming a very obtuse angle. The distance between the eyes considerably greater than the length of the snout measured from them. The nasal flap distinctly emarginate, delicately fringed.

Tail variable in length, sometimes longer than disk, as a rule shorter, but always more than half as long, without dorsal fin or cutaneous folds; serrated spine usually present in the adult but absent or concealed in the young.

Colour.-The dorsal surface of the new-born young is of a pale greenish grey profusely covered with small, round, blackish spots and with more sparsely scattered and larger white ones. The ventral surface and the tail are white, but there is a row of relatively large, longitudinally oval, blackish spots on the dorsal surface of the latter. Soon after birth the spots disappear from the body, while those on the tail coalesce in pairs and grow round the greater part of the circumference of the tail. A white spot is, however, left in the middle of each of the double black ones on the tail. As the fish grows older the tint of the dorsal surface darkens to deep slate-colour or brownish grey, the spots on the back having completely disappeared before this happens although those on the tail become more distinct and more extensive with age.

This species is more commonly captured by the methods employed by Indian fishermen than its two congeners, because it is mainly a littoral form. Large numbers of small individuals were taken at Puri in January and February practically on the beach.

Day states, on the authority of Jerdon, that P. micrura grows to 6 feet across the disk (Fishes of India, ii, p. 74I); but in the large series of specimens taken by the 
"Golden Crown", the gravid females have measured less than 3 feet across the disk, while the adult males have all been smaller. The members of the genus are so closely allied that it is not improbable that a large species not yet described exists in Indian seas. Day refers also to a drawing in Sir Walter Elliot's collection of an example covered all over with small brown spots. Probably the original of this drawing was a young specimen of $P$. zonura.

P. micrura appears to be common off the coasts of Burma, Chittagong and Orissa at all seasons, but always to remain in very shallow water. Like its two Indian congeners it is gregarious; so far as can be judged from the specimens in the "Golden Crown " collection sent to the Museum, the shoals of the three species keep separate from one another. P. micrura is rather widely distributed in Indo-Malayan seas.

$$
\text { Pteroplatea zomura (Bleeker). (P1. iv, fig. 4.) }
$$

Size moderate (adult females $85 \mathrm{~cm}$. across disk, males slightly smaller).

Disk.-Proportions almost as in P. micrura. Nasal flap almost straight, barely fringed.

Disk often with a distinct though short projection in front.

Tail variable, often more than half as long as disk but probably never quite so long.

Dorsal fin twice as long as high, about a third as long as the free part of the pelvic fins; its anterior border situated slightly in front of the distal border of these fins. Serrated spine minute or absent. A low cutaneous fold sometimes present on the ventral surface.

Colour.-Dorsal surface olive-green, minutely and closely speckled with dots of a darker shade, boldly marked with large round or irregular spots of greenish yellow and often joined together by irregular lines and blotches of the same colour, sometimes ocellate. In the young the dark spots are paler and less numerous, while the spots are less irregular and have a brownish colour. The ventral surface is devoid of pigment. Tail coloured like that of P. micrura.

This fish is evidently common on the Orissa coast in depths of from $\mathrm{I}_{5}$ to 20 fathoms. Numerous individuals of both sexes have been taken there by the "Golden Crown " at different seasons, especially in winter. I saw a young female taken in the seine-nets on the beach at Puri in February.

The species was originally described from Java.

$$
\text { Pteroplatea tentaculata (Müller and Henle). (P1. iv, fig. 4.) }
$$

Size moderate (adult females $73 \mathrm{~cm}$. across the disk).

Disk a little less than twice as broad as long in the adult, more than twice as broad in the young; the pectoral angles somewhat rounded in both. The distance between the eyes as a rule nearly the same as (a little greater than) the length of the snout measured from them. The snout has a distinct though short projection. The tentacle at the posterior angle of the spiracle is variable in length, always slender and pointed.

Tail variable in length, as a rule less than half as long as the disk in the adult, sometimes with faint dorsal and ventral cutaneous folds. The dorsal fin about 
twice as long as high, more than half as long as the inner edge of the pelvic fins ; its anterior border situated nearer the base than the distal end of the pelvic fins. Serrated spine minute or absent.

Colour.-In the young the dorsal surface of the disk is of a greenish slate-colour, marked with irregular roundish spots of a dark brown, and with a faint and close reticulation of a paler shade of brown. This reticulation separates closely set roundish areas of the ground colour. As the fish grows, the brown spots enlarge and assume a greenish colour, finally becoming dark olive and occupying the greater part of the surface. The faint reticulation disappears and large spots and blotches of yellowish green are developed. The tail is faintly barred at all ages. The coloration of the adult, therefore, differs from that of the adult $P$. zonura, so far as the dorsal surface is concerned, in the absence of minute dark dots and in the faint markings of the tail. The ventral surface of the young is white, but in the adult it is marbled and clouded with dark pigment.

This species is probably confined to water from. I5 to 30 fathoms deep. A considerable number of specimens were taken together in about 30 fathoms at the mouth of the Eastern Channel of the river Hughli in February, I9o9. Others were taken off the Orissa coast in the autumn of Igo8, but never many at a time; several were taken off the Ganjam coast in from 24 to 27 fathoms in March.

The species probably is widely distributed in the Red Sea and the Indian Ocean.

\section{Family TORPEDINID死.}

Naked Batoidei with a broad, flat, circular or elliptical disk. At least one dorsal fin usually present (absent in one genus). A honeycomb-like electric organ developed between the head and the pectoral fins.

Two genera of Torpedoes are recorded by Day as occurring in Indian seas, while a third has since been described by Alcock. Two more are here added, one being new and the other represented by a species not hitherto recorded with certainty from the Indian Ocean. The following key will serve to separate the Indian genera :-

I. Two dorsal fins on the tail.

A. Eyes well developed.

(a) Spiracles distinctly separated from the eyes ..

$\left(a^{1}\right)$ Spiracles not distinctly separated from the eyes

. Torpedo.

B. Eyes degenerate.

(a) Pectoral fins feebly developed

.. Narcine.

Benthobatis.

II. One dorsal fin on the tail.

A. Pectoral fins moderately well developed _. . . Astrape.

B. Pectoral fins reduced externally to mere rudiments Bengalichthys.

III. No dorsal fin

. Temera.

I include in this key the genus Temera because it will probably be found in Indian seas, having been originally taken at Penang. There is a very small specimen (of 
T. hardwickii?) in the collection of the Indian Museum, but unfortunately I have not been able to trace its history or provenance. The specific characters of the only known species of the genus are so imperfectly recorded that I hesitate to identify the specimen, which is both immature and faded.

Benthobatis is a deep-sea genus, but the relations between it and Narcine correspond so closely with those between my new genus Bengalichthys (which is a shallow-water genus) and Astrape, that I am obliged to discuss it at some length.

Both the species and the genera of the family are in some cases closely related, and it is often difficult to distinguish between them unless fresh or well-preserved material is used. This is particularly the case as regards the genera Narcine and Torpedo. Stuffed skins of these forms are practically useless for purposes of identification, unless the greatest care has been taken to preserve the natural features. The naked, glandular skin is particularly liable to become distorted, while the colour, although sufficiently permanent in spirit unless the specimens are exposed to a strong light, invariably darkens in skins, so that all the markings disappear.

The ridges or processes on the roof and floor of the mouth form in some genera as useful a diagnostic character as is the case in certain genera of Trygonidæ, but one that can only be investigated properly by dissecting out the mouth.

The Torpedoes do not appear to be used as food in India, at any rate habitually. Those caught in the seine-nets at Puri are invariably thrown away.

\section{Genus Torpedo, Duméril.}

Disk distinct from tail, which is stout, bears a well-developed caudal and two dorsal fins and has a fold on either side. Pectoral fins well developed; pelvic fins not joined behind the anus. Eyes distinctly separated from spiracles. Nasal valves confluent into a quadrangular flap. Teeth pointed, with a single cusp and a flat base ; cleft of mouth wide and U-shaped.

Only one species has as yet been found in Indian seas, or at any rate definitely identified. I am much indebted to Mr. Boulenger for examining photographs of an Indian specimen of this species and confirming my identification.

$$
\text { Torpedo marmorata, Risso. (Pls. iii } a \text {, fig. 4, and v, fig. 3.) }
$$

T. galvanii, Bonaparte, Faun. Ital., vol. iii, Pesci, plate (I832-4I).

T. marmorata, Günther, op. cit., p. 450 .

Disk broadly truncated in front, broader than long, rather longer than the tail. The latter very broad at the base. The dorsal surface covered with minute wrinkles, which run longitudinally on the anterior part of the disk and transversely on the posterior. The eyes nearly as large as the spiracles, from which they are separated by a distance less than their own diameter. The posterior and lateral margins of the spiracles provided with a row of somewhat stout, irregular, conical processes.

The mouth is situated between two deep, rather lengthy longitudinal folds, which approach one another posteriorly and diverge anteriorly. The teeth occupy nearly 
the whole of the mandibular surface ; their cusps are long and very sharp, directed obliquely backwards. There is a low cutaneous ridge behind the teeth on either jaw but no outstanding processes.

Colour.-The colour is variable in European specimens; in the three Indian ones I have seen the dorsal surface was of a peculiar livid dark purple-brown, densely spotted with purplish buff. These markings extended over to the ventral margin of the pectoral fins; but the greater part of the ventral surface was dull white.

The only specimen I have examined in detail is one brought by Dr. Travis Jenkins in December, I908, from Puri, where it had been taken in a seine-net worked from the shore. In November of the same year, however, I saw a very similar specimen, which had been captured in the same way, at Quilon on the Travancore coast. Dr. Jenkins's specimen measures (in spirit) $245 \mathrm{~mm}$. across the disk, which is $227 \mathrm{~mm}$. long; the tail is $\mathrm{I} 73 \mathrm{~mm}$. long, the total length being thus $400 \mathrm{~mm}$. The specimen is a female and contained ripe ovarian eggs; a good photogiaph is reproduced on pl. v, fig. 3 .

\section{Genus Narcine, Henle.}

Disk longer than broad, distinct from tail, which bears two dorsal fins and has a fold of skin along each side. Pectoral fins well developed; pelvic fins not united behind the anus. Eyes close to the spiracles, well developed. Nasal valves confluent. Mouth tubular and protrusible; its cleft narrow and straight. Teeth pointed, with a single cusp, which is directed backwards and in some species feebly developed.

At first sight this genus is very near Torpedo, from which Gïnther says that it " differs in having the spiracles almost immediately behind the eye." He also says that the teeth sometimes have a median point, which, however, does not project. I cannot, however, see any real difference between the two genera in respect to the teeth ; whether the " median point", projects or not is due to the position of the mouth and to the angle at which the teeth' are examined, while the absence of a median point is often due to its being worn away. So far as the Indian species are concerned, there is a very marked difference between the two genera in respect to the shape of the mouth, which in Torpedo is evidently capable of being widely opened, although it appears to be somewhat protrusible, while in Narcine it can be thrust out bodily as a tubular structure with a narrow, transverse, slit-like aperture.

Narcine has long been known to be represented in Indian seas by two shallowwater forms, which Day regarded as mere colour varieties, while Lloyd has recently described a deep-sea species. I feel obliged to separate the two former from one another as distinct species for reasons given below. Here I may say that Lloyd's $N$. mollis is closely related to the form I have described as $N$. brumnea, although clearly distinct from that form. It is distinguished by the uniform dark colour of its dorsal and

In comparing the teeth of these genera great care must be taken to select teeth from the back of the jaws, where they have not been worn. Some of Duméril's figures (Nat. Hist. Poiss., pl. xi) rather suggest that he did not adopt this precaution. 
ventral surfaces, the flabby consistency of its muscular tissue, and the structure of the interior of its mouth and teeth, the cusp of the latter being very wide transversely and forming a flat triangle rather than a spine-like process.

The Indian species may be recognized as follows :-

I. Dorsal surface spotted. Dorsal fins subequal

II. Dorsal surface brown ; ventral surface white. Dorsal fins sub-

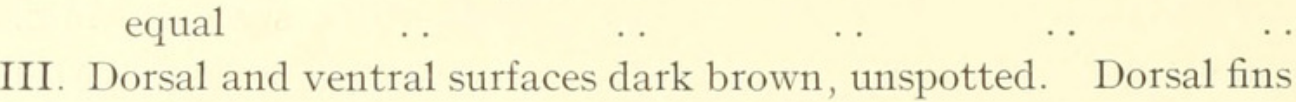

N.timlei. $\begin{array}{lllllllll}\text { subequal } & \ldots & \ldots & \ldots & \ldots & \ldots & \ldots & \text { N. mollis. }\end{array}$

The eyes in all the Indian species are large, and the margins of the spiracles are smooth.

$$
\text { Narcine timlei (Bloch and Schneider). (P1. iii } a \text {, fig. I.) }
$$

N. timlei and N. indica, Henle and Müller, op. cit., p. I30.

N. timlei, Günther, op. cit., p. 452 ; Day, op. cit., vol. i, p. 45 (in part, not the figure) ; Fishes of India, vol. ii, p. 733 (in part).

Disk variable in outline, sometimes regularly oval and only slightly broader than long, sometimes considerably narrower, sometimes with the pectoral fins projecting in such a way that it becomes, even in fresh specimens, almost rhomboidal. The tail strongly developed, depressed, nearly as long as or longer than the disk; the two dorsal fins subequal, separated by about the length of one of them; the posterior margin of the pelvic fins reaching or nearly reaching the anterior border of the first dorsal. Extent backwards of the pectorals variable; sometimes they fall short of the anterior margin of the pelvic fins, sometimes reach it, and frequently overlap it.

Colour.-Dorsal surface chocolate-brown (which sometimes turns to purplish grey in preserved specimens) profusely marked on the back, lateral fins and tail with large spots of a dark purple-brown colour. In the young these spots are surrounded by rather indefinite pale rings, which sometimes persist in the adult, giving them an ocellate appearance. The posterior margins of the dorsal and caudal fins are somewhat broadly, the anterior margins narrowly edged with white. Ventral surface dead white, sometimes clouded with dark pigment in large individuals.

The mouth can be protruded as a depressed tube measuring, in the case of a large individual, $35 \mathrm{~mm}$. in length, $\mathrm{I}_{5} \mathrm{~mm}$. in transverse diameter at the distal extremity, and $8 \mathrm{~mm}$. longitudinally. The teeth occupy about a third of each jaw ; they have long, narrow, acutely pointed inner projections, which (in the unworn tooth) are nearly as long as the transverse diameter of the bases. On the roof of the mouth behind the teeth there is a pair of irregular, distinctly separated, compressed vertical processes, and on the floor a similar pair ; in both pairs the inner margins are emarginate on the basal half. The nasal flap straight, very finely and shortly fringed, with a narrow, smooth stretch in the middle. 
Adult specimens measure about $34 \mathrm{~cm}$. in total length and about I $7 \mathrm{~cm}$. across the disk.' Numerous specimens have been taken off the Orissa coast by the "Golden Crown,' and I have recently had an opportunity of examining many living ones on the beach at Puri, where large numbers are caught daily in seine-nets worked from the shore during calm weather. Two points at once become clear as a result of the examination of fresh specimens, (I) that it was impossible to separate Henle's Narcine indica from $N$. timlei, Bloch and Schneider, on the ground of the shape of the disk, and (2) that the specimens examined fell into two very distinct groups separated from one another not only by colour but also by size.

As regards the first of these points, the variation in the outline of the disk is remarkably wide and does not appear to be correlated with any difference in size, sex, or coloration. It is due mainly to differences in the development of the pectoral fins, the rays of which vary greatly not only in length but also as regards their position on the body.

Another point in which variation is very marked is the size of the eyes as compared with that of the spiracles. Occasionally the eyes are nearly as large as the spiracles, sometimes they have not more than half the superficial area of these structures.

The size and proportions of the dorsal and caudal fins are also variable.

As regards the important question of coloration, variation exists as regards the size and regularity (or otherwise) of the spots on the dorsal surface, which in one set of specimens are always present.

Day, in the "Fauna"' and in the Fishes of India, remarks that some specimens have no spots on the dorsal surface and that the absence of spots is not due to age, sex or locality. These statements are fully borne out by the large series of living and preserved specimens I have seen; but I do not think that the two forms are specifically identical and have therefore been forced to describe the immaculate one as a new species. Unfortunately it is the one figured by Day as typical of N.timlei.

Narcine timlei is very sluggish in its movements. I have failed repeatedly to induce it to give an electric shock even when it was in a bucket of sea-water.

$$
\text { Narcine brumea, sp. nov. (P1. iii } a \text {, fig. 2.) }
$$

N. timlei, Day, Fishes of India, pl. cxcii, fig. 3; Faun. Brit. Ind., Fishes, vol. i, fig. I 8 , p. 45 .

Closely related to $N$. timlei, from which it differs in the following characters: (I) coloration, (2) size, (3) form of the teeth, (4) outline of the free edge of the nasal flap, and (5) form of the processes in the mouth.

(I) The dorsal surface is of a warm chocolate-brown without spots, the ventral surface creamy white. A narrow margin of the latter shade runs round the disk, being more distinct anteriorly than posteriorly ; the dorsal and caudal fins, as well as the lateral ones, are edged with greyish white.

1 Day's statement that this species grows to at least I8 inches in total length (Fishes of India, vol. ii, p. 733) is perhaps due to a confusion with some species of Torpedo. Judging from old specimens in the Indian Museum, such a confusion actually existed in his diagnoses. 
(2) Large individuals of either sex measure about $22 \mathrm{~cm}$. in length and II $\mathrm{cm}$. in breadth across the disk.

(3) The posterior projection of the teeth is much shorter than the transverse diameter of the base, broader and blunter than is the case in $N$. timlei.

(4) The free edge of the nasal flap has a distinct projection in the middle line.

(5) On the roof of the mouth, behind the teeth, a cutaneous ridge with irregular serrations occurs, while on the floor there is a similar ridge, with or without a notch in the middle line, but never divided into two distinct processes.

The difference in colour between this species and $N$. timlei is constant in fresh specimens, although naturally difficult to detect in faded ones. The difference in size exists as regards the smallest specimens I have seen. There are in the Indian Museum, from different localities, seven examples of $N$. brunnea which measure between $55 \mathrm{~mm}$. and $70 \mathrm{~mm}$. in length, and between $30 \mathrm{~mm}$. and $35 \mathrm{~mm}$. across the disk. None of these specimens exhibits any trace of spots on the dorsal surface or retains any external rudiment of the yolk-sac. The smallest specimen of $N$. timlei I have seen was taken by the "'Golden Crown', at the mouth of the river Hughli in January, Igog. It measures $80 \mathrm{~mm}$. in length and $50 \mathrm{~mm}$. across the disk and has numerous large ocelli on its dorsal surface. There is a yolk-sac $23 \mathrm{~mm}$. long attached to the belly, and from the general appearance of the specimen I think that it was probably born prematurely.

The structural differences between $N$. brunnea and $N$. timlei are of considerable interest, but they can only be seen distinctly if the specimens examined are dissected.

\section{Genus Benthobatis, Alcock.}

This genus, which is known from several specimens of a single bathybial species, differs from Narcine mainly in the degeneracy of the eyes, a character of which no trace can be detected in the only known deep-sea species ( $N$. mollis) of the latter genus. The teeth are not very different from those of some species of Narcine.

Genus Astrape, Müller and Henle.

Tail with one dorsal fin. Eyes small but not markedly degenerate. Teeth neariy flat, with a broad, backwardly directed ridge, which is very bluntly pointed. Mouth protrusible but not tubular, the cleft nearly straight. Other characters as in Narcine.

Only two species of this genus are recorded by Günther: Astrape capensis, from the coast of S. Africa and Madagascar, with the tail distinctly shorter than the disk, and $A$. dipterygia, from the seas of India, China and Japan, with the tail and disk of about the same length.

$$
\text { Astrape dipterygia (Bloch and Schneider). (P1. iii } a \text {, fig. 6.) }
$$

A. dipterygia, Day, Fann. Brit. Ind., Fishes, p. 46, fig. I9.

Disk longer than broad, of approximately the same length as the tail, somewhat truncate in front. The pectoral fins well developed, especially posteriorly, thin 
and distinct from the trunk. Eyes about half as large as the spiracles, protuberant in life, separated by a concave interspace about half as long as their distance from the anterior border of the disk. Margins of spiracles smooth. Mouth surrounded posteriorly by a semicircular fold, about half as wide as its distance from the anterior border of the disk, provided with thick, tuberculate lips, which are discontinuous in the middle of the anterior border. Teeth occupying nearly the whole of the mandibular surface, with a broad, bluntly pointed transverse ridge. A bilobed, prong-like, vertical process on the roof of the mouth and a similar one on the floor. Nasal flap with a distinct median longitudinal groove and a median process on the free edge.

Colour.-Dorsal surface dull chocolate colour with a purplish tinge. Ventral surface, edge of disk and fins, a large oval spot on each side of the back some distance in front of the posterior margin of the pelvic fins, and a forwardly directed streak on each side of the anterior part of the tail, cream colour.

This species exhibits much the same variation as Narcine timlei and N. brunnea in respect to its fins. It has been taken by the "Golden Crown", in considerable numbers off the Orissa coast and appears to be common all over the Bay in shallow water. It is not so common as $N$. timlei and $N$. brunnea, however, and perhaps inhabits slightly deeper water.

Iarge specimens measure $16 \mathrm{~cm}$. in total length and $9 \mathrm{~cm}$. across the disk.

Genus Bengalichthys, gen. nov.

Closely allied to Astrape, from which it is distinguished by its thick, fleshy disk, rudimentary pectoral fins, and degenerate eyes.

I think it well to separate a form represented by two individuals in the " Golden Crown " collection from Astrape as a distinct genus, in order to emphasize the peculiar manner in which this form has become adapted for a more or less sedentary existence. In several respects the adaptation is of a nature closely similar to that which has brought about the evolution of Benthobatis from Narcine, although the environment in which this evolution has taken place is not the same in the two cases. Benthobatis, as I have already pointed out, is a deep-sea form-it occurs at depths from about 4 oo to about 700 fathoms - and, like many deep-sea forms, has degenerate eyes. The disk, moreover, is thick and muscular and bears on the dorsal surface numerous little glandular pits; the pectoral fins are not clearly marked off from the body. In all of these points the species of Bengalichthys to be described immediately resembles Benthobatis, although it is not a deep-sea form, having been taken in only $\mathrm{I}_{5}$ fathoms. In two striking characters, however, it differs from Benthobatis, viz., in coloration and in the number of the dorsal fins. The former difference is probably due to its environment, the latter to its ancestry; in other words, the former is an adaptive character, the latter a morphological one. A character common among deep-sea fish of all kinds is a dark and uniform coloration of both the dorsal and the ventral surface, while among the rays of shallow water it is unusual for the ventral surface to be dark, although this is the case 
in a few species. The only known species of Benthobatis has a dark ventral surface, the only known species of Bengalichthys a pale ventral surface. The genera of the Torpedinidæ, on the other hand, fall naturally into several groups separated by the number (or absence) of their dorsal fins. Benthobatis belongs to one of these groups, Bengalichthys to another. There can be little doubt, therefore, that the two genera have not had the same ancestry but have become like one another owing to parallel or rather convergent lines of evolution. Although Bengalichthys does not live in the dark abysses of the sea, we may suppose that its mode of life is very similar to that of Benthobatis. Neither can be a powerful swimmer, but both, judging from the manner in which the muscles of the disk are developed, must be powerful wrigglers and squirmers. It must be remembered in this connection that the flabbiness of the flesh (i.e., the muscles) of deep-sea fish which have been brought to the surface is mainly an artificial condition, ' not one that would be apparent if it were possible to examine the fish in their natural environment. Now, quite apart from the question of the depth at which a fish lives, it is quite clear that eyes may be inconvenient to an animal which wriggles about in the mud at the bottom of the sea, and I have little doubt that both the fish under discussion live in this way, perhaps actually burrowing into the mud, through which the movements of their disks assist them to make their way. Their mouths, like those of their nearest allies in both cases, are feebly developed and probably suctoria! in function. Neither they nor their allies can attack large organisms of any kind, and it is clear that their electric organs must be weapons of defence rather than offence. Perhaps both Benthobatis and Bengalichthys have become more perfectly adapted for obtaining their food by sucking it from the mud owing to the degeneracy of certain organs that are of no use for this particular purpose.

$$
\text { Bengalichthys impennis, sp. nov. (P1. iii } a \text {, fig. 7.) }
$$

Disk stout and muscular, pear-shaped, the broader end being in front; the anterior margin broadly convex; the length about the same as the maximum transverse diameter. Numerous white glandular pits are present on the dorsal surface, on which they are arranged in much the same way as on that of Benthobatis moresbyi. Pectoral fins consisting externally of a fringed ridge $2-3 \mathrm{~mm}$. broad near the edge of the dorsal surface of the posterior half of the disk.

Tail stout, longer than the disk; the caudal fins rounded posteriorly; the dorsal small, situated about half-way between the posterior border of the pelvic fins and the caudal. The pelvic fins distinct from the disk and apparently situated on the sides of the tail.

Colour.-Dorsal surface of disk and tail deep buff clouded with dark brown. Ventral surface, margin of disk and fins, a large oval spot on each side of the back in front of the root of the tail, a forwardly directed streak on each side of the tail, in front

1 The muscles of Torpedo marmorata, however, which is not a deep-sea fish, are much more flabby than those of any species of Narcine (except Narcine mollis), Astrape or Bengalichthys with which I am acquainted. 
of the dorsal fin and a backwardly directed streak on the base of the disk at either side, cream colour.

Eyes minute, deeply sunk, colourless, close to the spiracles, which have smooth edges. Mouth closely resembling that of Astrape dipterygia externally; the teeth with the triangular transverse ridge somewhat more pointed than in that species. A somewhat narrow, long rectangular process on the roof of the mouth, directed backwards rather than vertically downwards, and having its distal edge sinuous but not bilobed; a similar but smaller process on the floor of the mouth. *

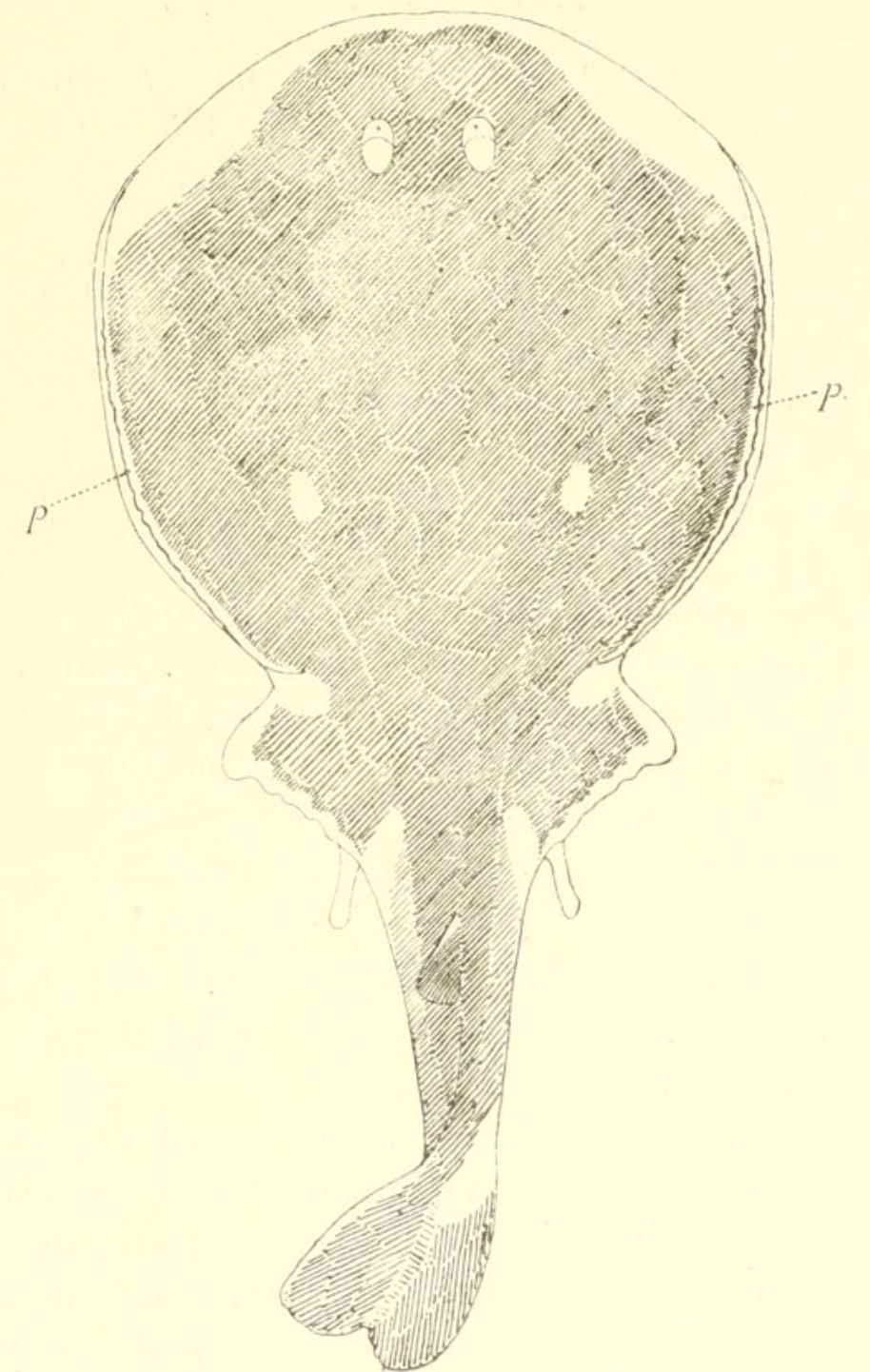

FIG. 9.-Bengalichthys impennis, nat. size: $p .=$ pectoral fin.

This species is represented by two specimens (a male and a female) taken by the "Golden Crown "' in about I 5 fathoms of water in Balasore Bay on the coast of Orissa in October, I9o8. The following measurements are taken from the specimens after preservation in spirit:-

$\begin{array}{lllllllll}\text { Total length } & \ldots & \ldots & \ldots & & \ldots & & & \end{array}$

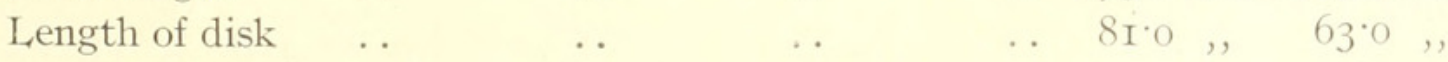


Length from anterior border of anus to anterior border of

우 disk

Length of tail

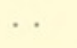

.. $86.0 \mathrm{~mm} .59^{\circ} \mathrm{O} \mathrm{mm}$.

Maximum width of disk

$$
\text { ,, thickness of disk }
$$

Distance between the eyes

,, from eyes to anterior border of disk

Height of dorsal fin

Length of dorsal fin

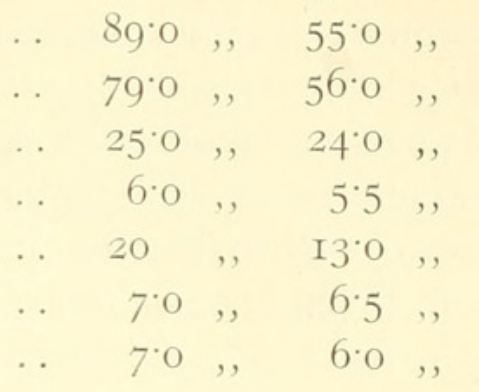

Owing to the strong muscles of the disk, it is liable to undergo great changes in shape; the two specimens I have examined exhibit this very clearly. The degeneracy of the pectoral fins causes the disk to terminate, when viewed from above, some little distance in front of the anus.

The mouth, as in Astrape, is to some extent protrusible, but cannot be thrust out bodily as a tubular structure like that of Narcine.

The number of the type $(\delta)$ in the Museum register is F. $\frac{23,5}{1}$.

\section{Family MYLIOBATID王.}

Head distinct from disk, with a prominent snout or a pair of processes on the front of the head supported by two groups of cartilaginous jointed rays (cephalic fins) ; skull rectangular and box-like. Teeth flat, rectangular and pavement-like, large. Disk wide in proportion to its length. Tail long and thin, with a dorsal fin at its root, with or without a serrated spine.

Taking into consideration the great differences between the skull and teeth of the "Myliobatina"' and the "Ceratopterina," I think it as well to follow Müller and Henle, and also Jordan (Guide to the Study of Fishes, vol. i, pp. 55I, 559, I905), in regarding them as distinct families, although I have not adopted the American name " Mobulidæe" for the latter group.

The Myliobatidæ, if this view be accepted, consist of the genera Rhinoptera, Myliobatis and Aëtobatis, each of which is represented by at least two species in Indian seas. Of Rhinoptera I have only seen the skeleton and teeth, and I do not, therefore, propose to discuss its Indian representatives. Of Myliobatis and Aëtobatis, however, the " Golden Crown "' has obtained large numbers of specimens, which have afforded invaluable material for the elucidation of several doubtful points. The three genera may be distinguished by the following characters:-

I. Head provided with a pair of distinct rayed appendages (cephalic fins) on the ventral surface. Teeth tesselated, in five or more series, the central one being the broadest and the others decreasing in breadth from within out-

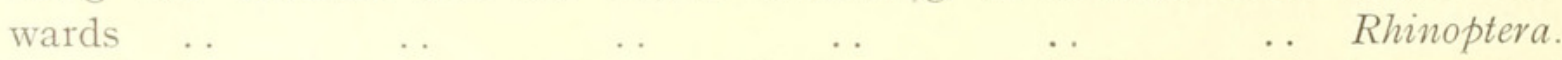

II. Cephalic fins encased in muscle and skin to form a single more or less conical snout. 
A. Teeth in a single broad series .

Aëtobatis.

B. Teeth in several series, of which the lateral ones are much narrower than the central one

Myliobatis

\section{Genus Myliobatis, Cuvier.}

This genus is sufficiently defined in the description of the family and the generic key printed above. At least two species occur in Indian seas and have been taken by the "Golden Crown," namely, $M$. nieuhofii and $M$. maculata. A new variety of the former is described below.

\section{Myliobatis nieuhofii (Bloch and Schneider).}

Size moderately small (adults $42-64 \mathrm{~cm}$. across the disk, young about $\mathrm{I}_{5} \mathrm{~cm}$.).

Disk considerably more than twice as long as the distance between the mouth and the

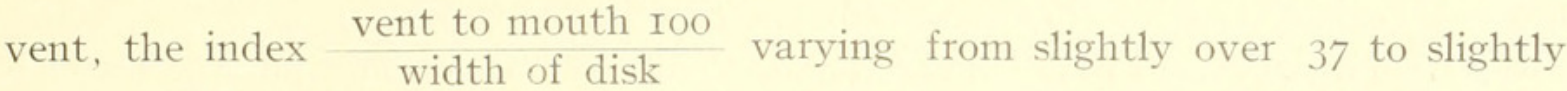
over 43 , but usually being between 40 and $4 \mathrm{I}$. The pectoral fins acutely pointed, their anterior margin nearly straight, their posterior margin broadly concave. Snout (measured from anterior borders of skull) $\frac{1}{1 \frac{1}{3}}$ to $\frac{1}{2}-$ as long as the distance between the mouth and vent and from $\frac{1}{2}$ to $\frac{5}{7}$ as long as broad at the base, not sharply pointed.

Tail much longer than disk, without a serrated spine. The dorsal fin arises nearer the base of the pelvic fins than their distal margin and does not reach, or barely reaches, the level of that margin posteriorly.

Colour. - The fresh fish has the dorsal surface of a bright greenish golden colour with five broad cross-bars of a darker and more livid shade across the disk, and two across the head. Not only do these markings disappear in spirit or even in ice, but they are very superficial, and any rough handling causes the tissues which contain them to be rubbed away. The ordinary spirit specimen of the adult has the dorsal surface of a dark slate-grey. The cross-bars are more conspicuous in the young and remain visible longer in spirit. The ventral surface is white.

Skin soft and at first sight naked. The back, however, is more or less completely covered with minute, star-shaped denticles buried in the skin and sometimes extending on to the ventral surface. They can usually be felt by drawing the tip of the finger across the back of the disk.

Mouth nearly straight. The teeth truncate in front and not projecting from the jaw Their proportions are very variable and the number of series of smaller teeth at the sides of the broad central one is not always the same on the two sides of one jaw. The nasal flap is always straight.

As this is one of the most variable species with which I am acquainted, I have examined and measured a large number of specimens with the greatest care. The first result of this examination was to prove that two forms of the species existed side by side, one with the area immediately above the orbits smooth, the other with a 
definite ridge running along the upper limit of each orbit and produced in front into a short, horn-like structure measuring in adult specimens from $2-4 \mathrm{~mm}$. in length. I cannot detect any other peculiarity that seems to be correlated with the presence of this horn, and Capt. Lloyd tells me that horned and hornless individuals are taken together in the same haul of the trawl. I therefore propose to name the horned form Myliobatis nieuhofii, var. cornifera, var. nov. (P1. ii, fig. 4.)

The presence or absence of horns has been considered a specific character in other species of the genus, but Jordan and Snyder ${ }^{1}$ suggest that these structures are deciduous in a Japanese species ( $M$. tobijei $)$. This is not the case as regards the Indian species. In an embryo in the collection of the Indian Museum which measures II $5 \mathrm{~mm}$. across the disk, the horns are already apparent, but they are absent from several other embryos of about the same size; unfortunately I have not been able to obtain a gravid female of the variety comitera. In some half-grown and old specimens they are absent, in others present. In some horned individuals the denticles on the back are rather more strongly developed than is usually the case in the typical form.

The hornless form is much commoner than the horned one, but the latter is not rare. Both have been taken in large numbers off the coasts of Orissa, Chittagong and Burma, and less abundantly off the mouth of the Ganges. Apparently the species prefers a rocky bottom, on which it is possible that it finds more food in the way of molluses. Its diet is not confined to molluscs, however, as both fish and prawns have been found in its stomach. These are swallowed whole and are not crushed by the teeth.

The following measurements are interesting as illustrating the variation that occurs as regards the teeth in this species :-

\begin{tabular}{|c|c|c|c|c|c|c|c|}
\hline \multirow{2}{*}{ No. } & \multirow{2}{*}{\multicolumn{2}{|c|}{$\begin{array}{c}\text { Breadth of teeth of upper } \\
\text { jaw. }\end{array}$}} & \multicolumn{2}{|c|}{ Number of small teeth. } & \multicolumn{3}{|c|}{ Measurements of central tooth. } \\
\hline & & & Left. & Right. & Breadth. & Leng & th. \\
\hline I & $20.0 \mathrm{~m}$ & $\mathrm{~nm}$. & 3 & 3 & $\mathrm{I} 3.5 \mathrm{~mm}$. & $2 \cdot 25$ & $\mathrm{~mm}$ \\
\hline 2 & I $60^{\circ} \mathrm{O}$ & ,. & 3 & 3 & II'O , , & $2 \cdot 25$ &, \\
\hline 3 & I9.5 & , & 3 & 3 & $\mathrm{I} 2 \cdot \mathrm{O}$ & $I \cdot 75$ & , \\
\hline 4 & $\mathrm{I} 7^{\circ} \mathrm{O}$ & , & $3-4$ & $2-3$ & II'O , , & I.5 & , \\
\hline $5^{*}$ & I $6 \cdot 5$ & , & 2 & 3 & $12 \cdot 0$ & $2 \cdot 25$ & , , \\
\hline 6 & I $2 \cdot 0$ &, & 3 & 3 & $7.5 \quad$, & I.25 & , \\
\hline 7 & $23 \cdot 0$ & , & 3 & 2 & II ${ }^{\circ} \mathrm{O}$ & $3 \cdot 0$ & , , \\
\hline 8 & $\mathrm{I} 7^{\circ} \mathrm{O}$ & , & 3 & 3 & I0.5 & I.O & , \\
\hline 9 & $\mathrm{I}^{\circ} \mathrm{O}$ & , & 3 & 3 & IO.5 & $2 \cdot 25$ & , \\
\hline Io & $27^{\circ} 0$ & ,", & 3 & 3 & $20^{\circ} 0$ & $2 \cdot 25$ & , \\
\hline
\end{tabular}

Proc. U.S. Nat. Mus., xxiii, p. 338 (I900). 


\begin{tabular}{|c|c|c|c|c|c|}
\hline \multirow{2}{*}{ No. } & \multirow{2}{*}{$\begin{array}{c}\text { Breadth of teeth of upper } \\
\text { jaw. }\end{array}$} & \multicolumn{2}{|c|}{ Number of small teeth. } & \multicolumn{2}{|c|}{ Measurements of central tooth. } \\
\hline & & Left. & Right. & Breadth. & Length. \\
\hline II * & $\mathrm{I} 9.5 \mathrm{~mm}$. & 3 & 3 & $12.5 \mathrm{~mm}$ & $\mathrm{I}^{\prime} 5 \mathrm{~mm}$. \\
\hline $12 *$ & I $8 \cdot 0 \quad$, & 4 & 3 & I I 25 & $2 \cdot 0 \quad$, \\
\hline I3 & $2 \mathrm{I} \cdot \mathrm{O}$, & 2 & 2 & I7.0 , , & $3 \cdot 0 \quad$, \\
\hline I 4 & $20^{\circ} 0 \quad$, & 3 & 3 & I6*o , , & I'75, , \\
\hline
\end{tabular}

The numbers marked with a * refer to the specimens of the variety cormifera, the remainder to those of the typical form of the species.

The measurements printed above show how little reliance can be placed on exact relative proportions in diagnosing the species of the Myliobatidæ. Palæontologists in particular have attempted to separate the species of Myliobatis and even Aëtobatis by examining the relative length and breadth of the teeth. Of one species only $(M$. nieuhofii) have I been able to examine a series of adult teeth. The measurements speak for themselves. So far as the other Indian representatives of the family are concerned, most of the jaws I have examined have been those of immature specimens. So far as evidence founded on such specimens goes, however, there is every indication that variation is no less wide in the allies of $M$. nieuhofi than it is in that species.

\section{Myliobatis maculata, Gray and Hardwick.}

This species may be distinguished from $M$. nieuhofii by (I) its large size, (2) its coloration, (3) the arrangement and nature of its denticles, and (4) the shape of the snout.

(I) The size of the adult appears to be nearly twice that of the adult of $M$. nieuhofii.

(2) The young (which are often as large as the adult of the other species) have the dorsal surface of a deep bronze or greenish grey colour with rather large bluish spots scattered profusely on the posterior part of the disk. These spots are a sign of immaturity, although exactly the contrary is the case as regards Aëtobatis punctata. The adult M. maculata has the back of a uniform dark slate-grey.

(3) The most conspicuous feature of the scaling in this species is a longitudinal band, consisting of several closely adjacent rows, of flat denticles situated on the mid-line of the scapular region. The small star-shaped denticles in the skin of the back are also as a rule better developed in $M$. maculata than in $M$. nieuhofii.

(4) The snout in $M$. maculata appears to be decidedly more prominent than it is in $M$. nieuhofii, but this is largely due to the fact that its sides form a more acute angle.

I have seen comparatively few fresh specimens of this species, and only one that appeared to be an adult. It was taken by the " Golden Crown "' off the Orissa coast, 
but unfortunately only the head and tail were preserved. The teeth of the upper jaw measure $28 \mathrm{~mm}$. in transverse diameter, but there is some evidence to show that the mouth is relatively smaller in this species than it is in $M$. nieuhofir. Judging from the analogy of the few young examples of $M$. maculata I have examined in detail, the adult specimen (a female) must have measured about $78 \mathrm{~cm}$. across the disk, but in making this statement I take it for granted that there is little difference in proportions between the adult and the young of the species.

I have not seen any specimen of $M$. maculata with a superciliary horn, ${ }^{1}$ or of either of the Indian species of the genus with a caudal spine.

\section{Genus Aётоватіs, Müller and Henle.}

This genus is separated from Myliobatis by the character of the teeth. In all the specimens I have seen those of the lower jaw project from the mouth in the form of a plate with parallel sides and an obtusely pointed tip. The nasal flap in these specimens is deeply emarginate. Day says that the tip of the lower tooth-band is sometimes broken off and that the free edge of the nasal flap is then straight as it is in Myliobatis (Fishes of India, ii, p. 743), but it is clear from specimens named by him that he confused Aëtobatis guttata with Myliobatis maculata in some cases.

Great confusion still exists as regards the species of Aëtobatis. Most recent authors, following Günther (Cat. Fishes, viii, p. 492), recognize only one species, namely $A$. narinari; but at least two distinct forms occur in Indian seas and it is clear that neither is the same as the American and African species.

As regards the last point, there is of course no positive proof that there are not two forms (or even more) in the Atlantic Ocean (one or more of which may be rare), as there are in the Bay of Bengal. But figures published by Duméril (Arch. Mus., x, p1. 20, Paris, I86I) and by Jordan and Everman (Bull. U. S. Nat. Mus., No. 47, vol. iv, pls. 37 and 38 , I900) represent a species which differs in at least two charactersnamely, the shape of the snout and coloration-from any Indian specimen I have seen. Duméril shows, moreover, that the adult of the form he called Aëtobatis latirostris, the type specimens of which came from the mouth of the Gaboon, does not differ materially from the young as regards coloration.

Jordan, who examined specimens from Florida (Guide to the Study of Fishes, vol. i, fig. 349, I905) as well as from the West Indies and Mazatlan (Bull. U. S. Nat. Mus., No. 47, vol. iv, p. 2753) and found no difference between them, decided with Everman that " this species"' [i.e., Aëtobatis laticeps, Gill] " is probably not different from A. narinari......',

There is little doubt that Aelobatis laticeps, Gill, is a synonym of A. latirostris, Duméril, while Euprasen (Kong. Svens. Vet. Akad. Nya Handl., xi, p. 2I8, I790) says regarding the species he described as Raja narinari :- "Habitat in India occidentali, juxta Insulas Caribæas, in portu Carenage Insulæ St. Bartholemei." The figure

' In a half-grown specimen taken in a seine-net on the beach at Puri in March there is a distinct but low rounded eminence on either side just in front of the eye. 
(p1. $\mathrm{x}$ ) accompanying the paper from which this quotation is taken is by no means accurate but shows the white spots extending as far forwards as the spiracles and, moreover, represents the snout as exceedingly short.

It seems indisputable, therefore, that the name Aëtobatis narinari belongs to the American form, which there is every reason to think was redescribed by Duméril as A. latirostris and by Gill as A.laticeps. For the common Indian form, on the other hand, the name A. guttata (Shaw) is available. There is, however, a second Indian form, much rarer than the first in the Bay of Bengal, which, in Mr. Boulenger's opinion, is identical with Bloch and Schneider's Raja flagellum, and corresponds very closely with the description of that species given by Müller and Henle (" Plagiostomen,'” p. I8o). I therefore recognize the following species in the genus: Aetobatis narinari (Euprasen), A. guttata (Shaw) and A. Alagellum (Bloch and Schneider). Possibly others exist.
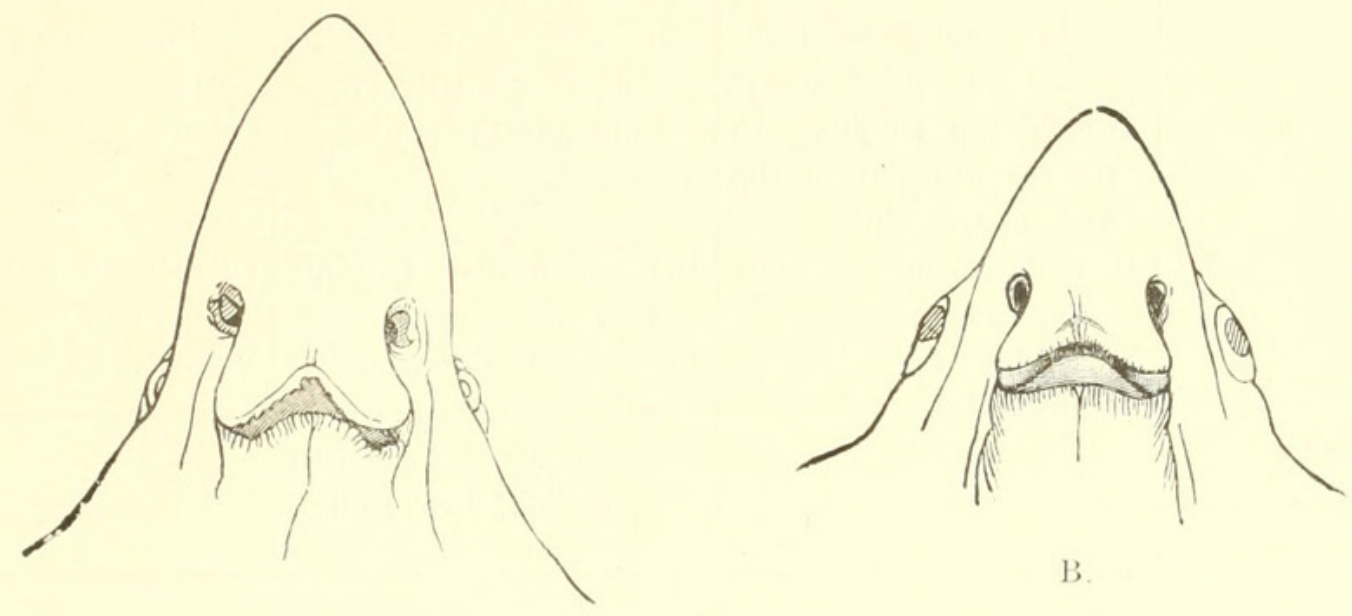

B.

A.

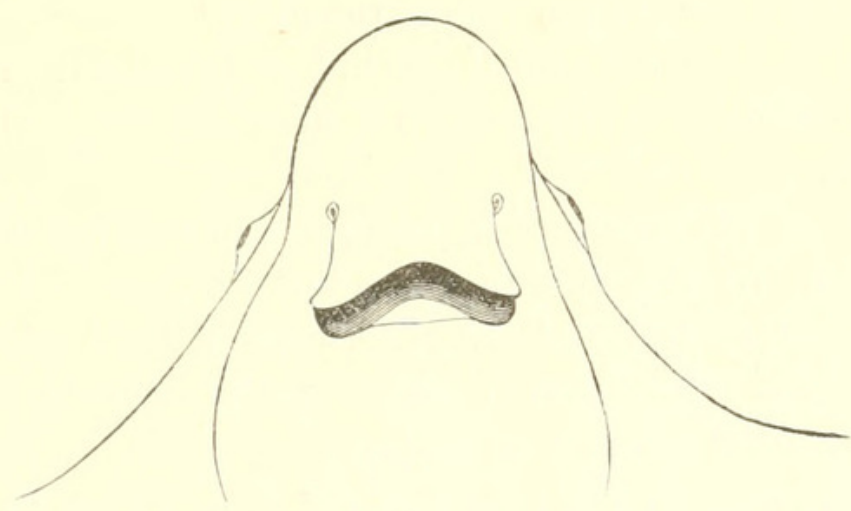

C.

FIg. Io.-Heads of Aëtobatis: A, A. flagellum; B, A.guttata ; C, A. narinari (enlarged from Jordan and Everman's figure).

${ }^{1}$ See Shaw's General Zoology or Systematic Natural History, vol. v, part ii, p. 285 (I804). Shaw did not distinguish the Atlantic from the Oriental species, and his figure of "Raja guttata " is quite indefinite: but as he clearly meant to include the common Indian species in his description, his name may stand. 
Granted that there are three species of Actobatis, ' it is necessary to inquire how they can be distinguished from one another. If only dried specimens are examined, the diagnosis is very difficult, if not impossible, and as regards the Atlantic form I am wholly dependent on published figures and descriptions. The following table gives the differences that are apparent from careful examination on the one hand of these figures and descriptions and on the other of fresh specimens of the Indian forms :-

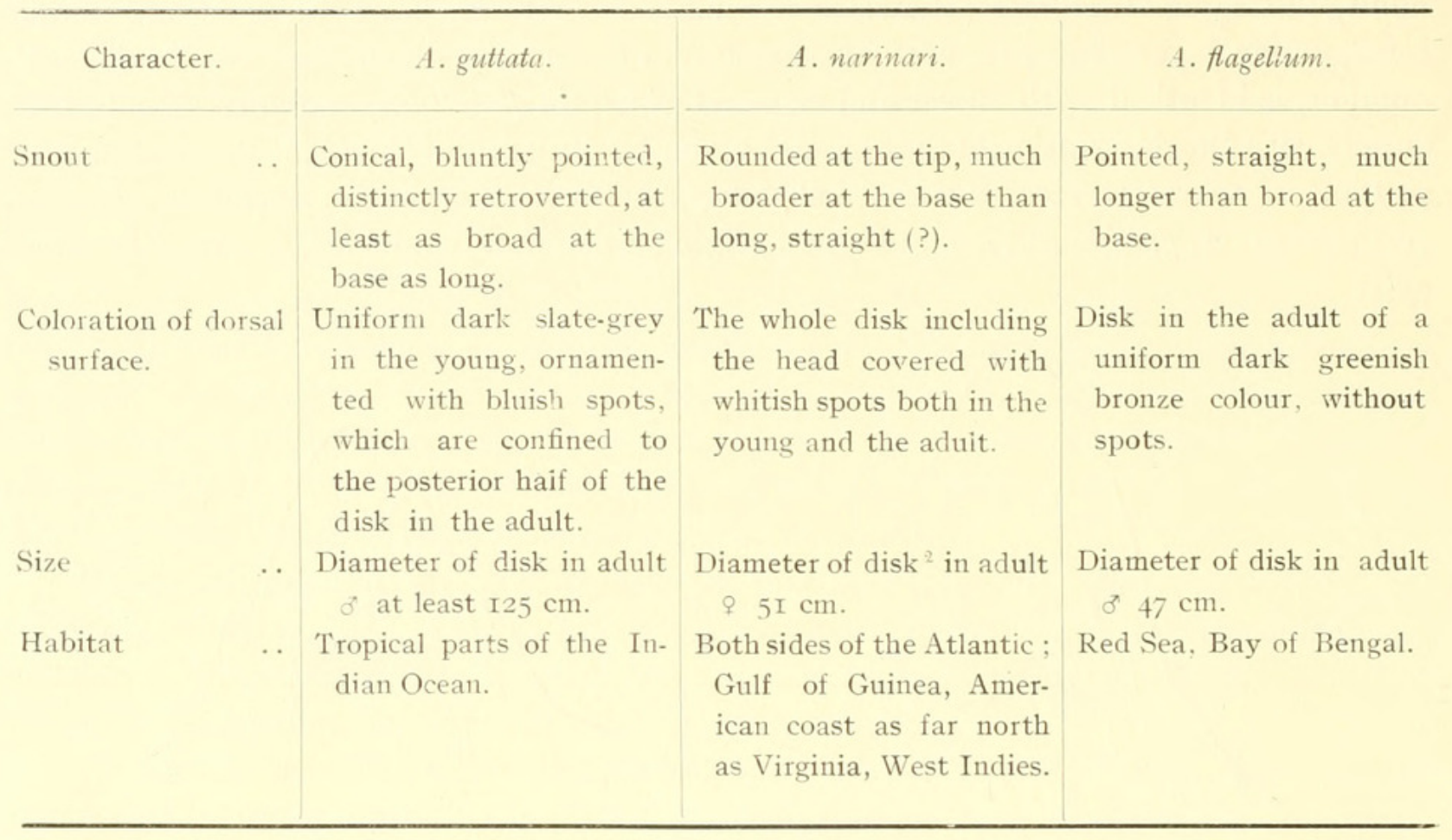

\section{Aëtobatis guttata (Shaw).}

Size considerable (adult male $125 \mathrm{~cm}$. across the disk).

Disk shaped much as in Myliobatis nieuhofii, but quite naked.

Tail much longer than disk, always bearing at least one serrated spine, often two, sometimes three.

Colour.-Dorsal surface of young of a uniform dark slate-grey, without a trace of spots. The spots on the disk of the adult are confined to the posterior half. They are of a bluish tint and are edged with a faint greenish halo. Their size varies considerably. The ground colour of the back of the adult has, in fresh specimens, a beautiful greenish refulgence.

This is a very common species in the Bay of Bengal and, like Myliobatis nicuhofii, is evidently gregarious and probably also migratory in habits, at least while it is young.

${ }^{1}$ I am much indebted to Messrs. Boulenger and Tate Regan for examining a photograph and drawings of Indian specimens of Aetobatis and for comparing them with the original figures of A. flagellum, which I have not been able to consult.

${ }^{2}$ Gilbert and Starks (Mem. Calif. Acad. Sci., iv, p. I8, I904) give the width of the disk of a specimen from Panama Bay as 6 5 mm. but do not state its sex. 
Adults are seldom caught even in the trawl and may be solitary. I have only seen one large specimen, which was taken off the Orissa coast. Its measurements are given below.

$$
\text { Aëtobatis flagellum (Bloch and Schneider). (P1. iv, fig. 5.) }
$$

A. flagellum, Müller and Henle, Syst. Beschr. d. Plag., p. I8o.

The differences between this species and the preceding one are noted in the table showing the specific characters of the three species of the genus. I have not been able to discover any other points that call for notice. Perhaps the tail is longer in proportion to the body ; but in most large specimens of Myliobatidæ the tail is mutilated.

Müller and Henle's description is accurate, as is always the case in the work of these authors, whose monograph, in spite of the fact that it contains a certain number of specific descriptions that refer actually to the young stages of forms described as distinct, is still by far the most reliable guide as regards the identification of the Oriental Batoidei.

A. flagellum is apparently rare in the northern part of the Bay of Bengal. I have only seen two examples, a male taken by the " Golden Crown " off the Orissa coast in November, and a severed head brought from the mouth of the Chilka Lake on the same coast in December by Dr. Jenkins.

Measurements of Indian species of Myliobatis and Aëtobatis.

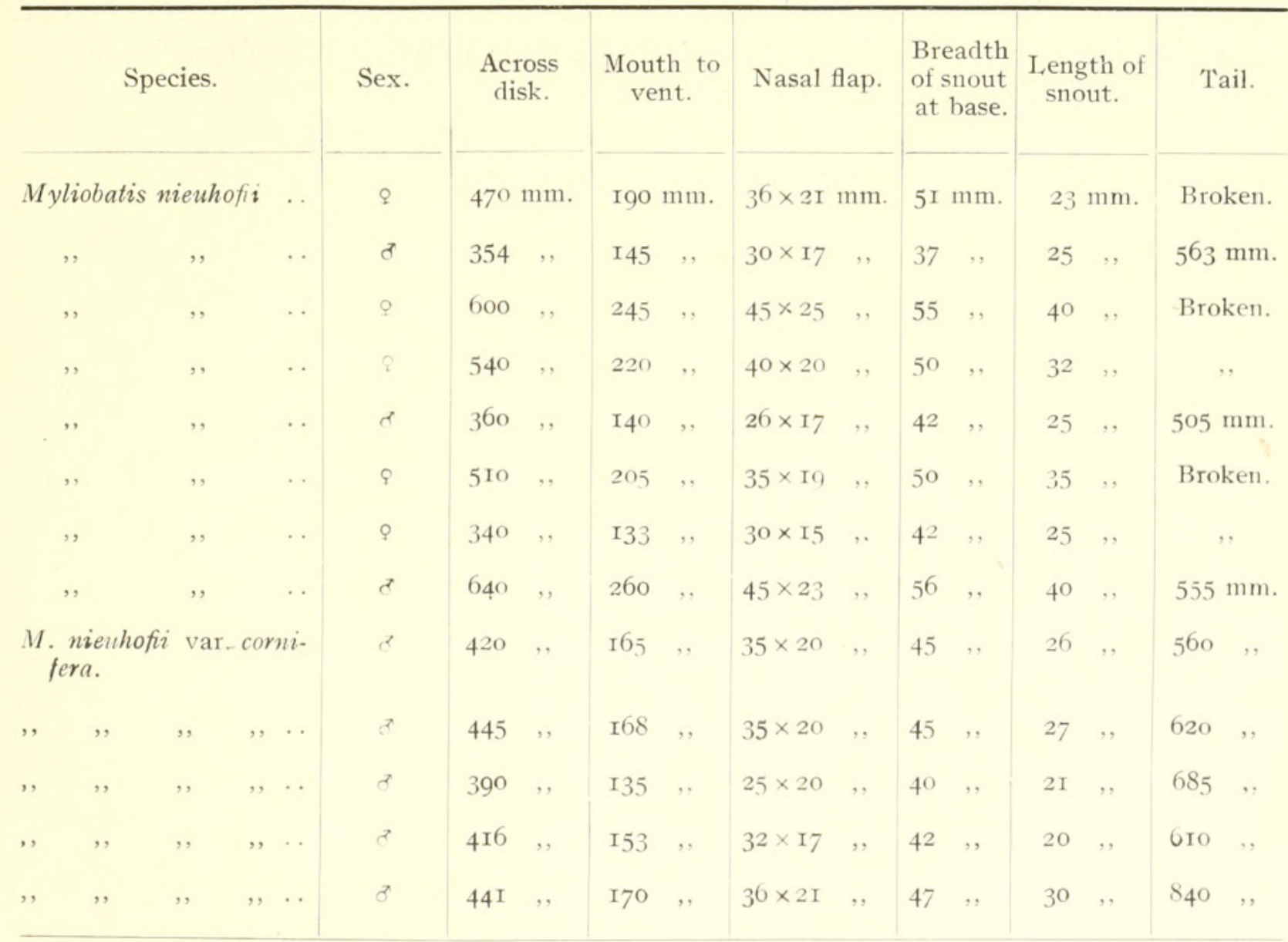


Measurements of Indian species of Myliobatis and Aëtobatis-Contd.

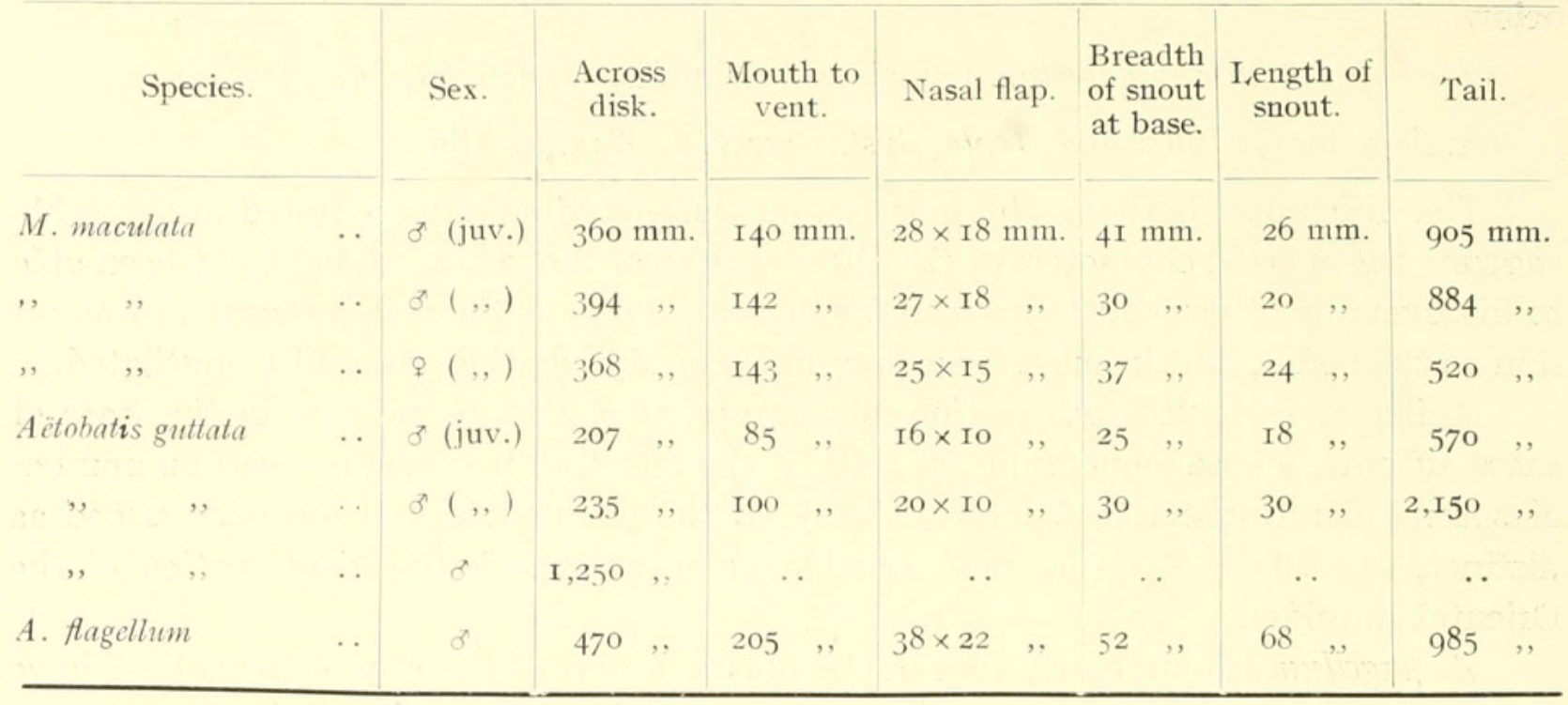

In a future report on the Selachians of the "'Golden Crown," the distribution of the Indian Elasmobranchs will be discussed. As Capt. Lloyd ' has recently made use of all the information at present available in India regarding the Ceratopteridæ, it is unnecessary for me to discuss the species of that family, especially as no specimens have been taken by the "Golden Crown." I may say, however, that an examination of the specimens in the Indian and Madras Museums fully confirms Lloyd's remarks as to the peculiarities of the Ceratopterid skuli.

${ }^{1}$ Rec. Ind. Mus., ii, p. I75 (I908). 


\section{APPENDIX.}

\section{Analysis of the OILs pRoduced by certain Indin Rays and other Aquatic Vertebrates. \\ By D. Hooper, F.C.S., Industrial Section, Indian Museum.}

Among the specimens of fish captured by the " Golden Crown "' and handed over to the Indian Museum for determination have been several species which yield large quantities of oil. The collection and use of marine animal oils in some parts of the world constitute important industries, but in India these fats are very rarely utilised, and their chemical composition and properties have never been studied. Whale and seal oils are occasionally imported for leather dressing and other purposes, and it does not appear that any serious attempt has been made to exploit the oils of Indian fish.

The first oil examined was that of the Gangetic Dolphin (Platanista gangetica). This animal is called susu, sehu and sisar, and the oil is locally used as an embrocation for rheumatism and as an illuminating agent. The oil is yellowish-brown becoming reddish-brown on keeping, has a faint fishy smell, and deposits no solid fats at the winter temperature of Calcutta ( $18-22^{\circ} \mathrm{C}$.).

The following constants were obtained :-

\begin{tabular}{|c|c|c|c|c|}
\hline Specific gravity at $15^{\circ} \mathrm{C}$. & $\ldots$ & $\ldots$ & . & $92 \mathrm{I}$ \\
\hline Acid value $\quad \ldots$ & & . & . & $2 \mathrm{I} \cdot 36$ \\
\hline Saponification value & . & & . & I9 $8 \cdot 8$ \\
\hline Iodine value $\quad \ldots$ & & . & . & I06.9 \\
\hline Reichert-Meissl value & . & . & . & $7 \mathrm{I}$ \\
\hline Fatty acids, per cent. & . & . & . & $94^{\circ} \mathrm{O}$ \\
\hline Melting point of & . & . & . & $25.5^{\circ} \mathrm{C}$ \\
\hline Acid value of & . & . & . & $205^{\circ} \mathrm{O}$ \\
\hline Iodine value of & . & . & . & I $16 \cdot 5$ \\
\hline
\end{tabular}

Although it is allied to the sperm whale, the oil of this animal contained no spermaceti. There is a fair amount of free fatty acids, but there is only a small proportion of the more volatile fatty acids. The solid fatty acid, calculated as palmitic acid, amounted to about I6 per cent. Such an oil would be of value for currying purposes, for burning and for lubricating fine machinery. The other oils examined were those of the livers of certain large fish brought from the Bay of Bengal, and identified by Dr. Annandale. The livers were from the following species :-

I. White Sting-Ray (Trygon microps).

2. Common Saw-Fish (Pristis perottetii).

3. Spotted Shark (Stegostoma tigrinum).

4. Shark Ray (Rhamphobatis ancylostomus). 
The livers of these animals were of an enormous size; that of the Sting-Ray weighing $89 \frac{1}{2}$ pounds and that of the Saw-Fish IO $2 \frac{3}{4}$ pounds. These livers were very rich in oil ; that of the Sting-Ray afforded $7 I^{\cdot} 6$ parts of oil, $I 7 \cdot 7$ parts of water and I0.7 parts of hepatic tissue in Ioo parts. The hepatic tissue contained over 5 per cent. of nitrogen and would form a valuable manure. All the oils deposited varying amounts of white fats, chiefly palmitin, at the cold weather temperatures. When freshly expressed the oil has a not unpleasant odour, similar to cod-liver oil, and a colour varying from light yellow to reddish-yellow.

The following constants were obtained :-

\begin{tabular}{|c|c|c|c|c|c|}
\hline Specific gravity at $50^{\circ}$ & C. & $\begin{array}{l}\text { I. } \\
\text { 9I4 }\end{array}$ & $\begin{array}{l}2 . \\
900\end{array}$ & $\begin{array}{c}3 . \\
9 \mathrm{IO}\end{array}$ & $\begin{array}{l}4 . \\
909\end{array}$ \\
\hline Melting point & & . $22^{\circ} \mathrm{C}$ & $27^{\circ}$ & $26 \cdot 5^{\circ}$ & $25.5^{\circ}$ \\
\hline Acid value & . & . $\quad 98$ & I*O & $I \cdot I 6$ & I'I3 \\
\hline Saponification value & . & $\ldots \mathrm{I} 94^{\circ} \mathrm{O}$ & I $87 \cdot \mathrm{I}$ & I $85+$ & I $87 \cdot 4$ \\
\hline Iodine value & & $\ldots \mathrm{I} 247$ & $92 \cdot 9$ & $\mathrm{I} 23 \cdot 2$ & II $8 \cdot 5$ \\
\hline Reichert-Meiss1 & . & .. $\quad 26$ & $\cdot 28$ & $\cdot 2 \mathrm{I}$ & $\cdot 23$ \\
\hline Fatty acids, per cent. & . & . $93 \cdot 2$ & 947 & $94 \cdot 2$ & $94 \cdot 6$ \\
\hline Melting point of & . & . $37.5^{\circ} \mathrm{C}$. & $39^{\circ}$ & $39^{\circ}$ & $39^{\circ}$ \\
\hline Acid value of & . & $\ldots 203 \cdot 4$ & $\mathrm{I} 92 \cdot 2$ & I $89^{\circ} 9$ & $\mathrm{IgO}_{4} 4$ \\
\hline
\end{tabular}

All these oils contained a cholesterol affording a rose-red or purplish-red colour with sulphuric acid. The slight acidity of these oils is much in their favour should they be employed for edible purposes. According to Hosmann the presence of free acids is characteristic of fresh cod-liver oil. Comparatively neutral oils such as these would be much more suitable for medicinal purposes. The large quantity of solid fats would render these oils useful for soap manufacture, while the liquid oil, separated from the palmitin, would be serviceable for leather dressing, lighting and lrubicating purposes.

The livers of various fish have not the same uniform composition as the above.

The small skate known as Trygon gerrardii in a fresh state possessed a liver weighing only 37.5 grams. This was composed as follows in one hundred parts :-

$\begin{array}{llllll}\text { Water } & \ldots & \ldots & \ldots & \ldots & 56 \cdot 5 \\ \text { Oil } & \ldots & \ldots & \ldots & \ldots & 28 \cdot 3 \\ \text { Tissue } & \ldots & \ldots & \ldots & \ldots & 15 \cdot 2\end{array}$

The hepatic tissue contained II $4^{8}$ per cent. of nitrogen, an amount equal to that found in dry blood. 


\section{EXPLANATION OF PLATE I.}

FIG. I. - Photograph of a female specimen of the typical form of Trygon uarnak which measured $5 \mathrm{ft} .3$ in. across the disk.

,, 2.-Photograph of a female specimen of T. uarnak var. variegatus which measured about $5 \mathrm{ft}$. across the disk.

, 3.- Photograph of the type specimen ( $\&$ ) of Trygon favus. This specimen measured ${ }_{4} \mathrm{ft} .4$ in. across the disk. 

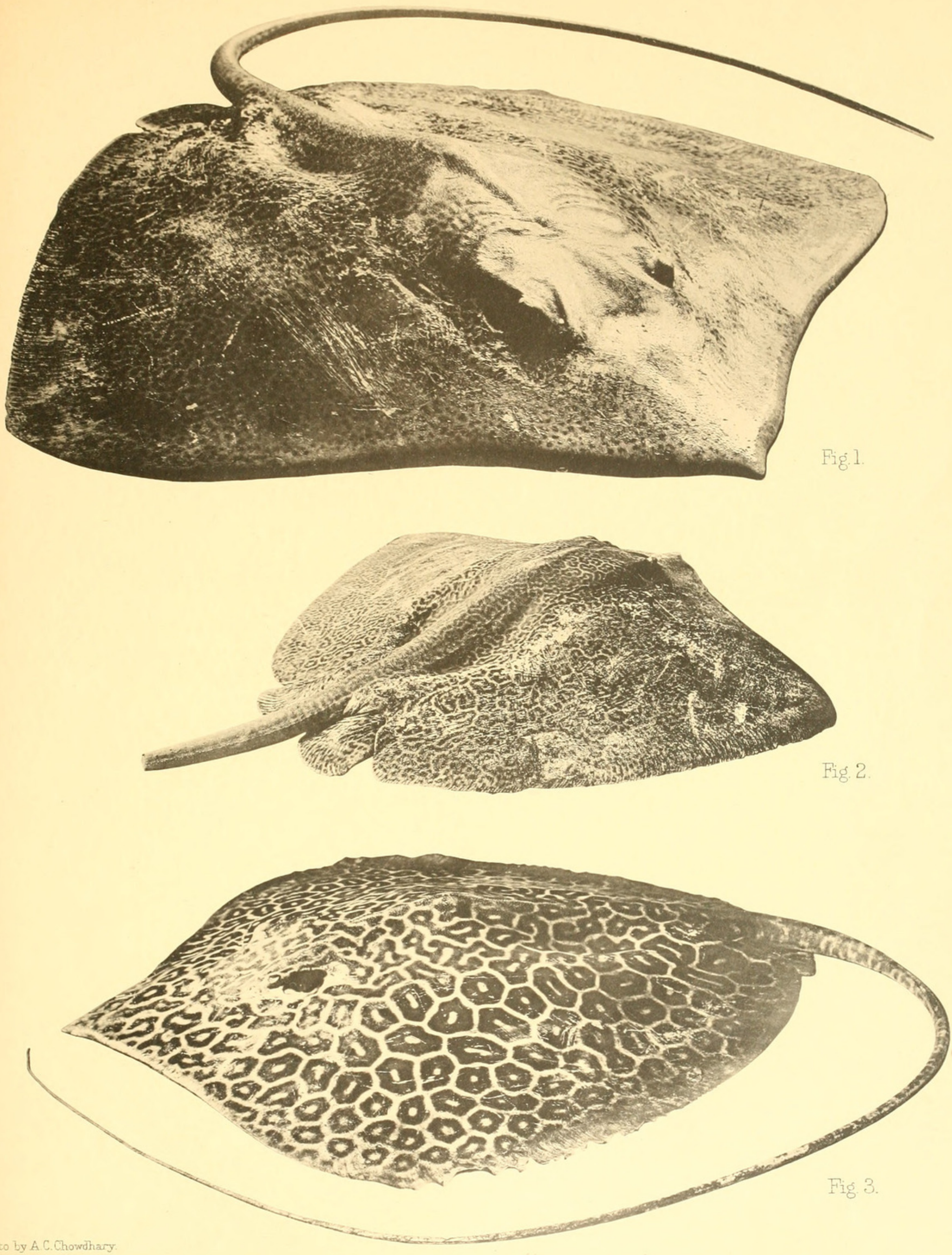


\section{EXPLANATION OF PLATE II.}

FIG. I. - Trygon uarnak var. variegatus (adult female). Scale about $\frac{1}{15}$.

,, I a.-Trygon uarnak (young). Scale $\frac{1}{4}$.

, 2.-Trygon gerrardii (adult female). Scale $\frac{1}{6}$.

,, 3.-Denticles on upper surface of tail of Trygon microps (nat. size).

, 3a.-Denticles on centre of back of same species, $\times 2$.

,, 4.- - Head of Myliobatis nieuhofii var. cornifera (nat. size).

,. 4a.-Denticles on back of same species, much enlarged. 


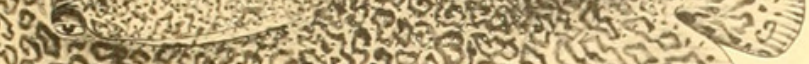

ons

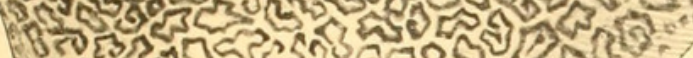

हत्र 3 ?

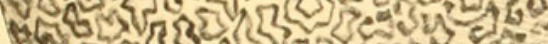

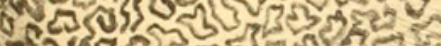
ces

4 ives

sings

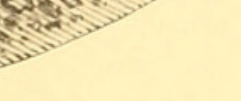

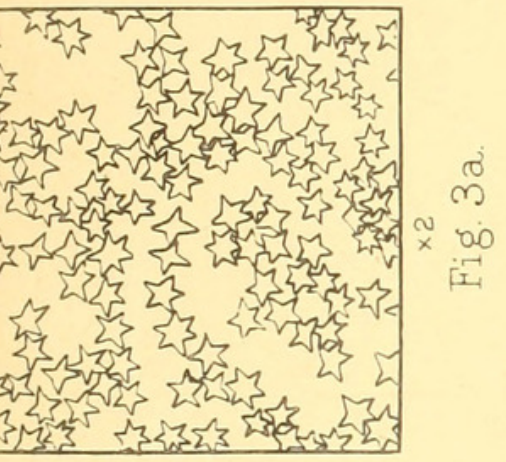
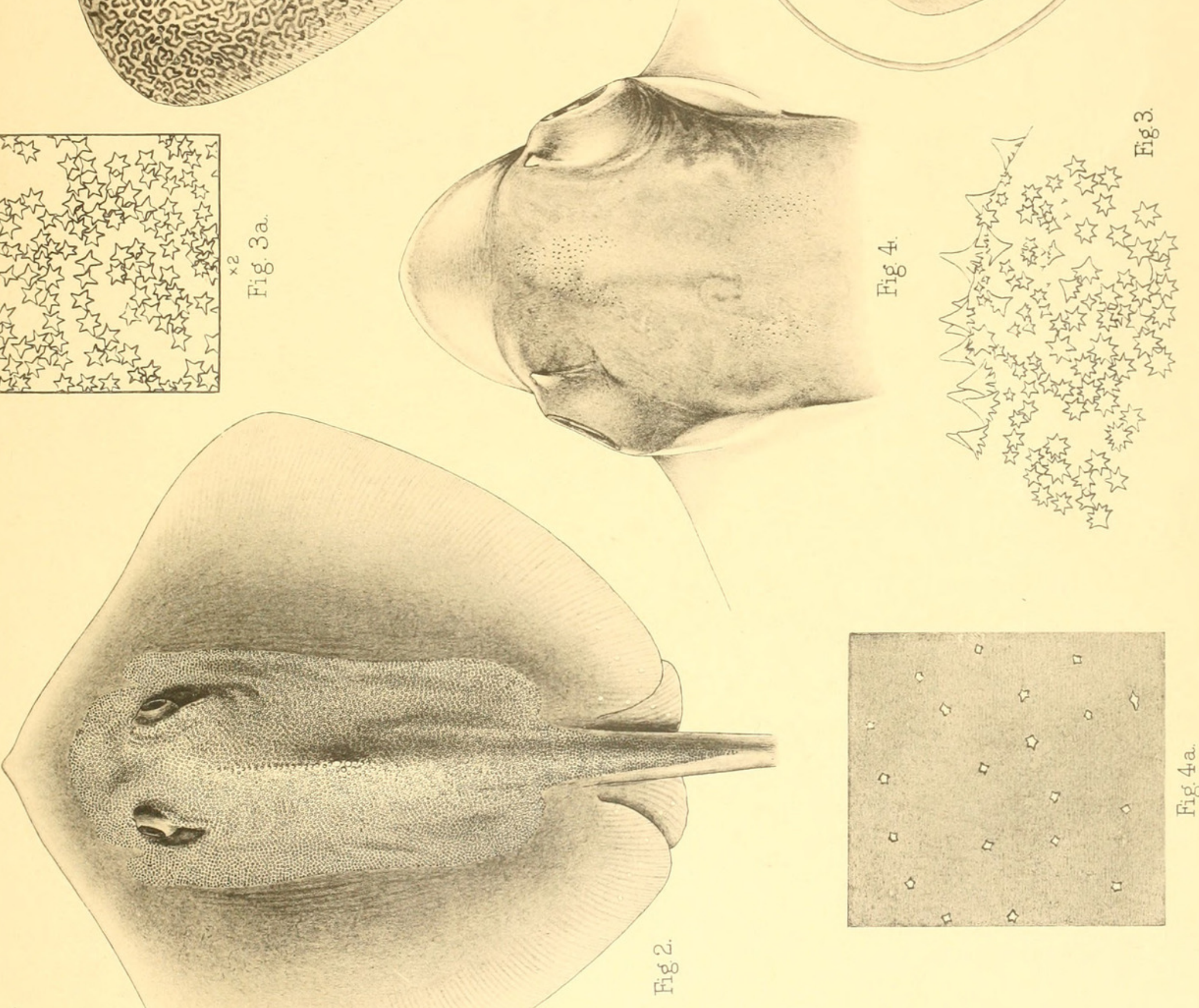


\section{EXPLANATION OF PLATE III.}

\section{MOUTHS OF INDIAN TRYGONIDE.}

FIG. I.-Internal view of mouth of Trygon microps (much reduced).

\begin{tabular}{|c|c|c|c|}
\hline , 2. & ,', & ,', & ,, T. uarnak (much reduced). \\
\hline 3. & , , & , & ,, Hypolophus sephen (much reduced). \\
\hline 4. & , , & , , & , Trygon kuhlii. \\
\hline 5 & , & , & ,, ,, imbricata or walga. \\
\hline 6. & , , & , & gerrardii. \\
\hline $\begin{array}{l}7 . \\
8\end{array}$ & , & ', & ," ,, zugei. \\
\hline 8. & ,' & , & ,, Urogymmus asperrimus (much reduced) \\
\hline $\begin{array}{c}9 . \\
\text { IO. }\end{array}$ & ,' & , & ,, Trygon bleekeri (reduced). \\
\hline II. & " & , & ,' , , favus (much reduced). \\
\hline & "' & ', & marginatus (much reduced). \\
\hline
\end{tabular}



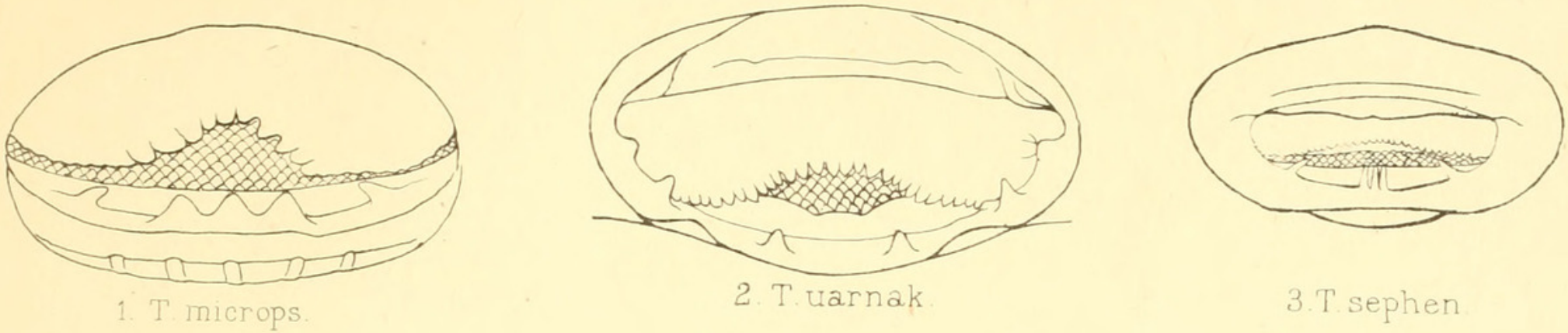

3.T sephen

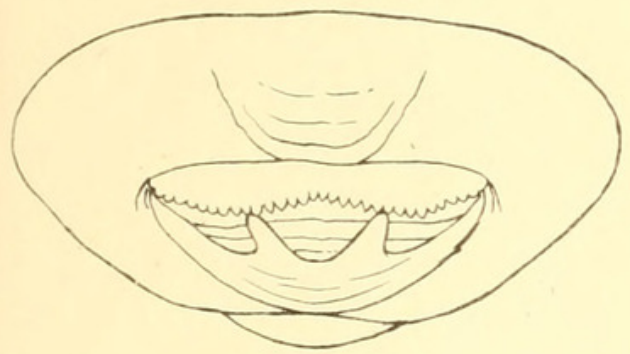

4. T. Kuhlil

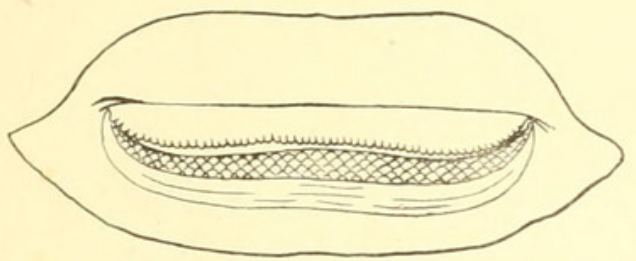

7. T.zugei

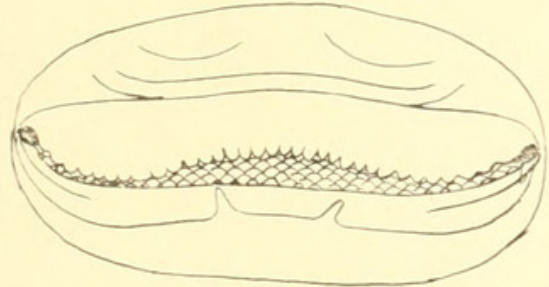

9.T bleekeri

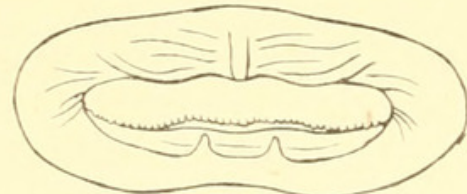

5 T walga

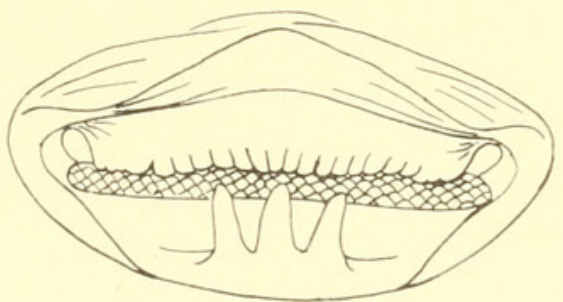

8. Urogymnus asperrimus

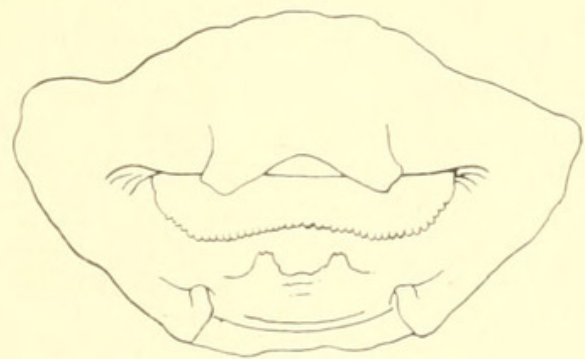

10. T favus

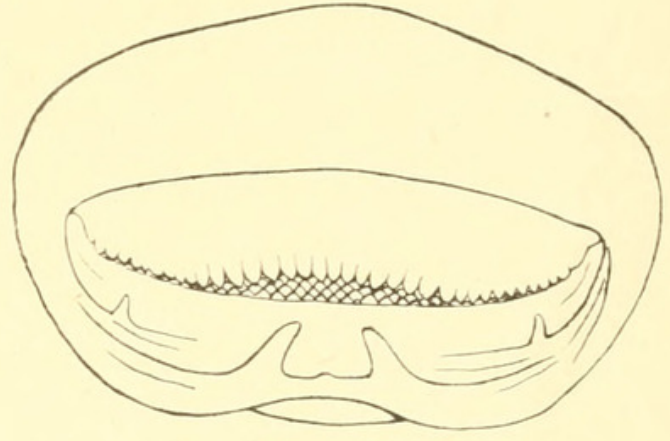

6. T gerrardi

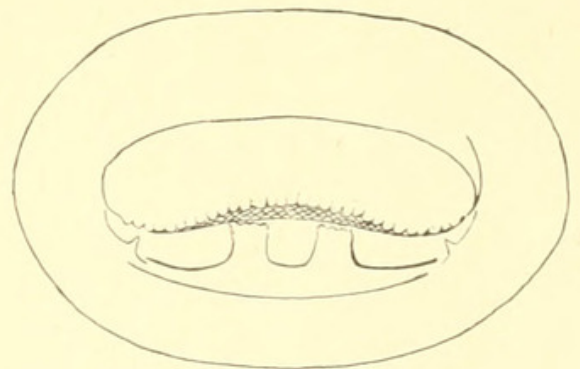

6a. T.gerrardi

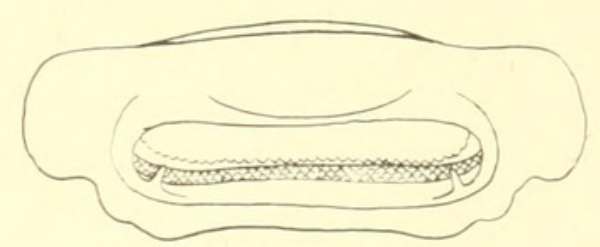

11. T marginatus 


\section{EXPLANATION OF PLATE IIIA.}

\section{Mouths and TeEth of Indian Torpedinid}

[All the teeth are drawn from preparations mounted in canada balsum.]

FIG. I.- Internal view of the mouth of Narcine timlei, $\times 4$.

,, I $a$.-Teeth of the same, $\times 75$.

,, 2.- Internal view of the mouth of Narcine brunnea, $\times 4$.

,2 $2 a$.-Teeth of the same, $\times 75$.

, 3.-Internal view of the mouth of Narcine mollis, $\times 6$.

, $3 a$.-Teeth of the same, $\times 75$.

,, 4.-Teeth of Torpedo marmorata, $\times 20$.

,, 5.-Mouth of Benthobatis moresbyi, $\times 8$.

, 5 a.-Teeth of the same, $\times 75$.

, 6.-Mouth of Astrape dipterygia, $\times 6$.

, $6 a$.- Teeth of the same, $\times 75$.

, 7.-Mouth of Bengalichthys impennis, $\times 6$.

, 7 a.-Teeth of the same, $\times 75$. 

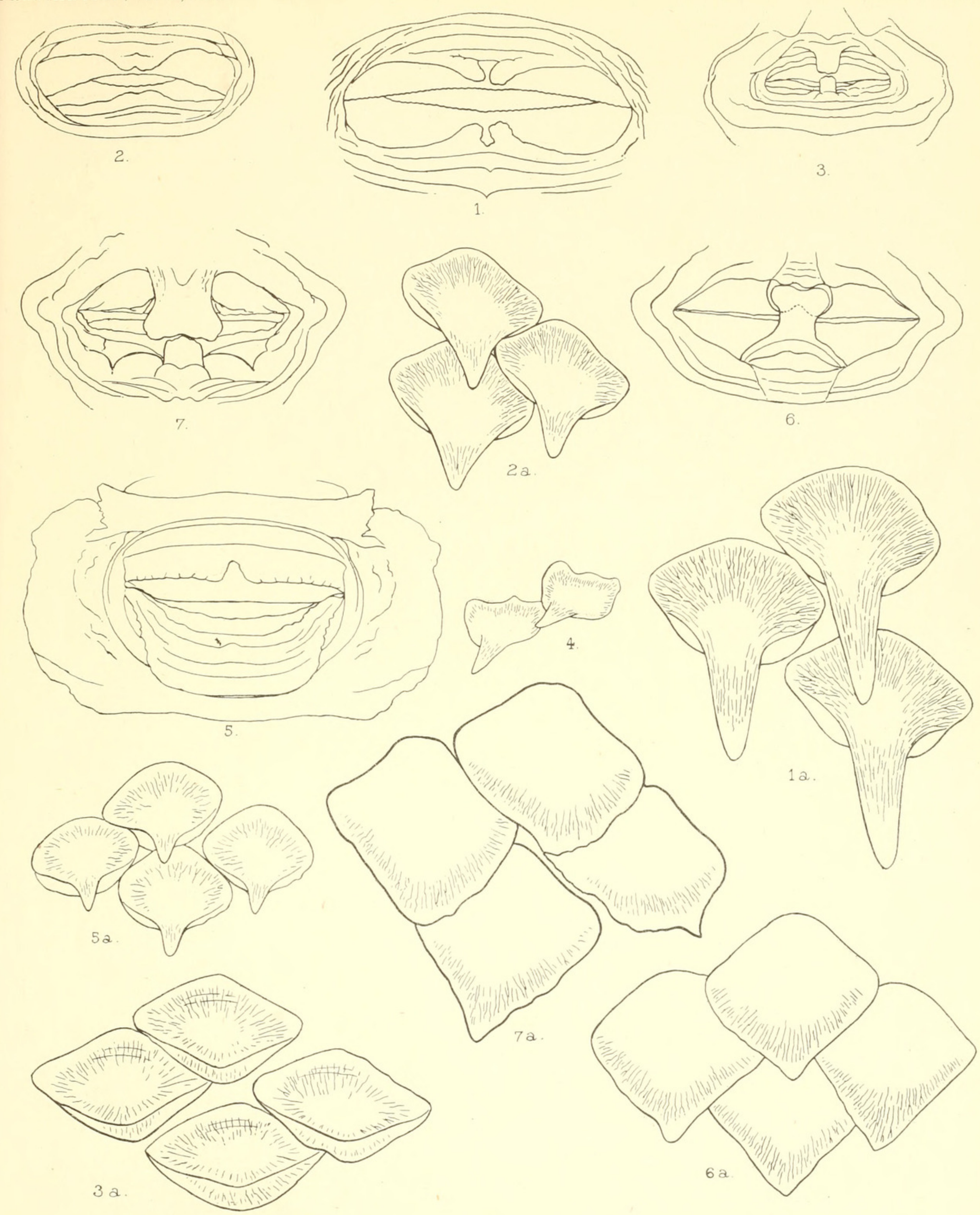

MOUTHS \& TEETH OF INDIAN TORPEDINIDAE. 


\section{EXPLANATION OF PLATE IV.}

FIG. I.-Photograph of type specimen ( $q$ ) of Trygon microps. This specimen measured $6 \mathrm{ft} .6$ in. across the disk.

,, 2.-Photograph of female specimen of T.zugei, $\times \frac{3}{10}$.

,, 3.-Photograph of female specimen of Pteroplatea zonura (considerably reduced).

,. 4.-Photograph of young specimen of Pt. tentaculata, $\times$ c. $\frac{1}{2}$. A piece of white paper has been placed beneath the left tentacle.

,, 5.-Photograph of a male specimen of Aëtobatis flagellum, $\times$ c. $\frac{1}{5}$. 


\section{EXPLANATION OF PLATE V.}

FIG. I.-Photograph of a male specimen of Hypolophus sephen in which the end of the tail has been lost (much reduced).

,, 2, 2a.-Photographs of a large female specimen of Urogymnus asperrimus in which the tail had been mutilated (much reduced). In fig. 2 the base of the disk is considerably foreshortened.

,, 3.-Photograph of a female specimen of Torpedo marmorata from the Orissa coast, $\times$ c. $\frac{2}{5}$.

,, 4.-Cast of the type specimen ( $\sigma$ ) of Pristis annandalei, Chaudhuri, $\times \frac{1}{14}$.

, 5.-Photograph of a male specimen of Rhamphobatis ancylostomus, $\times$ c. $\frac{1}{15}$. 


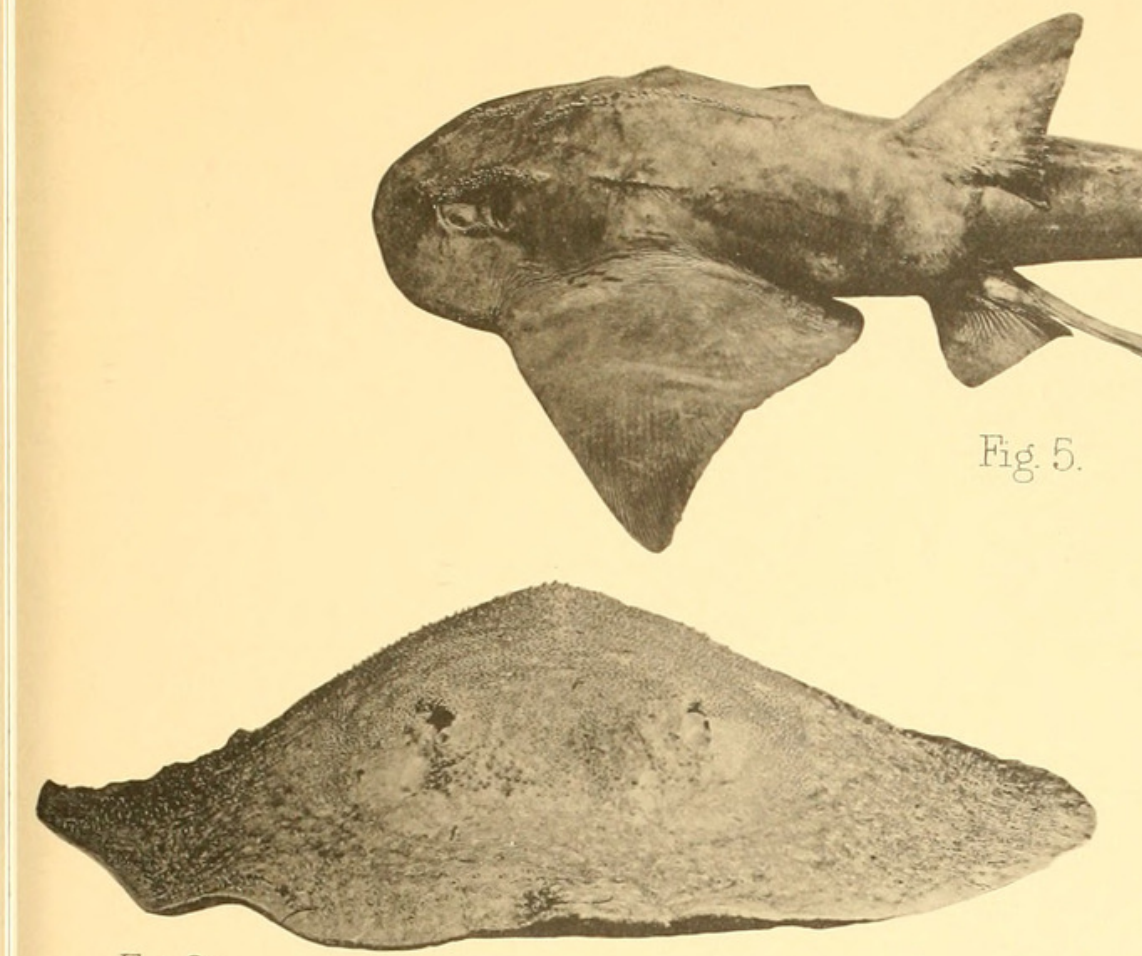

Fig. $2 a$
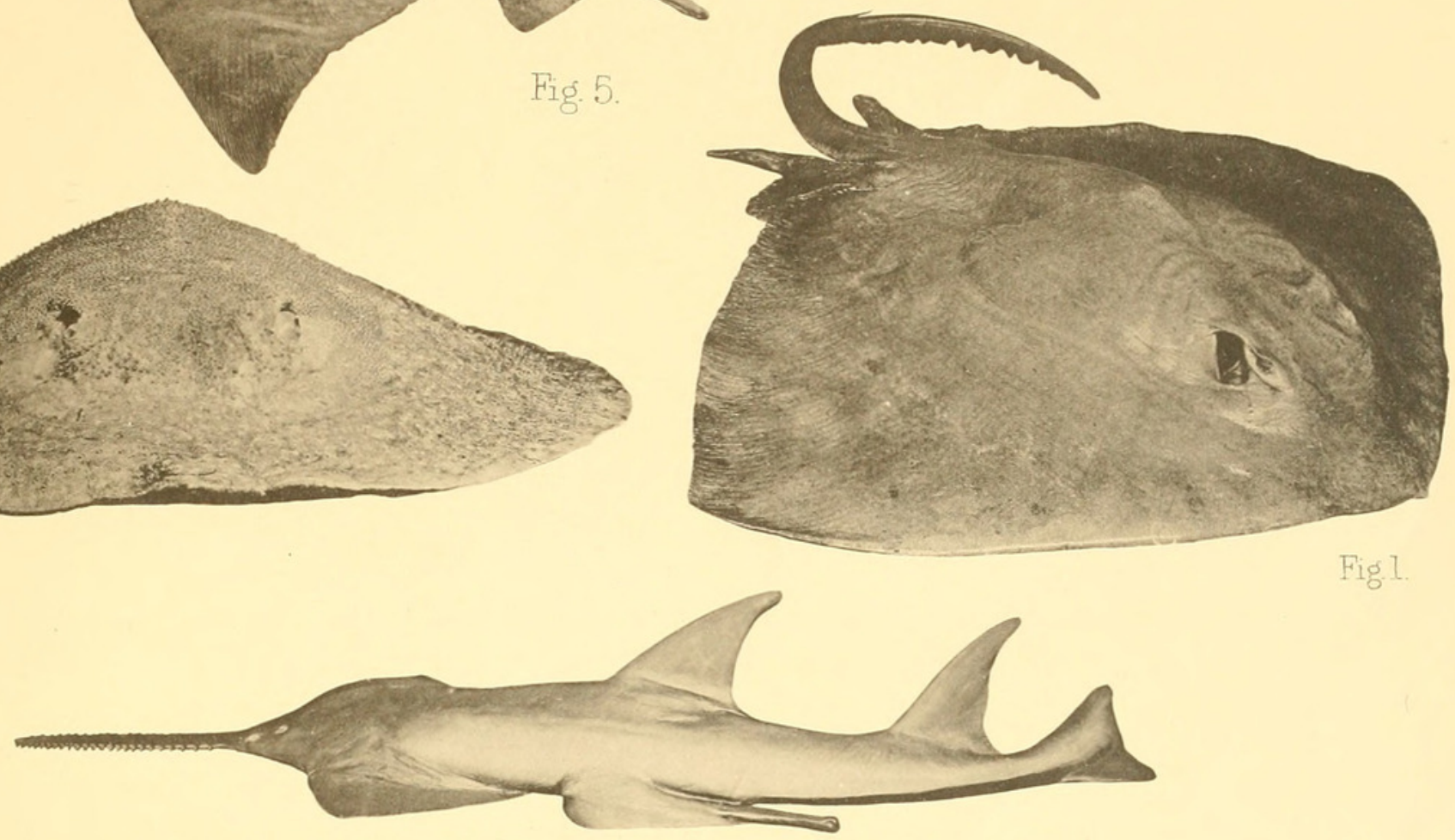

Fig. 1.
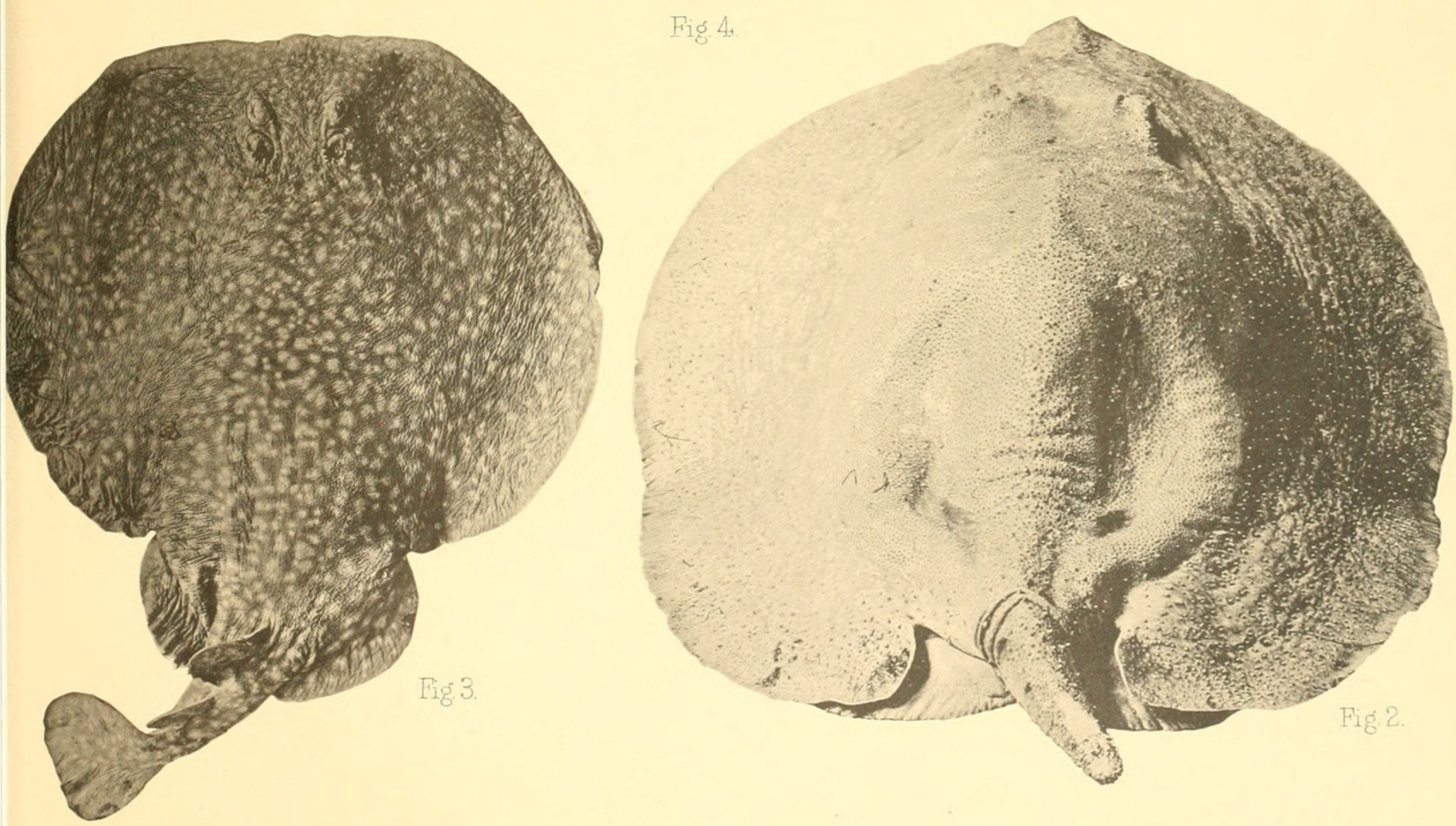

Photo by A.C. Chowdhary

Fig.1. Trygon sephen (tail abnormal). Fig.2,2a. Urogymnus asperrimus. Fig. 3. Torpedo marmorata. 


\section{$2 \mathrm{BHL}$ Biodiversity Heritage Library}

Annandale, Nelson. 1909. "Report on the Fishes taken by the Bengal Fisheries Steamer "Golden Crown." Part I. Batoidei." Report on the fishes taken by the Bengal fisheries steamer "Golden Crown." 2, 1-58.

https://doi.org/10.5962/bhl.part.29058.

View This Item Online: $\underline{\text { https://www.biodiversitylibrary.org/item/48570 }}$

DOI: https://doi.org/10.5962/bhl.part.29058

Permalink: https://www.biodiversitylibrary.org/partpdf/29058

\section{Holding Institution}

Smithsonian Libraries

\section{Sponsored by}

Smithsonian

\section{Copyright \& Reuse}

Copyright Status: Public domain. The BHL considers that this work is no longer under copyright protection.

This document was created from content at the Biodiversity Heritage Library, the world's largest open access digital library for biodiversity literature and archives. Visit BHL at https://www.biodiversitylibrary.org. 